LBNL-50023

\title{
An Engineering-Economic Analysis of Combined Heat and Power Technologies in a $\mu$ Grid Application
}

\author{
Prepared for the \\ United States Environmental Protection Agency \\ Principal Authors \\ Owen Bailey, Boubékeur Ouaglal, Emily Bartholomew, Chris Marnay, and Norman Bourassa \\ Ernest Orlando Lawrence Berkeley National Laboratory \\ 1 Cyclotron Road, MS 90-4000 \\ Berkeley CA 94720-8061
}

29 March 2002

This work was supported by the Energy Supply and Industry Branch of the U.S. Environmental Protection Agency, and prepared for the U. S. Department of Energy under Contract No. DE-AC0376SF00098. This work was also supported by the Edna Bailey Sussman Foundation. 
An Engineering-Economic Analysis of Combined Heat and Power Technologies in a $\mu$ Grid Application 


\section{Table of Contents}

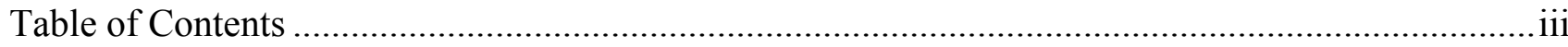

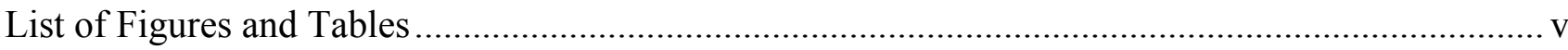

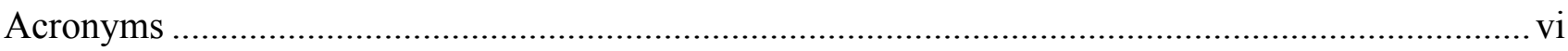

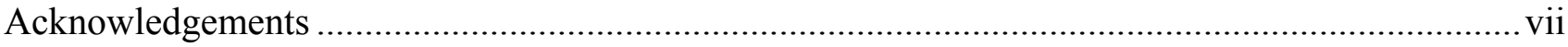

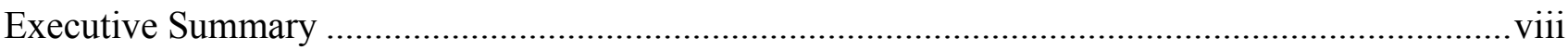

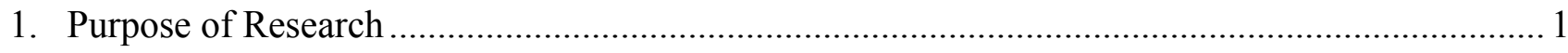

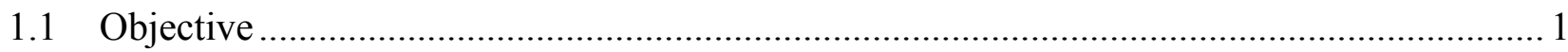

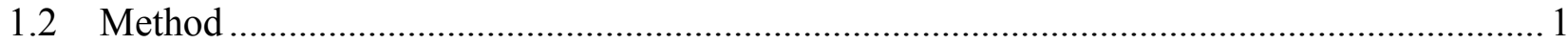

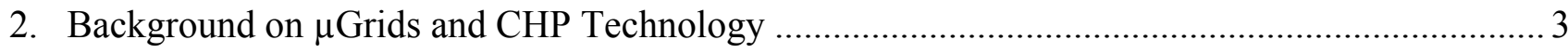

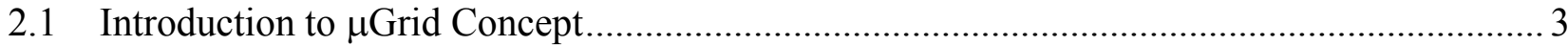

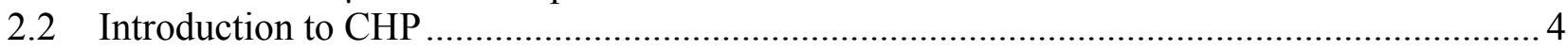

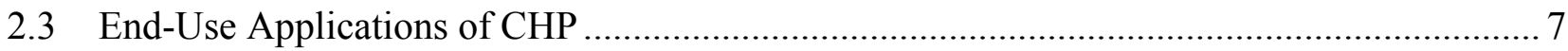

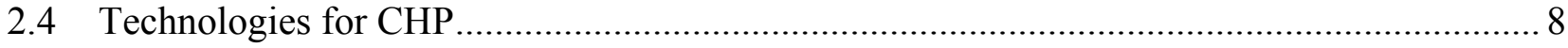

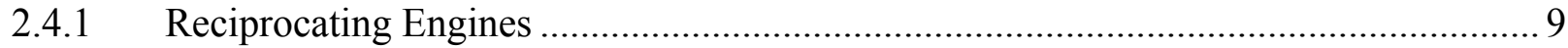

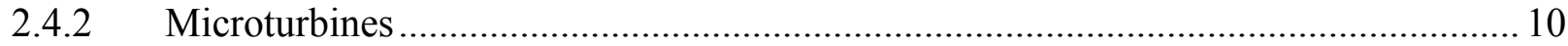

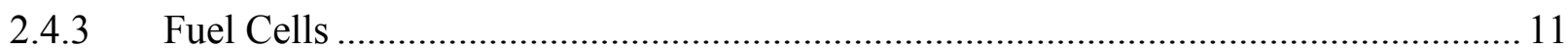

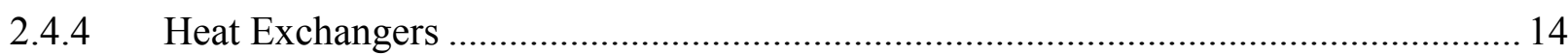

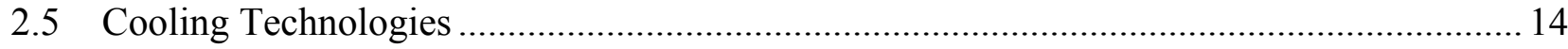

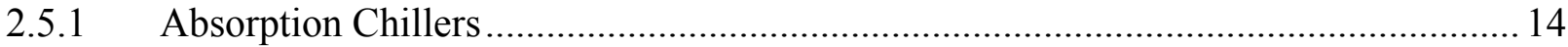

2.5.2 Desiccant Dehumidification........................................................................ 15

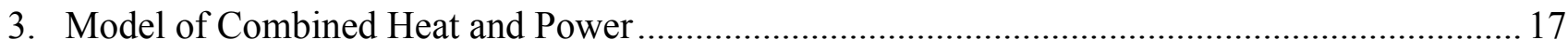

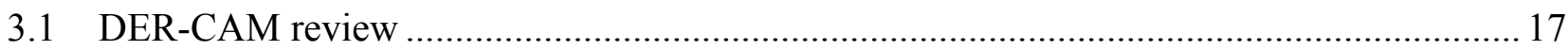

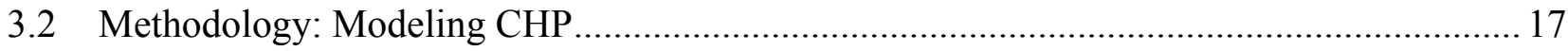

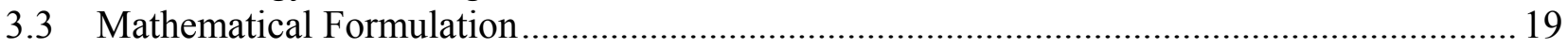

3.3.1 Parameters and Variables Defined for the CHP Model ........................................ 19

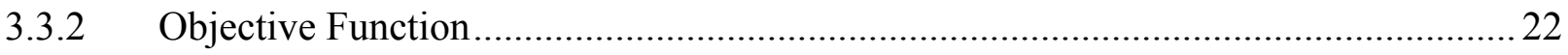

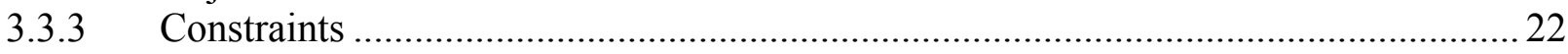

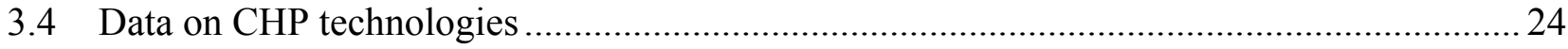

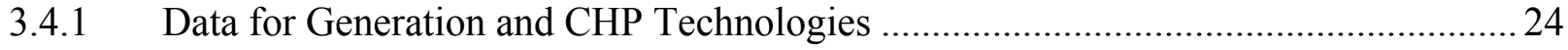

3.4.2 Absorption Cooling Technologies data ............................................................... 25

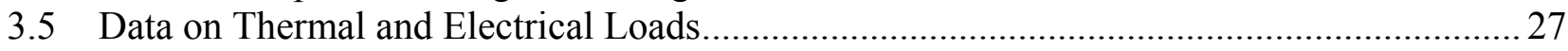

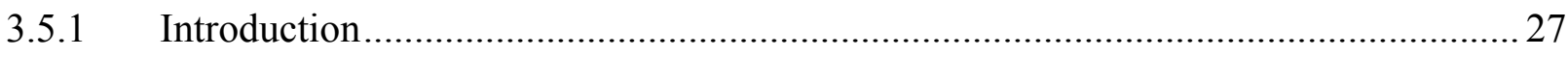

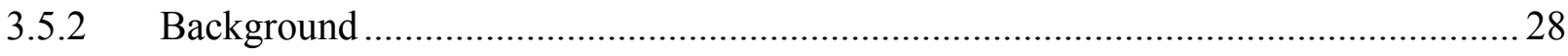

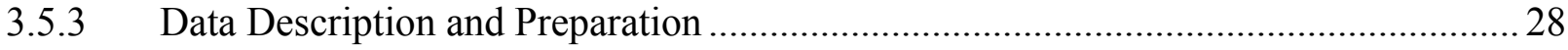




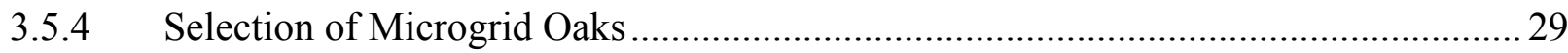

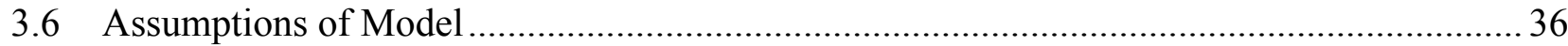

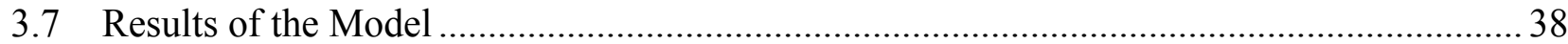

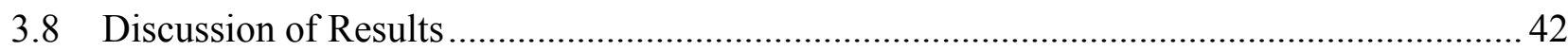

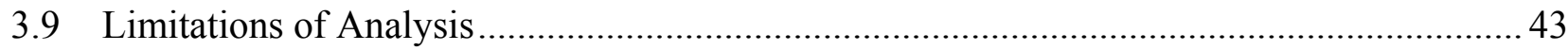

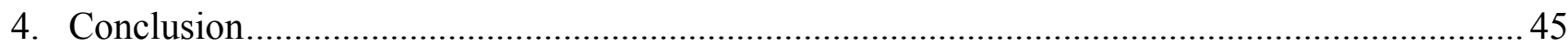

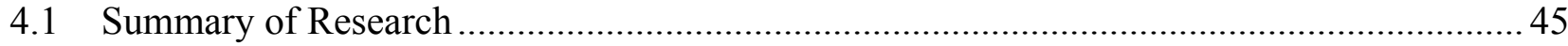

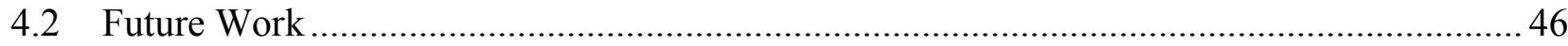

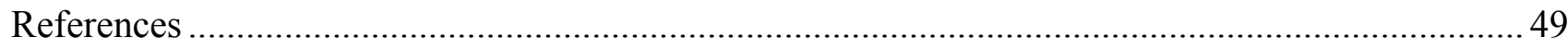

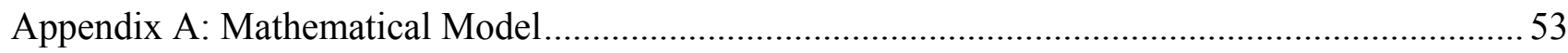

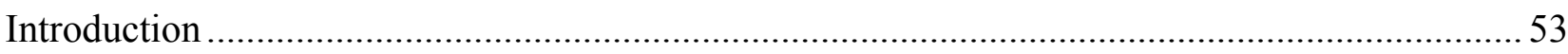

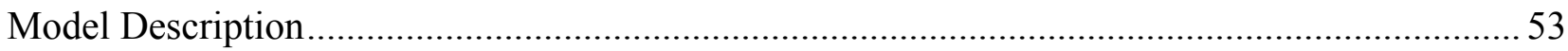

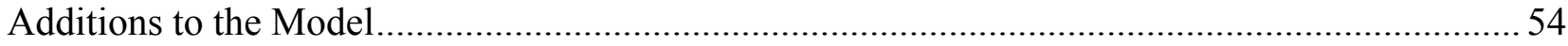

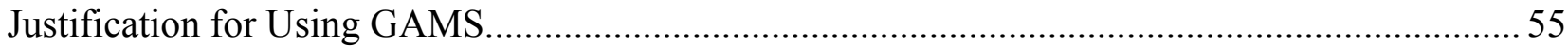

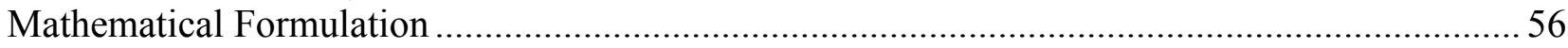

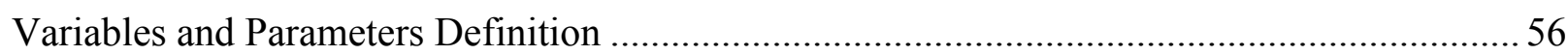

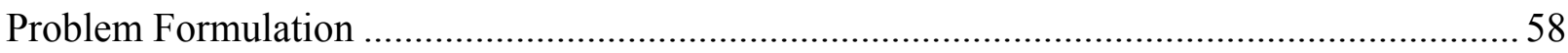

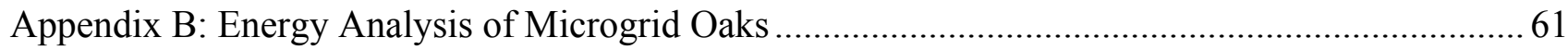

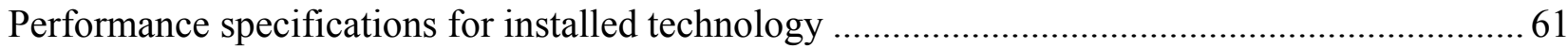

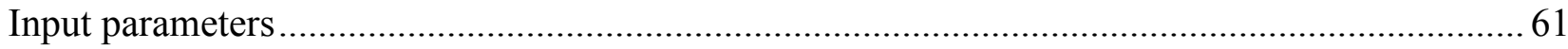

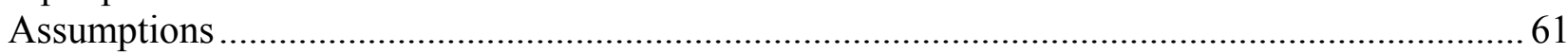

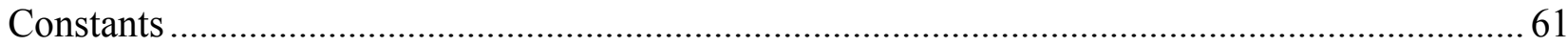

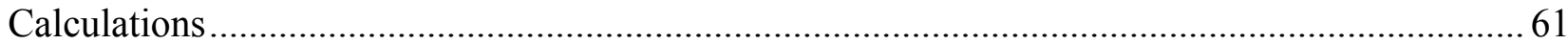




\section{List of Figures and Tables}

Table 1: Results of DER-CAM CHP Model of $\mu$ Grid ...................................................................... ix

Figure 1: CHP versus Separate Heat and Power Energy Flows............................................................ 6

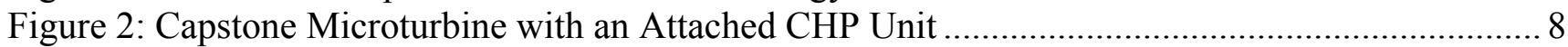

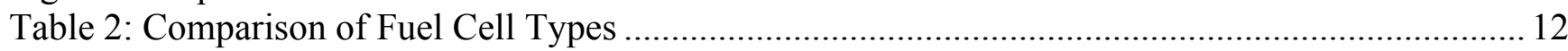

Figure 3: Single Effect Absorption Chiller .................................................................................... 15

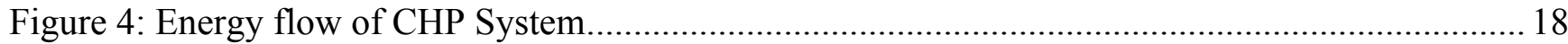

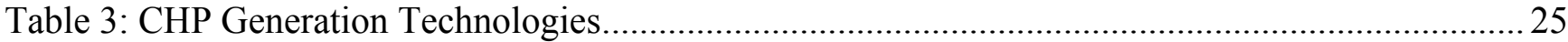

Figure 5: Thermal Cooling Capacity $(\$ / \mathrm{kW})$ versus Cooling Capacity for Absorption Chillers ........... 26

Figure 6: Thermal Cooling Capacity $(\$ / \mathrm{kW})$ versus Cooling Capacity for Small Absorption Chillers . 26

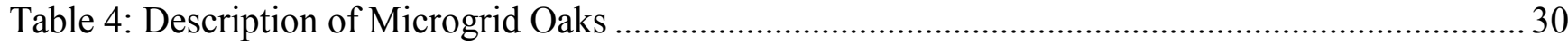

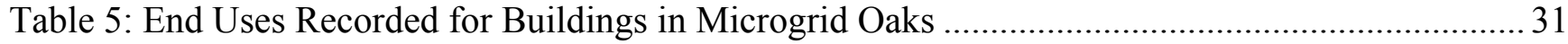

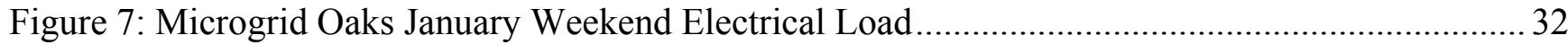

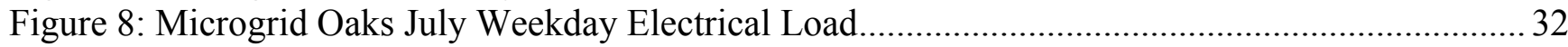

Figure 9: Microgrid Oaks January Weekend Natural Gas Load (simulated data) ................................... 33

Figure 10: Microgrid Oaks July Weekday Natural Gas Load (simulated data) ............................................ 33

Figure 11: Monthly Average Electrical Load for Microgrid Oaks ........................................................... 35

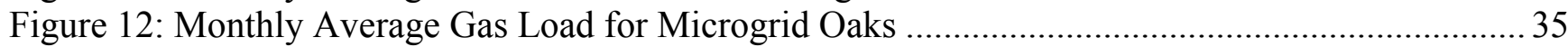

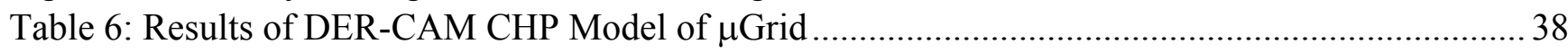

Table 7: Electricity Generation for Microgrid Oaks, Results of "DER plus CHP” Scenario ……............ 39

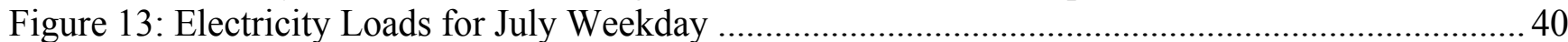

Figure 14: Electricity Load Supplied by Installed Capacity and Cooling Effect.................................... 40

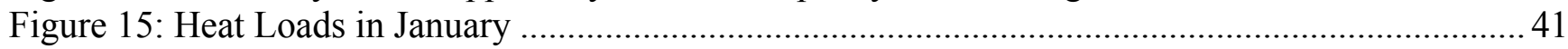

Figure 16: Heat Loads Supplied by NG purchases and CHP in January ............................................... 41 


\section{Acronyms}

$\begin{array}{ll}\text { AC } & \text { alternating current } \\ \text { CAISO } & \text { California Independent System Operator } \\ \text { CEC } & \text { California Energy Comission } \\ \text { CERTS } & \text { Consortium for Electric Reliability Technology Solutions } \\ \text { CHP } & \text { combined heat and power } \\ \text { COP } & \text { coefficient of performance } \\ \text { DC } & \text { direct current } \\ \text { DER } & \text { distributed energy resources } \\ \text { DER-CAM } & \text { Distributed Energy Resources Customer Adoption Model } \\ \text { DG } & \text { distributed generation } \\ \text { IEM } & \text { Imbalance Energy Market (of CAISO) } \\ \text { IERN } & \text { imbalance energy revenue neutrality } \\ \text { KPa } & \text { kilo Pascal } \\ \text { kW } & \text { kilowatt (power) } \\ \text { kWh } & \text { kilowatt hour (energy) } \\ \text { LHV } & \text { lower heating value } \\ \text { Mt } & \text { megaton } \\ \text { MWe } & \text { megawatt electric } \\ \text { MWth } & \text { megawatt thermal } \\ \text { NG } & \text { natural gas } \\ \text { NPV } & \text { net present value } \\ \text { OSEC } & \text { Onsite Sycom Energy Corporation } \\ \text { Pa } & \text { Pascals (unit of pressure equal to one Newton per meter squared) } \\ \text { ppm } & \text { parts per million (measure of particulate matter) } \\ \text { PQR } & \text { power quality and reliability } \\ \text { PV } & \text { photovoltaic } \\ \text { PX } & \text { Power Exchange market in California } \\ \text { PXRN } & \text { Power Exchange revenue neutral } \\ \mu \text { Grid } & \text { microgrid } \\ \text { UDC } & \text { utility distribution companionship } \\ & \end{array}$


An Engineering-Economic Analysis of Combined Heat and Power Technologies in a $\mu$ Grid Application

\section{Acknowledgements}

This work was supported by the Energy Supply and Industry Branch of the U.S. Environmental

Protection Agency, and prepared for the U. S. Department of Energy under Contract No. DE-AC0376SF00098. This work was also supported by the Edna Bailey Sussman Foundation. 


\section{Executive Summary}

This report describes an investigation at Ernesto Orlando Lawrence Berkeley National Laboratory (Berkeley Lab) of the potential for coupling combined heat and power (CHP) with on-site electricity generation to provide power and heating, and cooling services to customers. This research into distributed energy resources (DER) builds on the concept of the microgrid ( $\mu \mathrm{Grid}$ ), a semiautonomous grouping of power-generating sources that are placed and operated by and for the benefit of its members. For this investigation, a hypothetical small shopping mall ("Microgrid Oaks") was developed and analyzed for the cost effectiveness of installing CHP to provide the $\mu$ Grid's energy needs.

A $\mu$ Grid consists of groups of customers pooling energy loads and installing a combination of generation resources that meets the particular $\mu$ Grid's goals. This study assumes the $\mu$ Grid is seeking to minimize energy costs. $\mu$ Grids could operate independently of the macrogrid (the wider power network), but they are usually assumed to be connected, through power electronics, to the macrogrid. The $\mu$ Grid in this study is assumed to be interconnected to the macrogrid, and can purchase some energy and ancillary services from utility providers.

A previous study at Berkeley Lab created the Distributed Energy Resources Customer Adoption Model (DER-CAM), a software tool that optimizes DER technology choices to minimize energy costs for a given customer. Based on input data, including electrical loads and technical and cost specifications of DER equipment, DER-CAM determines the optimal combination of technology and a rudimentary operating schedule required to meet the electrical loads of the customer in the most economical fashion. In these studies, DER is used only to provide electricity to the customer, not cogeneration capability.

Incorporating CHP into the study of DER is a recent and significant effort. Adding CHP capabilities to a DER system can increase system efficiencies to as much as 80 percent, a dramatic improvement over producing electricity and heat separately, which generally has efficiencies of around 45 percent (DOE 2001). The added efficiency from CHP is a result of meeting thermal loads with the waste heat produced by electricity generation. Customers with substantial thermal loads and high electricity prices could have much to gain from investing in a CHP system. In many $\mu$ Grid systems, inclusion of CHP would provide sufficient additional economic benefit to make DER economically attractive to customers who might not otherwise have an incentive to join the $\mu$ Grid.

To analyze the cost effectiveness of installing integrated DER and CHP technologies, DER-CAM was expanded to include $\mu$ Grid thermal systems. The version of DER-CAM produced during this study determines the optimal least-cost combination of technologies to provide a $\mu$ Grid's power, heating, and cooling needs. Technologies available to the $\mu$ Grid are distributed generation (DG) technologies for producing electricity, including reciprocating engines, microturbines, fuel cells, and PV panels, and CHP technologies that capture waste heat to serve heating loads within the $\mu \mathrm{Grid}$. These heating loads include space and water heating, and building cooling and refrigeration loads that can be met by converting waste heat into cooling with absorption chillers.

To test the expansion of the DER-CAM model and to explore the possible benefits of CHP, the loads of the hypothetical buildings in Microgrid Oaks were analyzed. Unfortunately, Microgrid 
Oaks as it existed in the previous study is not an optimal candidate for CHP. This is mainly because the heat loads and electrical loads are not highly coincident. Despite this fact, there are significant potential benefits from CHP that are revealed in this study.

Three test cases were modeled to determine the impact of introducing CHP to Microgrid Oaks. The first was a "Do-Nothing" case, in which the $\mu$ Grid was modeled with no DER installed; in other words, the $\mu$ Grid had no alternative options to meet its loads other than purchasing power from the macrogrid. This scenario is the base case, which was compared to two cases that allowed for the installation of DER. The price paid for electricity purchased is based on the high 2000 California ISO imbalance energy market, resulting in an annual average price of $\$ 0.87 / \mathrm{kWh}$. The second scenario includes DER as an option for meeting loads, but no CHP technologies are included. The third test case allows both DER and CHP technologies as options.

Table 1: Results of DER-CAM CHP Model of $\mu$ Grid

\begin{tabular}{|c|c|c|c|}
\hline & Do-Nothing & No CHP & DER plus CHP \\
\hline $\begin{array}{l}\text { Total Cost } \\
\text { (Cost Index) }\end{array}$ & $\begin{array}{l}\$ 1,700,00 \\
(1.0)\end{array}$ & $\begin{array}{l}\$ 700,000 \\
(0.4)\end{array}$ & $\begin{array}{l}\$ 600,000 \\
(0.35)\end{array}$ \\
\hline Installed Capacity & 0 & $1,100 \mathrm{~kW}$ & $1,055 \mathrm{~kW}$ \\
\hline $\begin{array}{l}\text { On-site Generation } \\
\text { Technology }\end{array}$ & $\mathrm{N} / \mathrm{A}$ & $\begin{array}{l}\text { - One } 100-\mathrm{kW} \text { natural } \\
\text { gas reciprocating } \\
\text { engine } \\
\text { - Two 500-kW natural } \\
\text { gas reciprocating } \\
\text { engines }\end{array}$ & $\begin{array}{l}\text { - } \text { One 55-kW natural gas } \\
\text { reciprocating engine with } \\
\text { CHP heating } \\
\text { - Two 500-kW natural gas } \\
\text { reciprocating engines with } \\
\text { absorption chillers }\end{array}$ \\
\hline Cost Savings (\%) & 0 & $60 \%$ & $65 \%$ \\
\hline
\end{tabular}

Table 1 summarizes results from the DER-CAM analysis for the three test cases. Notably, in both cases that allowed DER technologies as options for energy sources, the model selected these technologies (indicated in bold in Table 1) as part of the optimal cost solution. Each successive scenario decreased energy costs. However, the test case allowing the installation of CHP systems show only marginally decreased energy costs for the $\mu \mathrm{Grid}$. The total energy cost of the $\mu$ Grid with DER installed is \$1.7 million, which is \$1 million more than the cost of energy with DER but without CHP. Adding CHP reduces the total cost by an additional $\$ 0.1$ million. In other words, providing the $\mu$ Grid's power with DER technologies reduces energy costs by about 60 percent, and providing the $\mu$ Grid's power and heat with DER plus CHP reduces the $\mu$ Grid's costs a further 5 percent.

The two DER scenarios optimize costs by installing different amounts of generation capacity. When DER are introduced, $1,100 \mathrm{~kW}$ of DG capacity is installed, which could cover 95 percent of the $\mu$ Grid's peak load of $1,159 \mathrm{~kW}$. Adding CHP lowered the installed capacity to $1,055 \mathrm{~kW}$, which potentially provides 91 percent of the peak electricity load. Even though less generation is installed and more electricity must be purchased from utilities, costs are lower for the CHP scenario because of smaller natural gas purchases. Saving gas by installing CHP to meet heat loads is more cost effective than installing enough generation capacity to meet all electrical demand. Moreover, 
extremely high electricity demand happens only a few times per year, so, for most of the time, the entire electrical load of the $\mu$ Grid can be met by the installed generation, if economics so dictate.

The total operating cost for each alternative is the levelized value of all the capital and operating costs of each system for one test year. Therefore, installing a system with a lower annual operating cost than the Do-Nothing scenario is financially equivalent to receiving an annual benefit each year for the lifetime of the system. The size of this annual benefit is determined by the difference between the total annual cost of the Do-Nothing scenario and the alternative scenario. The results indicate that installing a DER system to provide electricity is equivalent to saving approximately $\$ 1$ million each year for the lifetime of the DER system. Similarly, installing DER plus CHP is equivalent to saving roughly $\$ 1.1$ million in cash each year for the lifetime of the CHP/DER systems.

From the perspective of the macrogrid, the residual power load from the $\mu$ Grid is reduced considerably after the installation of DER. In the first case (DER without CHP) the $\mu$ Grid generated more than $6,000 \mathrm{MWh}$ of electricity, reducing its purchases from the macrogrid by the same amount. The CHP case also generated more than 6,000 MWh of electricity. These cases represented slightly less than a 100 percent reduction in electricity purchased from the macrogrid

Installing DER also meant that fewer natural resources were consumed to meet the same power load. Adding DER to the base case increased energy-efficiencies to 30 percent. This reduction in resource consumption is the result of meeting more loads with the same amount of fuel by capturing and using waste heat. The reason that the increase in energy efficiency is smaller than the theoretical 80 percent potential reduction is the small thermal load to electrical load ratio in Microgrid Oaks. The electrical load in Microgrid Oaks is 10 times larger than the thermal load (6,000 MWh electric and $600 \mathrm{MWh}$ thermal). As a result, the residual heat from electricity generation is not all used productively. Increasing the thermal loads would result in an increase system in energy-efficiency values beyond the 33 percent achieved by DER plus CHP in the current study. A higher efficiency level would result from thermal load to electric load ratios that are matched to the useable heat and electrical output ratios of the CHP technologies. 


\section{Purpose of Research}

\subsection{Objective}

This research investigates the effects of incorporating combined heat and power (CHP) technologies with distributed energy resources (DER) in a small collection of hypothetical businesses grouped together to form a microgrid ( $\mu \mathrm{Grid})$. The goal is to develop an engineering-economic model for the selection and adoption of technology options for meeting a $\mu$ Grid's energy needs.

A $\mu$ Grid is a semiautonomous grouping of power-generating sources (DER) that are located near the point at which the generated energy is consumed and are operated for the benefit of the $\mu$ Grid's members. A $\mu$ Grid can operate independently of the wider power network, but would more likely be connected to the macrogrid for much of the time.

DER include technologies such as fuel cells, microturbines, reciprocating engines, PV panels, small wind turbines, and energy-efficiency technologies. CHP technologies utilize waste heat produced by these on-site generators to serve heating and cooling loads. Incorporation of CHP capabilities is viewed as key to the economic viability of DER. This research tests that assumption by expanding the Distributed Energy Resources Consumer Adoption Model (DER-CAM) ${ }^{1}$. The cost of purchasing and maintaining a CHP system modeled by DER-CAM is compared to the baseline condition of providing heat and power separately by purchasing all electricity and natural gas from the macrogrid.

DER could offer many benefits to customers and distribution companies. These benefits include: reduced cost relative to retail rates, improved reliability and power quality, cogeneration capability, peak shaving, reduced electrical losses, and reduced emissions for many technologies (e.g., PVs) (Marnay et al. 2000). After many years of little development in CHP technology, CHP offers a promising opportunity to increase power and heat conversion efficiencies to 60 to 80 percent, substantially reducing emissions and providing financial benefits to customers (Laitner et al. 1999). However, few models exist to evaluate the potential economic benefits of integrating CHP with DER based on customer's electrical and thermal energy use patterns.

Previous DER-CAM work focused on analyzing the impact of aggregating businesses to increase load so that distributed generation (DG) is efficient and economically feasible. This study focuses on the economic energy-efficiency benefits of incorporating CHP technology into $\mu$ Grids.

\subsection{Method}

This research project develops a fictional $\mu$ Grid composed of a group of neighboring small businesses. DER-CAM, a mixed-integer linear cost-minimization model, is used to determine the most cost-effective combination of technologies for meeting this $\mu$ Grid's energy demands given its hourly energy consumption patterns over the year. The model optimizes energy costs by selecting

\footnotetext{
${ }^{1}$ DER-CAM was developed at Ernest Orlando Lawrence Berkeley Laboratory (Berkeley Lab) in order to analyze the economic impact of DER installation on customers.
} 
DER and CHP technologies and specifying their hourly-operating schedules to establish the leastcost scenario.

The DER-CAM model optimizes energy costs based on a set of input data that includes economic and technical specifications for existing CHP and DG technologies, heat and electricity loads of the buildings in the $\mu \mathrm{Grid}$, and market electricity and natural gas prices. Data on CHP technologies, including capacities, power and heat output, and capital and operating costs, were obtained from manufacturers. A year's worth of hourly electricity consumption profiles for different types of buildings that make up the $\mu$ Grid were obtained from an end-use metering data set compiled by SCE for the years 1988 and 1989. The corresponding hourly thermal loads were developed using DOE-2, a building energy simulation program developed at Berkeley Lab; simulated data was used because measured end-use thermal load data were not available. Electricity prices were set to the California Independent System Operator (CAISO) imbalance energy market prices from 2000. Natural gas prices were fixed at $\$ 8.66 /$ GJ, the average price for natural gas in San Diego during 2000 . 


\section{Background on $\mu$ Grids and CHP Technology}

\subsection{Introduction to $\mu$ Grid Concept}

The expectation that DER will, over the next decade, shape the way in which electricity is supplied stems from the following assumptions:

1. Small-scale generating technology, both renewable and thermal, will improve significantly.

2. Siting constraints, environmental concerns, fossil fuel scarcity, and other limits will impede continued expansion of the existing electricity supply infrastructure.

3. Customers' desire for control over service quality and reliability will intensify.

4. Power electronics will enable operation of semi-autonomous systems.

5. The potential for application of small-scale CHP technologies will tilt power generation economics in favor of generation based closer to heat loads.

Although assumption number five is the focus of this study, the fourth is the driving force behind the Consortium for Electric Reliability Technology Solutions (CERTS) approach to modeling DER, which is built upon the fundamental concept of the $\mu$ Grid. A $\mu$ Grid is a localized, semi-autonomous grouping of loads and generation operating under coordinated local control, which could be either active or passive (passive "plug and play" control appears to be the most economically attractive option). The $\mu$ Grid is connected to the current power system, or macrogrid, in a manner that allows it to perform as a traditional electricity customer or generating unit under macrogrid rules.

The $\mu$ Grid would most likely be a small, dense group of geographically contiguous sites that exchange electrical energy through a low-voltage (e.g., $480 \mathrm{~V}$ ) network and heat through the exchange of working fluids. The generators and loads within the $\mu$ Grid would be placed and coordinated to minimize the joint cost of serving electricity and heat demand, given prevailing market conditions, and to operate safely and maintain power balance and quality.

Traditional power system planning and operation hinged on the assumption that the selection, deployment, and financing of generation will be tightly coupled to changing requirements and that these decisions will rest in the hands of a centralized authority. The Public Utility Regulatory Policy Act (1978) was the first step toward abandoning this centralized paradigm. The on-going deregulation of macrogrid generation represents the second step, while the possible future emergence of $\mu$ Grids represents the third. $\mu$ Grids would develop their own independent operational standards and expansion plans. The development of $\mu$ Grids would significantly affect the overall growth of the power system, and it will tend to take place in response to the customers' incentives to form a $\mu \mathrm{Grid}$. In other words, the power system would expanding according to the dispersed independent goals of customers, not in response to coordinated global goals articulated by a centralized authority.

The $\mu$ Grid concept partially stratifies the current strictly hierarchical control of the power system into at least two layers. The upper layer macrogrid is the high-voltage meshed power grid with which current power engineers are familiar. In the macrogrid, a control center dispatches a limited number of large assets in keeping with contracts established between electricity and ancillary services buyers and sellers, and maintains energy balance and power quality, protects the system, 
and ensures reliability. The $\mu$ Grid would reside within the macrogrid and would control some generation and load locally to meet $\mu$ Grids members' end use requirements for energy as well as power quality and reliability $(\mathrm{PQR})$.

Control of the generating and transmission assets of the macrogrid would be governed by extremely precise uniform regional technical standards, and the key parameters of the macrogrid, such as frequency and voltage, would be strictly maintained within tight tolerances. This control paradigm would ensure overall stability and safety and would attempt to guarantee that power and ancillary service delivery between sellers and buyers is as efficient and reliable as reasonably possible. However, it should be recognized that uniform standards of PQR are unlikely to match precisely the optimal requirements of highly heterogeneous individual end uses (e.g. server farms at one end of the reliability requirement spectrum and irrigation water pumps at the other). $\mu$ Grids enable a higher level of control over PQR closer to the end uses that consume the power and thus allow the PQR standards to be effectively matched to the need of the end uses. $\mu$ Grids can improve the overall efficiency of electricity delivery at the point of end use so that the PQR standards of the macrogrid can ultimately be matched to the purpose of bulk power delivery.

Based on simple busbar ${ }^{2}$ cost, $\mu$ Grid electricity generation is unlikely to be competitive with central station generation in most instances and at most times. However, the $\mu$ Grid can deliver some offsetting benefits that could turn the economic tables very much in its favor. The first benefit is that the cost of on-site electricity generation competes only with retail grid electricity prices and not the busbar cost, the former being typically more than twice the latter in California. Another overarching potential benefit, as noted above, is improved PRQ at the point of end use. Finally, $\mu$ Grids offer the potential to employ CHP technologies, which utilize the waste heat from energy conversion of primary fuel to electricity. This process improves the fuel-to-power efficiency, thus decreasing the amount of fuel needed to meet the same power need. Purcahsing less fuel saves the customer money in fuel costs. Because one-half to three-quarters of the primary energy consumed in power generation is typically released unutilized to the environment as waste heat, the potential gains from using this heat productively are significant. In addition to decreasing fuel costs to individual customer, a general decrease in fuel demand would drive down the demand for fuel and fuel prices in general would fall as a result.

There are two main wider environmental benefits of increased overall conversion efficiency. First, carbon emissions from power plants and generators would be reduced. Second, the environmental problem of disposing of power plant waste heat into the environment would diminish. The emergence and deployment of technologies to facilitate efficient local use of waste heat, is, therefore, one of the key technologies that will enable $\mu$ Grids to emerge as significant contributors to the national electricity supply.

\subsection{Introduction to CHP}

CHP provides energy services by capturing excess heat from the electricity generation process and using the captured waste heat to meet other energy needs. CHP has also been called "cooling, heat, and power" in reference to the three energy services it provides (Sweetser 2001). Unlike electricity,

\footnotetext{
${ }^{2}$ Busbar cost is the net cost of producing electricity to the point it enters common facility wiring.
} 
heat, usually in the form of steam or hot water, cannot be easily or economically transported long distances. Therefore CHP systems typically provide thermal energy for local requirements such as space heating or cooling, process heat, refrigeration, or water heating needs. To make CHP systems viable, a sufficiently large need for heat must exist within a sufficiently dense area so that circulation of steam, hot water, or another appropriate medium is feasible and economic. Use of waste heat in CHP systems is more prevalent in non-U.S. economies; in the U.S. CHP applications are only commonly found in industrial facilities. However, in Denmark, for example, CHP plants supplied 48 percent of the domestic electricity demand in 1996 (Danish Energy Agency 1998). Reliance on CHP to this degree is estimated to reduce $\mathrm{CO}_{2}$ emissions by approximately 7 to $10 \mathrm{Mt}$ per year, or more than 10 percent of the total $\mathrm{CO}_{2}$ emissions of Denmark, compared the emissions from separate heat and power production (Hammar 1999). CHP units 2 to 4 MWe are typically the best size for the Danish local district heating systems; these units power approximately 100 to 250 households plus two large institutions or a net heat demand of approximately 20 TJ (Danish Energy Agency 1998). Other European countries relying on large-scale CHP include the Netherlands, which produces about 30 percent of its power from CHP systems, Germany, which produces about 14 percent, and Italy, which produces about 12 percent (Sargent 2001). In comparison, the U.S. produces only about 9 percent of its power from CHP systems (U.S. DOE 1998).

CHP is a method of increasing productivity by increasing the number of loads served by the fuel consumed to generate a particular amount of power. The average efficiency of producing separate heat and power, which is around 45 percent, can be increased to more than 80 percent if the waste heat produced from electricity generation is utilized (DOE 2001). Figure 1 shows the typical fuel input needed to produce 35 units of electricity and 50 units of heat using conventional separate heat and power. For typical electrical and thermal efficiencies, CHP is nearly twice as efficient. 


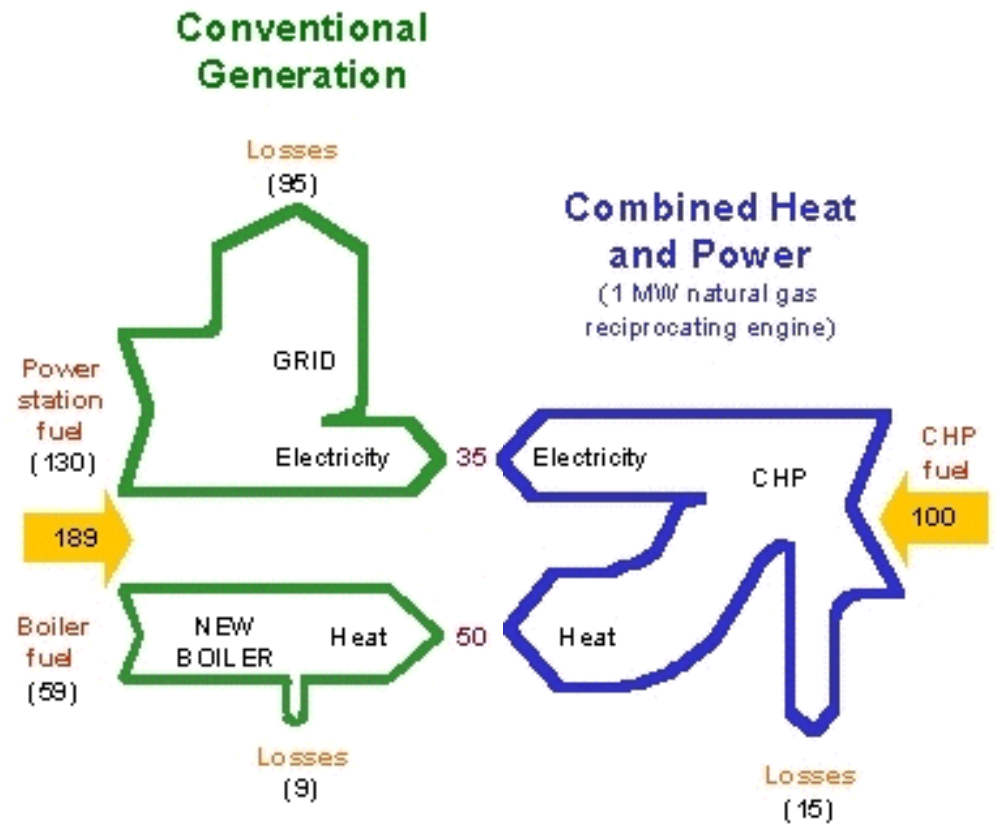

Figure 1: CHP versus Separate Heat and Power Energy Flows

Source: DOE's CHP Initiative http://www.eren.doe.gov/der/chp/.

CHP systems have the potential to use heat output from power generation for meeting cooling needs. A compressor-driven cooling system running on electricity could be replaced by an absorption chiller that provides cooling by using rejected heat from power generation or from a natural-gas-fired burner. This system reduces, peak load demand by shifting what is typically a large peak-coincident electrical load from air conditioning to a thermal load. From the perspective of the utility, this strategy reduces peak system load at times of greatest demand where the marginal cost of power is the highest. Similarly, at the $\mu$ Grid level, reduction in the demand for peak power has a direct effect on the capital and operating costs of meeting electricity requirements.

CHP systems installed in a $\mu$ Grid could have two significant advantages over CHP systems applied to independent installations:

1. The aggregation of power and thermal loads can provide opportunities to maximize the energy productivity from CHP systems. In addition to simple economies of scale, a $\mu$ Grid with a diverse profile of heating, cooling, and electrical loads is more likely to effectively utilize heat for thermal loads. $\mu$ Grids could be designed to have aggregate load factors that result in a favorable power to heat ratio. Careful design can enhance the financial benefits of sharing the capital and operating costs of the CHP equipment.

2. The production of heat can be deliberately located near its use to reduce thermal losses. In an extreme example, high-temperature fuel cells could be placed on every floor of a hospital to provide the hot water for that floor. Because electricity is more readily transported than heat, generation close to heat loads will usually make more sense than generation close to electrical loads. In fact, the same principle holds with large power plants, which tend to be sited close to sources of cooling water but distant from customers. Because $\mu$ Grids permit operation of small diverse generators in a passively coordinated manner, generators can be optimally placed 
An Engineering-Economic Analysis of Combined Heat and Power Technologies in a $\mu$ Grid Application

relative to loads, and electricity not used locally can be transported at low voltage to nearby loads.

\subsection{End-Use Applications of CHP}

DER and CHP technologies offer the greatest potential economic and energy productivity benefits where the following characteristics are present:

- Electric and thermal loads are relatively coincident,

- There are thermal energy loads in the form of steam or hot water,

- Thermal demand (steam and hot water) to electric demand ratios are similar to the ratios for available CHP technologies (for this analysis, a ratio of about 3:1), and

- The system is operated $>4000$ hours per year (OSEC 2000).

There are many applications for using excess heat from small-scale on-site generation systems, particularly in the industrial sector. In the commercial sector, the primary option is direct hot water use, e.g. for dish washing, sterilization or space heating. Commercial hot water usage tends to be concentrated at a limited number of types of sites, such as hospitals, hotels, and restaurants, which are promising hosts for DER with CHP capabilities. Extra electricity can be delivered to neighboring $\mu$ Grid customers that have minimal heat requirements, e.g., stores, offices, and residences. Some analysts have emphasized the potential for small-scale systems to serve the residential sector (Deppe \& Kaarsburg 2001). Most hot water and space heating applications are fairly simple, so there are few technical barriers to widespread adoption.

Domestic hot water demand is usually coincident with the electrical load in buildings and not significantly seasonally dependant, so it is a good CHP application (OSEC 2000). Space heating requirements vary significantly by season, so the economics of this CHP application are likely to be highly variable.

In most parts of the U.S., building cooling is required in addition to building heating. Meeting this peaky, weather-sensitive load imposes high costs on the centralized power system. For example, in California air conditioning is estimated to be responsible for about 29 percent of peak electricity demand, yet this end-use consumes only about 7 percent of the state's electrical energy (Brown \& Koomey 2001). Refrigeration, although it is less weather sensitive and has a high load factor, actually represents an even larger share of total electricity requirements in California, about 8 percent. The $\mu$ Grid must at a minimum be able to effectively provide electricity for these major end uses; using waste heat to provide cooling would be an additional benefit.

Absorption chillers (described in more detail in Section 2.5) are a CHP technology that converts waste heat into cooling power. These chillers can be used to convert waste heat into cooling for sites with significant refrigeration or air conditioning loads. Serving cooling loads with absorption chillers has many benefits. For one thing, absorption cooling decreases the electrical load at the same time it utilizes heat waste whereas other CHP technologies only decrease natural gas demand. Absorption cooling also increases the total thermal load and thereby provides a year-round sink for waste heat from electrical generation. Larger thermal loads tend to improve the efficiency and economy of a CHP system. Another major benefit of absorption cooling is that it can reduce the 
cooling load that is often a major part of a customer's daily and seasonal peak energy demand, which is the most expensive load to meet. Even if the $\mu$ Grid is not paying a true real-time price, lowering peak energy use may substantially reduce demand charges and provide immediate reductions in members' utility bills. Use of thermal storage can further flatten the load.

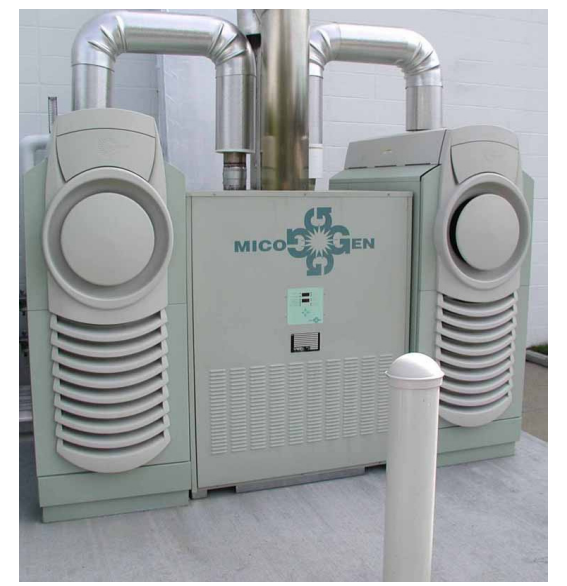

Figure 2: Capstone Microturbine with an Attached CHP Unit Source: Capstone Turbine www.capstoneturbine.com

\subsection{Technologies for CHP}

There are numerous small-scale generating technologies that could be used for CHP systems; these technologies use different methods to recover heat. The small-scale power generation technologies most favorable for CHP are reciprocating engines, microturbines, and fuel cells. Microturbines offer higher-temperature heat output than reciprocating engines and thus can provide greater benefits in cogeneration applications (EPRI 1999). Two European manufacturers specialize in CHP microturbines: Bowman (U.K.) and Turbec (a joint venture of Volvo and ABB). In the U.S., Capstone is developing a package system that captures waste heat from the Capstone microturbine and allows the captured heat to be used for serving thermal loads. High-temperature fuel cells also provide premium heat for CHP systems. The subsections below focus on reciprocating engines, microturbines and fuel cells and methods to extract useful heat from them. Note that renewable sources of electricity, such as PV panels, wind, or hydro are not potential CHP sources. However, if renewable technologies were used to fuel reciprocating engines, microturbines, or fuel cells, more useful energy would be extracted from these renewable fuels in the form of waste heat.

The source of the information in the subsections below is a 1999 Onsite Sycom Energy Corporation (OSEC) report titled Review of Combined Heat and Power Technologies (OSEC 1999) unless otherwise cited. This report was prepared for California Energy Commission (CEC) and the US DOE Office of Industrial Technologies. ${ }^{3}$ The OSEC report was the best publicly available source that could be found for performance specifications for DER technologies during the course of this study. The cost and performance numbers provided are general estimates for each class of technologies. Although values provide useful background information for each class of technology,

\footnotetext{
${ }^{3}$ This report is available at http://www.eren.doe.gov/der/chp/docs_resources.html
} 
they were replaced with data supplied by specific manufacturers in the DER-CAM modeling efforts for this study.

\subsubsection{Reciprocating Engines}

Reciprocating engines by far are the most common type of DG technology in use today. They are the most popular technology for providing back-up, mobile, or remote power. Reciprocating engines come in two common types: four-cycle spark-ignited (Otto cycle) and compression-ignited (diesel cycle) engines. Reciprocating engines can also be classified by the type of fuel they use; natural gas and diesel are common.

\section{Performance Characteristics}

The features that have made reciprocating engines a leading technology for CHP include:

- Cost per kilowatt is competitive for a large range of capacities.

- Rapid-start capability allows the engine to provide electricity quickly during rapid surges in demand or as an emergency back-up.

- In the event of an electric utility outage, reciprocating engines can be started with minimal auxiliary power requirements; generally only batteries are required for black-start.

- Reciprocating engines have typically demonstrated purchase availability in excess of 95 percent.

- In electric load-following applications, the high-part load efficiency of reciprocating engines maintains economical operation.

- Reciprocating engines, particularly diesel and industrial block engines, provide many years of satisfactory service given proper maintenance.

\section{Power and Heat Output}

Reciprocating engines typically have electrical efficiencies of 25 to 50 percent lower heating value (LHV). Larger engines and diesel engines tend to have higher efficiencies than smaller sparkignition engines. Energy from fuel is converted into mechanical drive power and heat. The heat is released as engine cooling jacket heat, which is removed by a fluid loop, and as heat in the combustion exhaust. Approximately 60 to 70 percent of the total input energy is converted to heat that can be recovered from the jacket coolant and engine exhaust. A closed-loop pressurized jacket hot-water cooling system is typically used for capturing engine heat, which accounts for about a third of the input energy. Hot water can be obtained at about $90^{\circ} \mathrm{C}-120^{\circ} \mathrm{C}$ from these systems.

Ebullient cooling systems reduce engine temperature by naturally circulating boiling coolant through the engine. This type of system is used more often for producing low-pressure steam. The coolant is limited to $120^{\circ} \mathrm{C}$ or saturated steam conditions. This system provides many benefits including extended engine life and improved combustion efficiencies because of uniform coolant circuit temperature.

About 10 to 30 percent of fuel input energy emerges in the engine exhaust at temperatures of about $450^{\circ} \mathrm{C}$ to $650^{\circ} \mathrm{C}$; less than 40 percent of this heat is recoverable in order to keep the gas above its condensation point. As a result, most heat-recovery units are designed for a $150^{\circ} \mathrm{C}$ to $177^{\circ} \mathrm{C}$ exhaust outlet temperature to avoid corrosive condensation in exhaust piping. This heat can be used to generate hot water at approximately $110^{\circ} \mathrm{C}$ or low-pressure steam at $100 \mathrm{kPa}$. The end result is 
that overall utilization of about 75 percent of the input energy of a reciprocating engine is possible with CHP technologies.

\section{Capital and Operating Costs}

The capital costs for reciprocating engines is typically around $\$ 800-1,500$ per $\mathrm{kW}$ depending on the capacity and site specific installation and operating costs other sources put this range as low as $\$ 500$ per kW (E Source 1996). Maintenance costs are typically \$0.01-0.015 per kWh including overhauls (OSEC 1999; E Source 1996). Yearly maintenance includes changing the oil and filters, spark plugs, spark plug wires, and adjusting valves, all of which cost about $\$ 150$ annually (E Source 1996).

\subsubsection{Microturbines}

Microturbines are small gas turbines with capacities from $30 \mathrm{~kW}$ to about $100 \mathrm{~kW}$, although larger ones are under development. The design of microturbines is simple with only one shaft with attached compressor, turbine, and permanent-magnet generator spinning at high rotational speed (up to $100 \mathrm{kr} / \mathrm{min}$ ) on air bearings. Microturbines can burn a variety of fuels including natural gas, gasoline, diesel, alcohol, and propane.

Microturbines typically include a recuperator that preheats the incoming compressed air, which increases electrical efficiency. Recuperators, however, also cool the exhaust gas and hence limit the residual thermal energy available for use. Some microturbine manufactures include a recuperator bypass value that reduces the electrical efficiency but can increase overall system efficiency by increasing the recoverable heat available. This option also provides increased flexibility to balance electricity and heat production to demands on site.

\section{Performance Characteristics}

A recuperator uses heat from combustion to preheat the inlet combustion air and increasing the electrical efficiency to approximately 20 to 30 percent LHV. These combustion temperatures are below NOx formation levels.

Currently the prices are approximately $\$ 1,200$ to $\$ 1,700 / \mathrm{kW}$ installed, but capital costs of $\$ 500$ to $\$ 1,000 / \mathrm{kW}$ installed for CHP applications are expected when microturbines are mass-produced. Estimated availabilities will be in the 90 percent to over 95 percent range.

\section{Power and Heat Output}

While typical microturbine efficiencies for power generation are at around 30 percent, the electrical efficiency falls to about half of that when the recuperator bypass is engaged. In this case, however, the overall thermal efficiency may rise to about 80 percent. The exhaust gas temperature is typically about $260^{\circ} \mathrm{C}$ while using the recuperator and $870^{\circ} \mathrm{C}$ with the recuperator bypassed (E Source 1996). Not all of this heat can be effectively transformed into useful energy. Capstone's unit, when joined with a CHP heat recovery unit, produces hot water at about $90^{\circ} \mathrm{C}$.

\section{Capital and Operating Costs}

Microturbines use a simple design with few moving parts to improve reliability and reduce maintenance costs. Most microturbines use air bearings and air cooling, eliminating the need for cooling water or oil. Combustion air filter changes and visual inspections are the expected routine 
maintenance. Because microturbines have not been in wide use for very long, the estimates for maintenance costs range from the OSEC estimate of $\$ .006$ to $\$ .01 / \mathrm{kWh}$ to other estimated costs of $\$ .04 / \mathrm{kWh}$ and $\$ .015 / \mathrm{kWh}$ (E Source 1996; Bowman 2001).

\subsubsection{Fuel Cells ${ }^{4}$}

Fuel cells operate by combining hydrogen with oxygen to produce electricity, heat, and water. A DC current and heat are produced by a chemical reaction rather than by a mechanical process driven by combustion. Fuel cells can operate as long as fuel is being supplied, as opposed to the fixed supply of chemical energy in a battery. They are quiet and depending upon the fuel source for the hydrogen atoms, are relatively clean sources of power.

Fuel cells operate at electrical efficiencies around 40 to 60 percent LHV of the consumed fuel, and up to 85 percent in CHP applications. The fuel cell's efficiency is independent of its capacity and these units may be combined into "stacks" to increase the power output. Due to the high price of fuel cells they are entering the market in specialized applications where their performance characteristics are worth the premium price.

A fuel cell is composed of several components: a fuel reformer to generate hydrogen-rich gas, a power section where the electrochemical process occurs and a power conditioner to convert the direct current (DC) generated in the fuel cell into alternating current (AC). The reforming process separates the hydrogen atom in the fuel from other contaminates that would contaminate the catalytic electrodes. The fuel is reformed externally in low temperature fuel cells and it may be reformed internally for high temperature fuel cells. The fuel cell generates electricity when a catalyst separates the electrons on a hydrogen molecule and the hydrogen ion passes through an electrolyte. The electrons flow around the electrolyte from the anode (negative electrode) to the cathode (positive electrode) creating electric current. The hydrogen ion and the electrons combine with oxygen $\left(\mathrm{O}_{2}\right.$ - the oxidant) supplied to the cathode forming $\mathrm{H}_{2} \mathrm{O}$ and releasing heat. Electrical energy is generated from the electrochemical oxidation of the fuel and the electrochemical reduction of the oxidant.

There are four main types of fuel cells being developed for the commercial power market. The form of their electrolyte typically defines them: proton exchange membrane (PEMFC), phosphoric acid (PAFC), molten carbonate (MCFC), and solid oxide (SOFC) fuel cells. The characteristics of these fuel cells are described in Table 2 and are listed in order of increasing operating temperature.

\footnotetext{
${ }^{4}$ The information on fuel cells was obtained from a Onsite Sycom Energy Corporation (OSEC 1999) report titled "Review of Combined Heat and Power Technologies" prepared for California Energy Commission and Office of Industrial Technologies, and the U.S. DOE, and from the "Fuel Cell Handbook," $4^{\text {th }}$ and $5^{\text {th }}$ editions produced for the U.S. DOE. See the reference section for details.
} 
An Engineering-Economic Analysis of Combined Heat and Power Technologies in a $\mu$ Grid Application

Table 2: Comparison of Fuel Cell Types

\begin{tabular}{|c|c|c|c|c|}
\hline & $\begin{array}{l}\text { Proton } \\
\text { Exchange } \\
\text { Membrane } \\
\text { (PEMFC) }\end{array}$ & $\begin{array}{l}\text { Phosphoric } \\
\text { Acid } \\
\text { (PAFC) }\end{array}$ & \begin{tabular}{|l|} 
Molten \\
Carbonate \\
(MCFC)
\end{tabular} & $\begin{array}{l}\text { Solid Oxide } \\
\text { (SOFC) }\end{array}$ \\
\hline Electrolyte & $\begin{array}{l}\text { Perfluorated } \\
\text { sulphonated } \\
\text { polymer (solid) }\end{array}$ & $\begin{array}{l}\text { Stabilized } \\
\text { Phosphoric acid }\end{array}$ & $\begin{array}{l}\text { Molten carbonate } \\
\text { solution }\end{array}$ & $\begin{array}{l}\text { Ceramic solid } \\
\text { electrolyte }\end{array}$ \\
\hline $\begin{array}{l}\text { Typical Unit } \\
\text { Sizes }(\mathrm{kW})\end{array}$ & $0.1-500$ & $\begin{array}{r}5-200 \text { (plants up } \\
\text { to } 5,000)\end{array}$ & $\begin{array}{l}800-2000 \text { (plants } \\
\text { up to } 100,000)\end{array}$ & $2.5-100,000$ \\
\hline $\begin{array}{l}\text { Electric } \\
\text { Efficiency }\end{array}$ & Up to $50 \%$ & $40-45 \%$ & $50-55 \%$ & $45-50 \%$ \\
\hline $\begin{array}{l}\text { Installed Cost } \\
(\$ / \mathrm{kW})\end{array}$ & 4,000 & $3,000-3,500$ & $800-2,000$ & $1,300-2,000$ \\
\hline $\begin{array}{l}\text { Commercial } \\
\text { Availability }\end{array}$ & $\begin{array}{l}\mathrm{R} \& \mathrm{D} / \text { close to } \\
\text { deployment }\end{array}$ & Yes & R\&D & $\mathrm{R} \& \mathrm{D}$ \\
\hline $\begin{array}{l}\text { Power Density } \\
\mathrm{kg} / \mathrm{kW} \\
\mathrm{m}^{3} / \mathrm{kW}\end{array}$ & $\begin{array}{l}4-5 \\
\sim 0.06\end{array}$ & $\begin{array}{l}\sim 11 \\
0.01\end{array}$ & \begin{tabular}{|l|}
$\sim 30$ \\
$\sim 0.03$
\end{tabular} & $\begin{array}{l}\sim 20 \\
\sim 0.03\end{array}$ \\
\hline $\begin{array}{l}\text { Heat Rejection } \\
\text { (kWh thermal/ } \\
\text { kWh electric) }\end{array}$ & $\begin{array}{l}0.481 \mathrm{kWh} \\
\text { (a) } 0.8 \text { volts }\end{array}$ & $\begin{array}{l}0.551 \mathrm{kWh} \\
\text { @ } 0.7 \text { volts }\end{array}$ & $\begin{array}{l}0.25 \mathrm{kWh} \\
\text { (a) } 0.8 \text { volts }\end{array}$ & $\begin{array}{l}0.522 \mathrm{kWh} \\
\text { (a) } 0.6 \text { volts }\end{array}$ \\
\hline $\begin{array}{l}\text { Electric/Thermal } \\
\text { Energy }\end{array}$ & $\sim 1$ & $\sim 1$ & Up to 1.5 & Up to 1.5 \\
\hline Oxidation Media & Oxygen from air & Oxygen from air & Oxygen from air & Oxygen from air \\
\hline Cooling Medium & Water & Boiling water & Excess air & Excess air \\
\hline Fuel & $\begin{array}{l}\text { H2 and reformed } \\
\text { H2 }\end{array}$ & $\begin{array}{l}\text { H2 reformed from } \\
\text { natural gas }\end{array}$ & $\begin{array}{l}\mathrm{H} 2 \text { and } \mathrm{CO} \\
\text { reformed } \\
\text { internally from } \\
\text { natural gas or } \\
\text { coal gas } \\
\end{array}$ & $\begin{array}{l}\mathrm{H} 2 \text { and } \mathrm{CO} \\
\text { reformed } \\
\text { internally from } \\
\text { natural gas or } \\
\text { coal gas } \\
\end{array}$ \\
\hline $\begin{array}{l}\text { Operating Temp } \\
\text { (C) }\end{array}$ & $\sim 100{ }^{\circ} \mathrm{C}$ & $\sim 200{ }^{\circ} \mathrm{C}$ & $\sim 680^{\circ} \mathrm{C}$ & $800-1000{ }^{\circ} \mathrm{C}$ \\
\hline $\begin{array}{l}\text { Operating } \\
\text { Pressure }(\mathrm{kPa})\end{array}$ & $101-510$ & $101-814$ & $101-303$ & $101->1030$ \\
\hline Applications & $\begin{array}{l}\text { Stationary power } \\
(1997-2000) \text { Bus, } \\
\text { railroad, } \\
\text { automotive } \\
\text { propulsion (2000- } \\
2010)\end{array}$ & $\begin{array}{l}\text { Stationary power } \\
\text { (1998) Railroad } \\
\text { propulsion (1999) }\end{array}$ & $\begin{array}{l}\text { Stationary power } \\
(2000->2005)\end{array}$ & $\begin{array}{l}\text { Stationary power } \\
\text { and railroad } \\
\text { Propulsion } \\
(1998- \\
>2005)\end{array}$ \\
\hline
\end{tabular}

Source: Onsite Sycom Energy Corporation. OSEC (1999). Review of Combined Heat and Power Technologies. (http://www.eren.doe.gov/der/chp/docs_resources.html) 


\section{Performance Characteristics}

- Direct energy conversion (without combustion) results in the quiet production of electricity with no moving parts, high reliability, and low pollution emissions

- Modularity allows for combining fuel cells to increase capacity and have good load following capabilities over their capacity range

- The thermal heat production is available at varying levels depending upon the type of fuel cell and the operating temperature. The higher temperature fuel cells (MCFC and SOFC) are capable of producing high-pressure steam.

\section{Power and Heat Output}

PEMFC have the lowest operating temperature and are being developed for transportation applications, due to their high power densities and fast start-up, but may be used for stationary power generation. Small-scale systems based on PEMFC are being developed and commercialized, and the potential of PEM-powered vehicles feeding power into $\mu$ Grids when parked is quite promising. Their low operating temperature, however, results in low heat production and restricts their CHP applications to water heating and low temperature steam.

Ballard Generation Systems produced a $250 \mathrm{~kW}$ PEMFC with natural gas fuel and a 40 percent LHV electric efficiency. The thermal energy production is $854,600 \mathrm{~kJ} / \mathrm{h}$ at $74^{\circ} \mathrm{C}$.

A $200 \mathrm{~kW}$ PAFC, the PC-25, designed by International Fuel Cells Corporation (IFC) and built by ONSI Corporation, both independent subsidies of United Technologies Corporation (UTC), was the first to enter the commercial market with over 80 installations worldwide. These units achieve 40 percent electrical efficiency and 80 percent thermal energy efficiency in CHP applications. The thermal energy production is $740,000 \mathrm{~kJ} / \mathrm{h}$ at $60^{\circ} \mathrm{C}$; module provides $369,000 \mathrm{~kJ} / \mathrm{h}$ at $120^{\circ} \mathrm{C}$ and $369,000 \mathrm{~kJ} / \mathrm{h}$ at $60^{\circ} \mathrm{C}$. The thermal energy may be used for water or space heating, or low-pressure steam. Measured emissions from the PAFC unit are less than $1 \mathrm{ppm}$ of NOx, $4 \mathrm{ppm}$ of $\mathrm{CO}$, and less than $1 \mathrm{ppm}$ of reactive organic gases (non-methane) and are so low that the plant is exempt from air permitting in the South Coast and Bay Area Air Quality Management Districts, which have the most stringent limits in the U.S. The sound pressure level is $62 \mathrm{dBA}$ at $9 \mathrm{~m}$ from the unit. The average availability of the fleet is over 95 percent.

The MCFC has efficiencies of over 55 percent LHV and generates a high exhaust temperature useful for CHP systems targeting 1-20 MW stationary power applications. The Energy Research Corporation (ERC) is developing a 2.8 MW natural gas fueled MCFC with an expected electric efficiency of 58 percent producing $4.2 \mathrm{GJ} / \mathrm{h}$ of thermal energy with an availability of 95 percent.

SOFC are expected to be a reliable technology, based on all-solid ceramic construction, with electrical efficiencies up to 50 percent LHV and high exhaust temperatures. A $100 \mathrm{~kW}$ SOFC produced by Siemens AG and operating at the NUON District Heating site in Westvoot, The Netherlands operated over $14,000 \mathrm{~h}$ with an electrical efficiency of 45 percent and supplied $80 \mathrm{~kW}$ of hot water at $110^{\circ} \mathrm{C}$ to the local district heating system.

Capital and Operating Costs

The increasing demand for fuel cells in both stationary and mobile power applications is expected to decrease their capital cost as production volumes rise. The capital costs of commercially available 
PAFC are currently around $\$ 3,000 / \mathrm{kW}$ - much higher than competing DER. Installation costs for the PC-25 start at $\$ 85,000(\sim \$ 40 / \mathrm{kW}$ and up). A Federal Grant rebate of $\$ 1,000 / \mathrm{kW}$ is available as the result of the Clean Air Act Program. The maintenance costs of PAFC (200kW) ranges widely due to site-specific requirements and has been in the $\$ 0.02-\$ 5 / \mathrm{kWh}$ range including periodic stack replacement. The maintenance costs are expected to be around $\$ 0.015 / \mathrm{kWh}$ over the 20 year life of the PAFC.

\subsubsection{Heat Exchangers}

Heat exchangers do not produce heat; they simply transfer heat from one system to another. Heat exchangers are designed from different materials depending upon the application. Stainless steel is expensive and not a high heat conductor but it holds up well against the corrosive effects of condensate from exhaust gases. Current heat exchangers are capable of capturing about 80 percent of the heat from exhaust gas and transfer it to the absorption chiller.

\subsection{Cooling Technologies}

The two major CHP technologies that provide cooling are absorption chillers and desiccant dehumidification systems. Both are described below.

\subsubsection{Absorption Chillers}

Absorption cooling is a way of using heat to drive a refrigeration cycle instead of the mechanical energy required to run a compressor, powered by electricity. Absorption cooling cycles take advantage of chemical processes using a refrigerant and an absorbent that combine at low pressure and low temperature to form a solution. Water and lithium bromide or ammonia $\left(\mathrm{NH}_{3}-\mathrm{H}_{2} \mathrm{O}\right)$ are common refrigerant/absorbent combinations. An example of the cooling cycle is described below for a refrigerant/absorbent combination of water and lithium bromide.

A device called the absorber is kept at very low pressure $(700 \mathrm{~Pa})$ so that the refrigerant boils at $2{ }^{\circ} \mathrm{C}$. The refrigerant vapor is absorbed by the lithium bromide, and becomes a saturated liquid forming a solution. This absorption process liquefies the refrigerant at a temperature and pressure at which it would normally be a vapor, releasing heat in the saturation process. The solution is then pumped to a device called a generator. The solution in the generator is at a higher pressure $(6,200$ $\mathrm{Pa})$ and temperature $\left(37^{\circ} \mathrm{C}\right)$ than the absorber side of the cycle. Applying heat drives the refrigerant from the absorbent. The refrigerant passes through a filter, which keeps the absorbent on its side of the cycle, and into the condenser. The condenser is at the same temperature and pressure as the generator and at these conditions the refrigerant then cools and becomes a liquid. The refrigerant is then sprayed into the evaporator, where it expands to a gas due to the low pressure. As the refrigerant becomes a vapor it picks up latent heat from its surroundings, producing a cooling effect (E Source 1997). Figure 3 provides a schematic presentation of the process. 


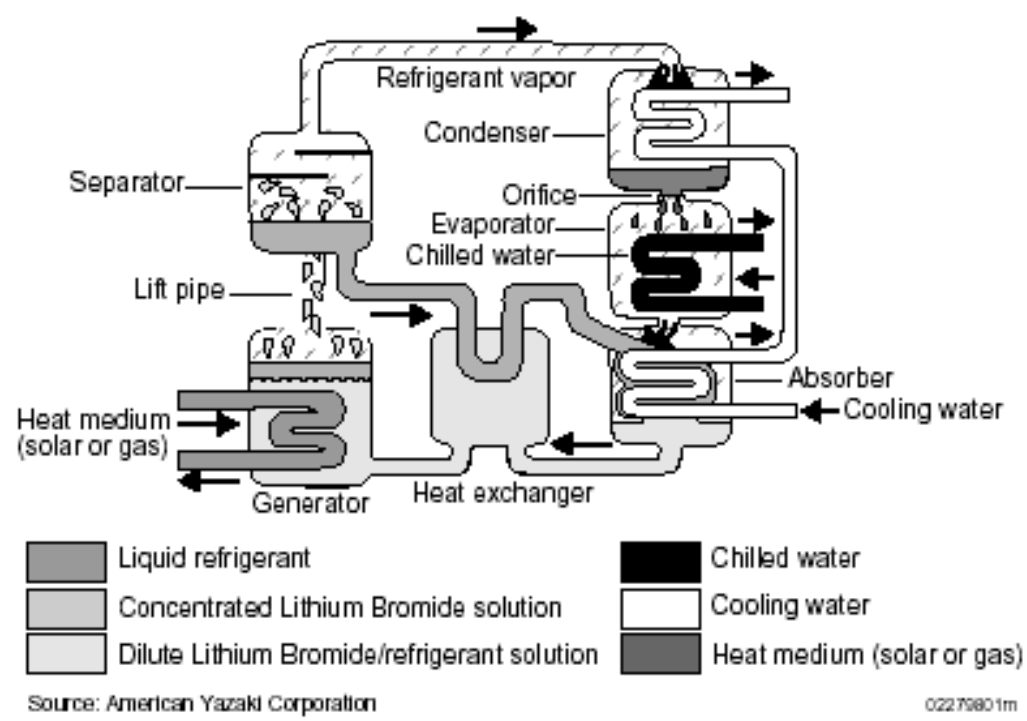

Figure 3: Single Effect Absorption Chiller

Source: Energy Efficiency and Renewable Energy Network (EREN), U.S. DOE.

(http://www.eren.doe.gov/femp/prodtech/parafta_appc.pdf)

These systems have been known and used for some time, but they are inefficient compared to compressors. Absorption chillers typically have a COP of 0.7 , whereas the COPs of compressors are around 5. Ongoing developments are being made to increase the efficiency of these cycles by capturing and using more of the rejected heat from the cycle or using multiple cycles at lower temperatures. Methods of increasing the efficiency of absorption cooling by adding additional generators and condensers utilizing remaining heat from the primary generation process are called double-effect and triple effect chillers and can have COPs of around 1.1 and 1.5, respectively (E Source 1997; Wang, Gao, and Chen 2000).

The fluid used as a heat input for absorption chillers should have a temperature of about $90^{\circ} \mathrm{C}$ to drive a single effect absorption chiller and temperatures between $120^{\circ} \mathrm{C}$ and $150^{\circ} \mathrm{C}$ to drive a double effect absorption chiller system (Grossman 2001). Absorption chillers are driven by hot water or steam from a rejected heat loop, or are direct fired from a natural gas or propane burner. The direct-fired units are all double effect systems due to the high temperature of the gas $\left(1,200^{\circ} \mathrm{C}\right)$ (Grossman 2001). These systems are common in Japanese commercial buildings.

\subsubsection{Desiccant Dehumidification}

Desiccant dehumidification and cooling is a method of removing latent heat load, in the form of moisture, from the air. This reduces cooling loads and allows air conditioning systems to operate more efficiently. Conventional cooling systems remove latent heat by using a cooling coil to condense water from the air. This requires more energy than would cooling air that has been dehumidified with a desiccant dehumidification system. By dehumidifying air prior to cooling, desiccant systems can reduce HVAC electricity use by 30 to 60 percent and peak electricity demand by 65 to 70 percent (E Source, Space Cooling Technology Atlas, 1997). Payback periods for desiccant systems typically ranged from two to four years (E Source Tech Update 1998). 
Desiccant systems work by using a material that absorbs moisture from the incoming airflow. This material is then rotated to a warm air stream to heat the material and dry it. DER may provide a source of heat for the desiccant system and thus help reduce the energy use of the cooling system.

Cost has been a prohibitive factor for desiccant systems, but recently these costs have been decreasing. In some applications the financial savings from reduced cooling costs offsets the cost of a desiccant system. The economic benefit of desiccant dehumidification is a function of the particular application and the potential benefit from humidity control, the humidity level during the summer, and the electricity tariffs. Desiccant systems are also well suited for applications where humidity control is important, including museums, supermarkets, hotels, hospitals, and industrial applications, especially in humid areas (E Source 1997).

Desiccant dehumidification may also be used in conjunction with compressor driven cooling to reduce the work required by the air conditioner to remove the moisture from the air - thus saving energy and operating costs. Capital costs may also be reduced in new construction or retrofit applications if the desiccant system allows for the purchasing of a smaller compressor chiller than would have been needed without a desiccant system. 


\section{Model of Combined Heat and Power}

\subsection{DER-CAM review}

DER-CAM is an economic model of customer DER adoption implemented in the General Algebraic Modeling System optimization software. It optimizes the cost-minimizing combination of on-site generation customers (individual businesses or a $\mu \mathrm{Grid}$ ). DER-CAM's objective is "to minimize the cost of supplying electricity to a specific customer by optimizing the installation of DG and the selfgeneration of part or all of its electricity."

For a detailed background of the DER-CAM model, the electricity data collection procedures, the technology cost forecasting, and descriptions of the DG technologies, please see Marnay et al. 2000 and Rubio et al. 2001.

\subsection{Methodology: Modeling CHP}

In this project, the DER-CAM model was modified to incorporate thermal loads and CHP technologies. The resulting model determines the combination of CHP and other on-site generating technologies customers should install to meet their needs for electricity, heating, and cooling at minimum cost over a test period. In order to do this, end use electrical, heating and cooling loads were required for the members of the $\mu$ Grid. Previous research focused only on total hourly electrical consumption. There are three different thermal end uses, including cooking, space heating and water heating. The electrical end-uses analyzed here included so-called "electricity only" loads, which include cooking, exhaust, and lighting, and cooling loads, including refrigeration and HVAC.

The model requires natural gas loads to be met either by purchasing gas from the macrogrid or producing power with CHP technologies, where possible. Some loads, such as the gas used in ovens, can only come from purchasing gas from the macrogrid. These are considered the "gas only" loads. Other heat loads, including space and water heating can be met by either, and was determined by the optimization algorithm.

Similarly, cooling loads could be met in two ways. Heat from DG technologies could be used to power an absorption chiller system, using this heat to meet a portion of the cooling load. Any remaining cooling load not met by CHP was met with an electric-powered compressor-driven air conditioning system. Displacing air conditioning with CHP cooling reduces the electricity load. Since the electricity load is an input to the model this creates a problem for the mixed-integer linear optimization model. This was addressed by having each unit of cooling output produced from CHP also produce a "phantom" output of electricity generation at no cost.

The electricity only loads could be met either by electricity generated on-site or with electricity purchased from the macrogrid.

Figure 4 describes the flow of resources from purchasing utility electricity or gas to the production of electricity and heat to serve different categories of loads within the $\mu \mathrm{Grid}$. 
Performance specification data on CHP technologies, including combination power/heat generators and power generators/absorption chillers, were required to determine the most economical combination of equipment to meet the needs of the customer. This performance specification information was the capital and operating costs, as well as the electrical and heat output of these technologies. The data on CHP and absorption cooling technologies came from technical specifications provided by the manufacturers. Additional information on the performance and cost data is included in section 3.4.

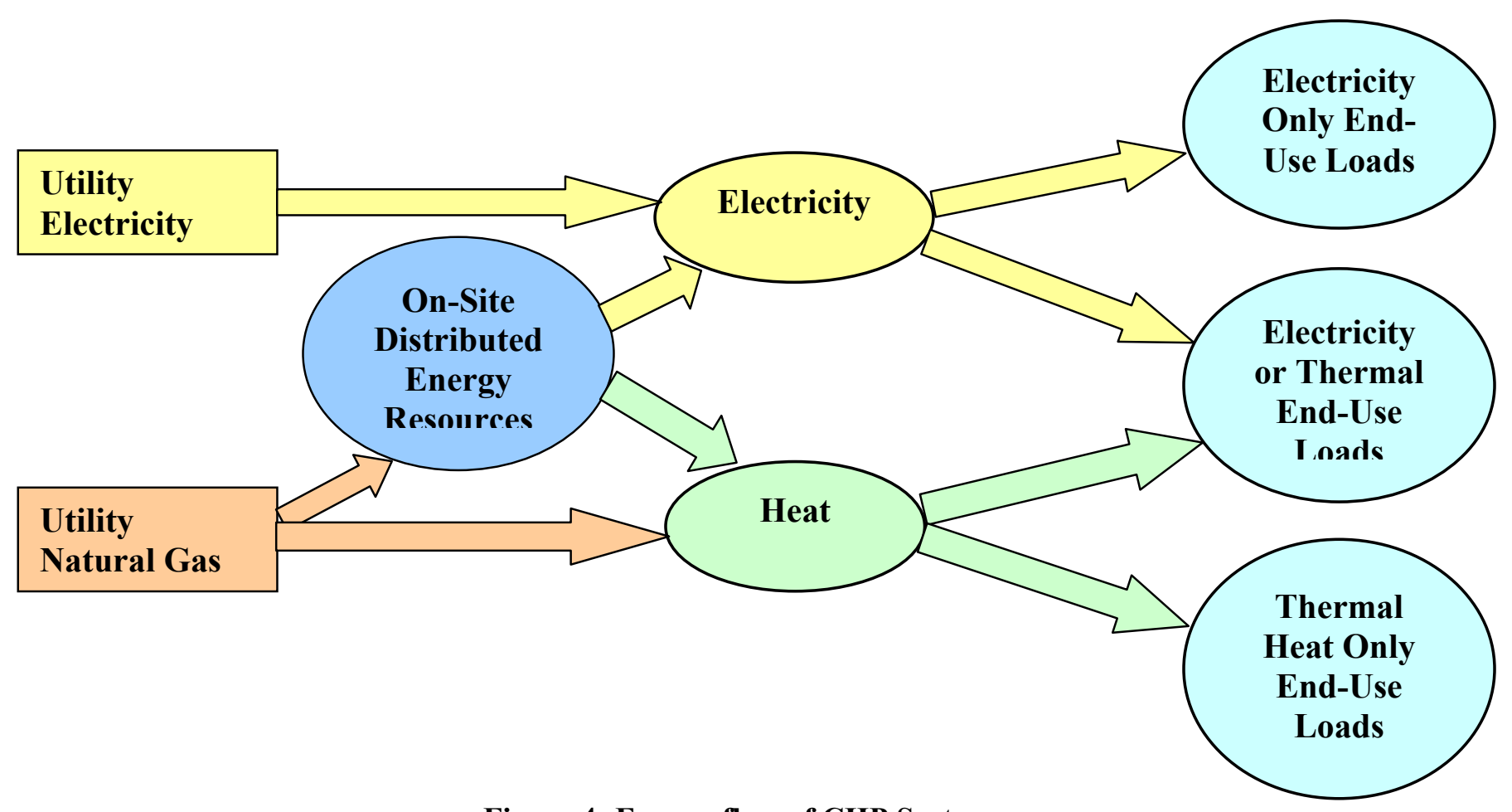

Figure 4: Energy flow of CHP System

The $\mu$ Grid was comprised of a variety of customers from different types of businesses. Some of these categories of businesses contained in the $\mu$ Grid are considered to have thermal loads that are inadequate to support CHP systems sized for the power demand such as grocery stores, office buildings, and restaurants (OSEC 2000). This presents an interesting challenge to apply CHP technologies to the $\mu \mathrm{Grid}$ in an economic manner. The derivation of heating loads for the customers is described in section 3.5.

Adapting the model to include CHP applications required the creation of new variables and new constraints that account for thermal load and gas consumption. The structure of the heating load component of the model was based on the initial electrical model. No end-use can be met both by natural gas and electricity, so the two structures do not interfere (except for cooling).

Adding additional functionality constraints and input data to the existing DER-CAM model increased the degree of complexity and the running time. The version of DER-CAM that optimized 
only electricity production took 30 minutes to run a simulation. Adding CHP increases the runtime to 5 hours.

A number of assumptions were made in running this model. The heating and cooling loads that could be met with CHP were selected based on general knowledge of the end-use applications for different types of businesses. It was also assumed that all the waste heat generated could not be used; there are losses from energy conversions and distribution. It was necessary to estimate how much of the recovered heat could serve different types of thermal loads based on knowledge of enduse conversion efficiency. The constraints ensure that the heating and cooling loads are met completely and that heat or power is not created without the operation of a sufficient capacity of CHP equipment. The model optimizes the end-use loads for power and heat separately.

\subsection{Mathematical Formulation}

DER-CAM is a mixed-integer linear-programming cost-minimization optimization model. The structure of the model, including its parameters, decision variables, objective function and constraints are described in the following sections.

\subsubsection{Parameters and Variables Defined for the CHP Model}

\section{Parameters}

Customer Data

\begin{tabular}{|l|l|}
\hline Name & Description \\
\hline Cload $_{1, \mathrm{~m}, \mathrm{t}, \mathrm{h}}$ & $\begin{array}{l}\text { Customer load in } \mathrm{kW} \text { during hour } h \text {, day type } t, \text { and month } m \text { for end } \\
\text { use } l \text { (Hot water, Space heating, Cooking Refrigeration or HVAC). }\end{array}$ \\
\hline
\end{tabular}

CHP and Absorption Cooling Technologies Information

(these characteristics are stored in the same Deropt Table)

\begin{tabular}{|l|l|}
\hline Name & Description \\
\hline CHPcapcost $i$ & Capital cost of CHP technology $i$ \\
\hline CHP cost operating $i$ & Operating cost per kWh electric produced $(\$ / \mathrm{kWh})$ for technology $i$ \\
\hline CHPom fixed $i$ & Fixed operating and maintenance costs of technology $i(\$ / \mathrm{kW})$ \\
\hline TE ratio $i$ & $\begin{array}{l}\text { Thermal output }(\mathrm{kWth}) \text { per } \mathrm{kW} \text { electric produced of CHP technology } i \\
\text { This coefficient multiplied by GenL } \mathrm{L}_{1} \text { determines how much residual } \\
\text { heat is available }\end{array}$ \\
\hline
\end{tabular}


An Engineering-Economic Analysis of Combined Heat and Power Technologies in a $\mu$ Grid Application

\section{Other parameters}

\begin{tabular}{|c|c|}
\hline Name & Description \\
\hline IntRate & Interest rate on DER investments ( \%) \\
\hline DiscoER & $\begin{array}{l}\text { UDC (utility distribution company) non-commodity revenue neutrality } \\
\text { adder }^{5}(\$ / \mathrm{kWh})\end{array}$ \\
\hline FixRate & Fixed energy rate $(\phi / \mathrm{kWh})$ applied in some cases ${ }^{6}$ \\
\hline StandbyC & $\begin{array}{l}\text { Standby charge in } \$ / \mathrm{kW} / \text { month that SCE currently applies to its } \\
\text { customers with autonomous generation }\end{array}$ \\
\hline Solar $_{m, h}$ & $\begin{array}{l}\text { Average solar insulation as a percentage of the maximum possible } \\
\text { during hour } h \text { and month } m(\%)\end{array}$ \\
\hline NGprice $_{m, t, h}$ & Price of natural gas during month $m$, day type $t$, hour $h(\$ / \mathrm{kWh})$ \\
\hline ConversionEfficiencyNG & Efficiency of converting purchased natural gas to useable heat $(\%)$ \\
\hline $\begin{array}{l}\text { Conversion factor from } \\
k W \text { electrical cooling to } \\
k W \text { thermal cooling }\end{array}$ & $\begin{array}{l}\text { Efficiency of converting from absorption cooling capacity produced } \\
(\mathrm{kWth}) \text { to a reduction in the use of compressor cooling }(\mathrm{kWe})\end{array}$ \\
\hline
\end{tabular}

\section{Market Data}

\begin{tabular}{|c|c|}
\hline Name & Description \\
\hline RTPower $_{s, p}$ & $\begin{array}{l}\text { Regulated demand charge under the default tariff for season }{ }^{7} s \text { and } \\
\text { period }^{8} p(\$ / \mathrm{kW})\end{array}$ \\
\hline RTEnergy $_{m, t, h}$ & $\begin{array}{l}\text { Regulated tariff for energy purchases during hour } h \text {, type of day } t \text {, } \\
\text { and month } m(\$ / \mathrm{kWh})\end{array}$ \\
\hline RTCCharge & Regulated tariff customer charge (\$) \\
\hline RTFCharge & Regulated tariff facilities charge $(\$ / \mathrm{kW})$ \\
\hline$I E M_{m, t, h}$ & $\begin{array}{l}\text { CAISO (California Independent System Operator) IEM } \\
\text { (imbalance energy market) price during hour } h \text {, type of day } t \text {, and } \\
\text { month } m(\$ / \mathrm{kWh})\end{array}$ \\
\hline RTGPower $_{s, p}$ & $\begin{array}{l}\text { Regulated demand gas charge under the default tariff for season }{ }^{9} s \\
\text { and period }{ }^{10} p(\$ / \mathrm{kW})\end{array}$ \\
\hline RTGEnergy ${ }_{m, t, h}$ & $\begin{array}{l}\text { Regulated tariff for gas purchases during hour } h \text {, type of day } t \text {, and } \\
\text { month } m(\$ / \mathrm{kWh})\end{array}$ \\
\hline RTGCCharge & Regulated tariff customer charge for gas $(\$)$ \\
\hline
\end{tabular}

\footnotetext{
${ }^{5}$ This value is added to the IEM price when the customer buys its power directly to the wholesale market.

${ }^{6}$ If the model user selects this option the customer always buy its energy at the same price.

${ }^{7}$ There are two seasons: summer and winter.

${ }^{8}$ There are three different time-of-use periods (for tariff purposes only): on-peak, mid-peak, and off-peak. Every tariff, TOU-8 for example, has a different definition of these periods.

${ }^{9}$ There are two seasons: summer and winter.

${ }^{10}$ There are three different time-of-use periods (for tariff purposes only): on-peak, mid-peak, and off-peak. Every tariff, TOU-8 for example, has a different definition of these periods.
} 


\section{DER Technologies Information}

\begin{tabular}{|l|l|}
\hline Name & Description \\
\hline DERmaxp $_{i}$ & Nameplate power rating of technology $i(\mathrm{~kW})$ \\
\hline DERlifetime $_{i}$ & Expected lifetime of technology $i($ years $)$ \\
\hline DERcapcost $_{i}$ & Overnight capital cost of technology $i(\$ / \mathrm{kW})$ \\
\hline DEROMfix $_{i}$ & $\begin{array}{l}\text { Fixed annual operation and maintenance costs of technology } i \\
(\$ / \mathrm{kW})\end{array}$ \\
\hline DEROMvar $_{i}$ & Variable operation and maintenance costs of technology $i(\$ / \mathrm{kWh})$ \\
\hline DERCostkWh $_{i}$ & Production cost of technology $i(\$ / \mathrm{kWh})$ \\
\hline DERhours $_{i}$ & $\begin{array}{l}\text { Maximum number of hours per annum that technology } i \text { is allowed } \\
\text { to generate (hours) }\end{array}$ \\
\hline
\end{tabular}

\section{Variables}

\begin{tabular}{|c|c|}
\hline Name & Description \\
\hline InvGen $_{i}$ & Number of units of the $i$ technology installed by the customer \\
\hline $\operatorname{GenL}_{. l, i, m, t, h}$ & $\begin{array}{l}\text { Generated power by technology } i \text { during hour } h \text {, type of day } t \text {, and } \\
\text { month } m \text { to supply the customer's load } l(\mathrm{~kW})\end{array}$ \\
\hline Heat $_{. l, i, m, t, h}$ & $\begin{array}{l}\text { Residual heat produced by technology } i \text { during hour } h \text {, type of day } \\
t \text {, and month } m \text { to supply the customer's load } l(\mathrm{~kW}) \text { when the load } \\
\text { is either Hot Water or Space Heating }\end{array}$ \\
\hline Cool $_{. l, i, m, t, h}$ & $\begin{array}{l}\text { Residual heat produced by technology } i \text { during hour } h \text {, type of day } \\
t \text {, and month } m \text { to supply the customer's load } l(\mathrm{~kW}) \text { when the load } \\
\text { is either Refrigeration or HVAC }\end{array}$ \\
\hline $\operatorname{Dump}_{. l, i, m, t, h}$ & $\begin{array}{l}\text { Dummy variable that allows more residual heat to be produced } \\
\text { than is demanded on site. }\end{array}$ \\
\hline$G e n X_{i, m, t, h}$ & $\begin{array}{l}\text { Generated power by technology } i \text { during hour } h \text {, type of day } t \text {, and } \\
\text { month } m \text { to sell in the wholesale market }(\mathrm{kW})\end{array}$ \\
\hline $\operatorname{DRLoad}_{l, m, t, h}$ & $\begin{array}{l}\text { Residual customer load } l \text { (purchased electric power from the } \\
\text { distribution company by the customer) during hour } h \text {, type of day } \\
t \text {, and month } m(\mathrm{~kW})\end{array}$ \\
\hline DRGLoad $_{l, m, t, h}$ & $\begin{array}{l}\text { Residual customer load } l \text { (purchased natural gas from the } \\
\text { distribution company by the customer) during hour } h \text {, type of day } \\
t \text {, and month } m(\mathrm{~kW})\end{array}$ \\
\hline
\end{tabular}




\subsubsection{Objective Function}

Objective function: the objective function is now taking into account the purchase of gas, the equations related to the billing structure are parallel to the electric model. The new variables added contain the capital letter $\mathrm{G}$ in their definition.

$$
\begin{aligned}
& \min _{\text {InvGen }_{i},} \quad \sum_{m} \text { RTFCharge } \cdot \max \left(\text { DRLoad }_{m, t, h}\right)+\sum_{m} \text { RTCCharge } \\
& G e n L_{l, i, m, t, h} \text {, } \\
& \text { GenX } X_{i, m, t, h} \\
& +\sum_{m} R T G F C h a r g e \cdot \max \left(\text { DRGLoad }_{m, t, h}\right)+\sum_{m} \text { RTGCCharge } \\
& +\sum_{s} \sum_{m \in s} \sum_{p} \text { RTPower }_{s, p} \cdot \max \left(\text { DRLoad }_{m,(t, h) \in p}\right) \\
& +\sum_{s} \sum_{m \in s} \sum_{p} R \text { GGOwer }_{s, p} \cdot \max \left(\text { DRGLoad }_{l, m,(t, h) \in p}\right) \\
& +\sum_{l} \sum_{i} \sum_{m} \sum_{t} \sum_{h}\left(\operatorname{GenL}_{l, i, m, t, h}+\operatorname{GenX} X_{i, m, t, h}\right) \cdot \operatorname{DERCostkWh_{i}} \\
& +\sum_{l} \sum_{i} \sum_{m} \sum_{t} \sum_{h}\left(\operatorname{GenL}_{l, i, m, t, h}+\operatorname{GenX}_{i, m, t, h}\right) \cdot \text { DEROMvar }_{i} \\
& +\sum_{i} \text { InvGen }_{i} \cdot\left(\text { DERcapcost }_{i}+\text { DEROMfix }_{i}\right) \cdot \text { Annuity } F \\
& +\sum_{m} \sum_{i} \operatorname{InvGen}_{i} \cdot \text { DERmaxp }_{i} \cdot \operatorname{StandbyC} \\
& -\sum_{l} \sum_{i} \sum_{m} \sum_{t} \sum_{h}\left(\operatorname{GenX}_{i, m, t, h} \cdot I E M_{m, t, h}\right)
\end{aligned}
$$

\subsubsection{Constraints}

- As the total loads were divided into end uses, the model became more complex. The number of variables was multiplied by the number of end uses.

- The balance equations take into account the specificity of each type of end user load.

- Residual heat must be produced by onsite electric generation.

- Electricity is not produced simply to provide waste heat. In other words, the production of waste heat is limited by the electrical load.

$$
\begin{aligned}
& \text { Cload }_{l, m, t, h}=\sum_{i} \text { Heat }_{l, i, m, t, h}+\text { DRGLoad }_{l, m, t, h} \forall_{l, m, t, h} \text { if } l \in\{\text { Heating }\} \\
& \text { Heating loads except cooking } \\
& \text { Cload }_{l, m, t, h}=\sum_{i} \text { GenL }_{l, i, m, t, h}+\sum_{i} \text { Cool }_{l, i, m, t, h}+\text { DRLoad }_{l, m, t, h} \forall_{l, m, t, h} \text { if } l \in\{\text { Cooling }\}^{\text {Cooling loads }}
\end{aligned}
$$




$$
\begin{aligned}
& \text { Cload }_{l, m, t, h}=\text { DRGLoad }_{l, m, t, h} \forall_{l, m, t, h} \text { if } l \in\{\text { Cooking }\} \\
& \text { Cooking loads } \\
& \text { Cload }_{l, m, t, h}=\sum_{i} \text { GenL }_{l, i, m, t, h}+\text { DRLoad }_{l, m, t, h} \forall_{l, m, t, h} \text { if } l \in\{\text { Electrical }\} \\
& \text { Electrical loads } \\
& \sum_{l} \operatorname{GenL}_{l, i, m, t, h}+\operatorname{GenX}_{i, m, t, h} \leq \operatorname{InvGen}_{i} \cdot \operatorname{DER} \max p_{i} \forall_{i, m, t, h} \\
& \operatorname{GenX}_{i, m, t, h}=0 \text { if } \sum_{l} \sum_{i} \operatorname{GenL}_{l, i, m, t, h}<\sum_{l} \operatorname{Cload}_{l, m, t, h} \forall_{i, m, t, h} \text { if } l \in\{\text { Electrical }\} \\
& \text { Annuity } F=\frac{\text { IntRate }}{\left(1-\frac{1}{\left(1+\text { IntRate }^{\text {DERlifetime }_{i}}\right.}\right)} \\
& \sum_{l} \operatorname{GenL}_{l, j, m, t, h}+\operatorname{GenX}_{j, m, t, h} \leq \operatorname{InvGen}_{j} \cdot \operatorname{DER} \max p_{j} \cdot \operatorname{Solar}_{m, h} \forall_{m, t, h} \text { if } j \in\{P V\}
\end{aligned}
$$

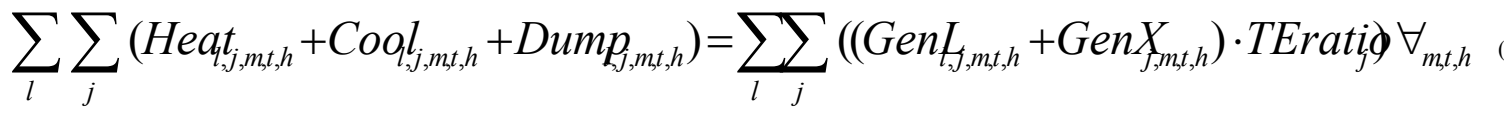

$$
\begin{aligned}
& \sum_{l} \sum_{m} \sum_{t} \sum_{h}\left(\text { GenL }_{l, i, m, t, h}+\text { GenX }_{i, m, t, h}\right) \leq \text { InvGen }_{i} \cdot \text { DER max } p_{i} \cdot \text { DERhours }_{i} \forall_{i}
\end{aligned}
$$

- Equation (1) is the objective function which says that the customer will try to minimize total cost, consisting of: total facilities and customer charges, total monthly demand charges, total on-site generation fuel and O\&M costs, total DER investment cost, total standby charges, and minus the revenues generated by any energy sales to the macrogrid.

- Equation (2) enforces energy balance for heating, cooling, cooking, and electrical loads.

- Equation (3) enforces the on-site generating capacity constraint.

- Equation (4) prohibits the customer from buying and selling energy at the same time. When this constraint is removed, the model assumes that the customer has a "double meter," i.e., the customer can buy from the UDC and sell to the IEM (Imbalance Energy Market) at the same time, but cannot buy from the UDC and resell the same energy to the IEM. Indeed, this would create an unbounded arbitrage possibility in some circumstances.

- Equation (5) simply annualizes the capital cost of owning on-site generating equipment.

- In Equation (6), if the customer is operating any PV cells, then their actual energy output is the rated capacity scaled down by the amount of solar insulation.

- Equation (7) constrains the maximum amount of residual heat available for cooling or heating depending on the operation level of the micro turbine.

- Finally, in Equation (8), the maximum total amount of energy that any given generator $i$ can produce throughout the year is effectively restricted by the parameter DERhours $i$. This constraint is intended mainly to prevent the diesel generators from operating more than the maximum legal allowable number of hours. 


\section{Comments on the Model.}

- The variables "Heat" and "Cool" are defined to be positive. Both include a coefficient of efficiency for each technology that adjusts the real value of these variables when they are present in the same equation with other variables, like Genl.

- The Dump variable insures that we are not forcing the model to use all the wasted heat available. This variable was frequently equal to zero for this study.

- The number of DER technologies has increased dramatically as we created different types of virtual turbines: turbines with a heat exchange, turbines with an absorption chiller or turbines with an absorption chiller and a heat exchanger. All the Characteristics of these "Combo's" have been derived from heat rate curve and waste heat curve extrapolated from actual turbine data.

\subsection{Data on CHP technologies}

\subsubsection{Data for Generation and CHP Technologies}

The DER-CAM CHP model uses data collected from the manufacturers of packaged CHP technologies either through personal communication or from manufacturer specification sheets. The previous versions of the DER-CAM model also used specific performance data from manufacturers or independent testing for specific technologies. Cost and performance data used in the model for the combined DG and absorption chiller units (producing power and cooling) and the combined CHP and absorption chiller units (producing power, heat, and cooling) were developed through functional estimates based on data from the DG, CHP and absorption chiller technologies.

The cost information for the DER technologies was an extension of the previous DER-CAM study. The cost information for the CHP technologies, however, was rough for a number of reasons. First, actual cost depends heavily on site-specific installation, shipping and purchasing information, which are difficult to generalize or model. Maintenance charges are also site specific, and had to be estimated. Also, because these are emerging technologies there is not a long history of cost experience to draw upon. Furthermore, these costs change as manufactures make advances in production methods and as demand goes up. In addition, only one source of cost was received from each manufacturer for their product line. Additional information is required in order to verify and provide additional information on the likely costs of purchasing, installing and operating these CHP technologies.

The data used in the model are provided in Table 3. Heat output for each unit is given for ideal atmospheric, inlet water temperature, and flow rate conditions. These ideal conditions vary depending on the product. For the Bowman this is typical water inlet temperatures of $70^{\circ} \mathrm{C}$, water flow rates of $1.3 \mathrm{~kg} / \mathrm{s}$ for 0 percent bypass and $3.3 \mathrm{~kg} / \mathrm{s}$ for 100 percent bypass, exhaust mass flow of $0.54 \mathrm{~kg} / \mathrm{s}$, and ISO conditions (i.e. sea level and $15^{\circ} \mathrm{C}$ ). Note the STM machine uses heat, instead of fuel, to power the generator and produces electricity and heated water as outputs. 
Table 3: CHP Generation Technologies

\begin{tabular}{|c|c|c|c|c|c|c|c|}
\hline Model & $\mathrm{kW}$ & $\$ / \mathrm{kW}$ & $\begin{array}{l}\text { Thermal/ } \\
\text { electric } \\
\text { ratio }\end{array}$ & $\begin{array}{l}\text { CHP output } \\
\mathrm{kW} \text { (th) }\end{array}$ & $\begin{array}{l}\text { Exhaust } \\
\text { heat } \\
\text { temperature } \\
\text { (C) }\end{array}$ & $\begin{array}{l}\text { Hot water } \\
\text { output temp } \\
\text { (C) }\end{array}$ & $\begin{array}{l}\text { Maintenance } \\
\text { costs } \$ / \mathrm{kWh}\end{array}$ \\
\hline Bowman & $50 \mathrm{~kW}$ & $\$ 1500$ & 3.83 & $190 \mathrm{~kW}$ & $\begin{array}{l}261^{\circ} \mathrm{C}, \\
650^{\circ} \mathrm{C}^{11}\end{array}$ & $90^{\circ} \mathrm{C}$ & $\$ 0.015$ \\
\hline Bowman & $80 \mathrm{~kW}$ & $\$ 1700$ & 3.60 & $288 \mathrm{~kW}$ & $\begin{array}{l}278^{\circ} \mathrm{C} \\
650^{\circ} \mathrm{C}^{12}\end{array}$ & $90^{\circ} \mathrm{C}$ & $\$ 0.015$ \\
\hline Capstone & $60 \mathrm{~kW}$ & $\$ 1600$ & 2.0 & $120 \mathrm{~kW}$ & $310^{\circ} \mathrm{C}$ & $93^{\circ} \mathrm{C}$ & $\$ 0.01$ \\
\hline GA (Katolight) & $55 \mathrm{~kW}$ & $\$ 834$ & 3.07 & $205 \mathrm{~kW}$ & $242^{\circ} \mathrm{C}$ & $90^{\circ} \mathrm{C}$ & NA \\
\hline GA (Katolight) & $500 \mathrm{~kW}$ & $\$ 678$ & 3.01 & $1500 \mathrm{~kW}$ & $350^{\circ} \mathrm{C}$ & $90^{\circ} \mathrm{C}$ & $\$ 0.0033$ \\
\hline Capstone & $30 \mathrm{~kW}$ & $\$ 1485$ & 3.05 & $190 \mathrm{~kW}$ & $320^{\circ} \mathrm{C}$ & $90^{\circ} \mathrm{C}$ & $\$ 0.0033$ \\
\hline GA K 100 & $100 \mathrm{~kW}$ & $\$ 764$ & 3.8 & $380 \mathrm{~kW}$ & $290^{\circ} \mathrm{C}$ & $90^{\circ} \mathrm{C}$ & $\$ 0.0033$ \\
\hline GA K 500 & $500 \mathrm{~kW}$ & $\$ 678$ & 3.00 & $1500 \mathrm{~kW}$ & $330^{\circ} \mathrm{C}$ & $90^{\circ} \mathrm{C}$ & $\$ 0.0033$ \\
\hline Turbec & $100 \mathrm{~kW}$ & $\$ 720-865$ & 1.67 & $167 \mathrm{~kW}$ & $55^{\circ} \mathrm{C}$ & $70^{\circ} \mathrm{C}$ & $\$ 0.01$ \\
\hline STM & $\begin{array}{c}25 \mathrm{~kW} \text { out, } \\
90 \mathrm{~kW}(\mathrm{th}) \\
\text { in }\end{array}$ & $\begin{array}{c}\$ 2000 \\
(\$ 500-800 \\
\text { in } 12 \text { mo.) } \\
\end{array}$ & 1.76 & $44 \mathrm{~kW}$ & Not applicable & $54^{\circ} \mathrm{C}$ & \\
\hline
\end{tabular}

Source: Various manufacturers

\subsubsection{Absorption Cooling Technologies data}

The economies of scale (cost per $\mathrm{kW}$ ) of cooling capacity for absorption chillers are illustrated below in Figure 5. As can be seen in the figures, as the capacity increases, the capital cost decreases. There are a wide variety of combinations of absorption chillers and DG technologies. Cost and performance information is shown as collected from eight manufactures of absorption cooling technology. Each manufacturer makes between 10 and 50 models of direct and indirect fired absorption chillers in various capacities. Some existing combinations of absorption chillers with DG equipment include a package combining a $30 \mathrm{~kW}$ Capstone microturbine with a Yazaki absorption chiller to produce $35 \mathrm{~kW}$ (10 tons) of cooling capacity. Carrier also noted it was joining with Yazaki to combine a $70 \mathrm{~kW}$ generator with a $105 \mathrm{~kW}$ (30 tons) capacity absorption chiller. For this study, however, the loads produced by the $\mu$ Grid are not large enough to take advantage of these economies of scale. Figure 6 focuses on absorption chillers with capacities below $300 \mathrm{~kW}$ to show the relationship between capital cost and size for these smaller units applicable to the $\mu$ Grid in this report.

\footnotetext{
${ }^{11}$ The two numbers represent exhaust heat temperatures with 0 percent recuperator bypass and 100 percent recuperator bypass, respectively.

${ }^{12}$ Again, these are exhaust heat temperatures with 0 percent recuperator bypass and 100 percent recuperator bypass, respectively.
} 


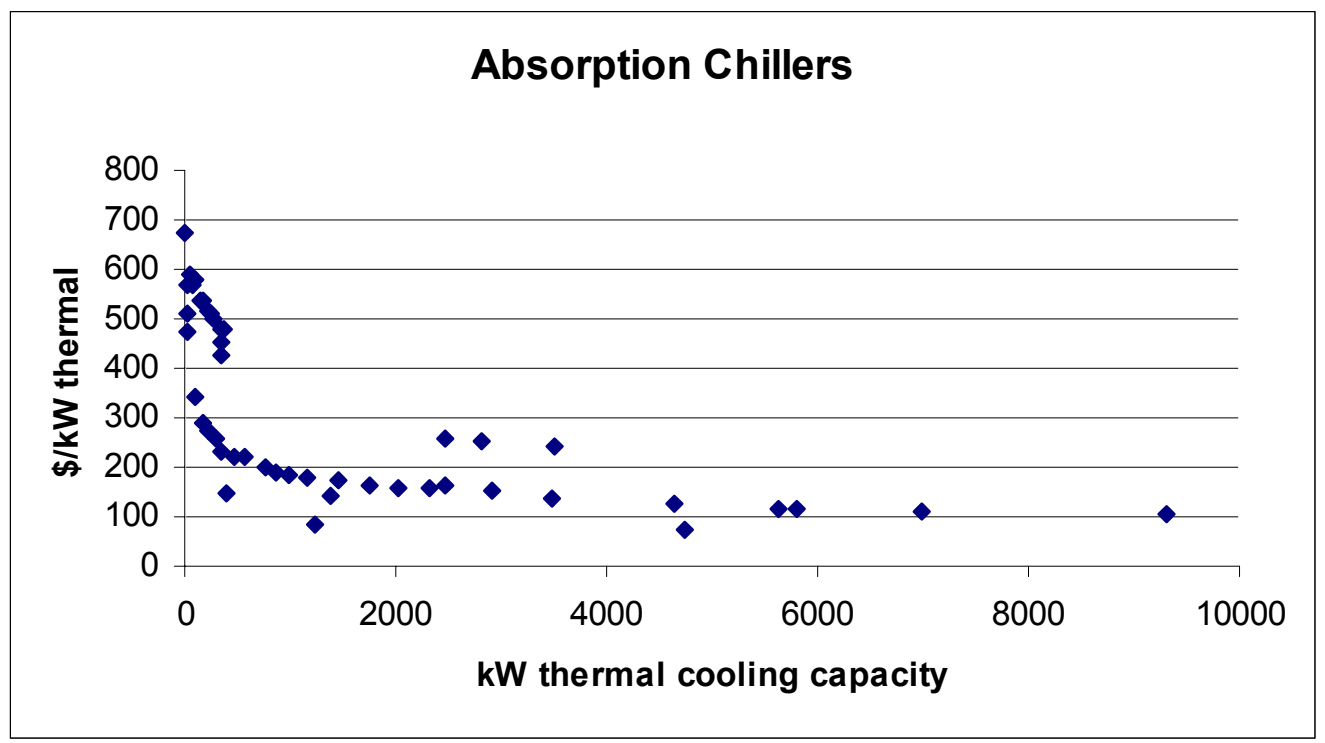

Figure 5: Thermal Cooling Capacity $(\$ / \mathrm{kW})$ versus Cooling Capacity for Absorption Chillers

Source: Data collected from manufacturers of absorption chillers.

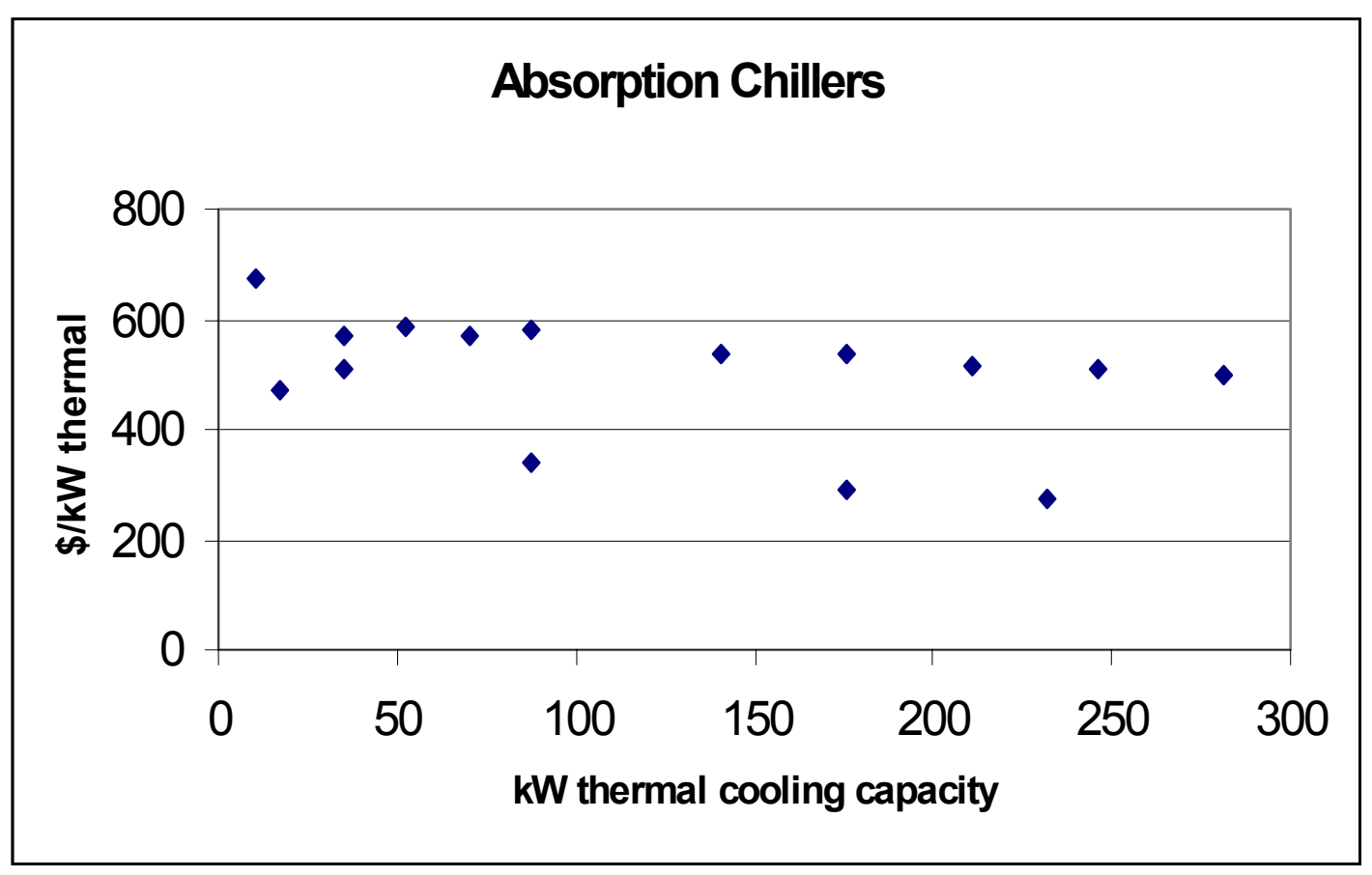

Figure 6: Thermal Cooling Capacity $(\$ / \mathrm{kW})$ versus Cooling Capacity for Small Absorption Chillers Source: Data collected from manufacturers of absorption chillers. 
The CHP technologies used in the model are hypothetical packages of technologies that produce power and cooling, or power, heat, and cooling. The performance characteristics of these technologies were based on combining the CHP packaged units and the absorption chiller units. Capital costs of these technologies were obtained from the manufacturers. The CHP/absorption chiller combination units developed in the model are most likely not available commercially. Installations would be site specific and involve an engineering design and installation process.

The prices of these combination technologies were derived by adding the capital cost of the generator to the calculated capital cost of the CHP device. This calculated value is as follows, where the coefficient is the electrical to waste-heat factor and is assumed to be 2.5:

$\operatorname{Cost}_{\mathrm{TOTAL}}=\operatorname{Cost}_{\mathrm{GEN}}+($ Coefficient $) * \alpha(\$ / \mathrm{kW})$

The value $\alpha$ relates the price of cooling capacity to the amount of capacity. Cooling capacity is defined as in the following equation. Efficiency is the efficiency of converting waste heat into useful heat, and is assumed to be 0.7 .

Cooling Capacity $=($ Efficiency $) *\left(\right.$ Heat Rate $\left._{\mathrm{GEN}}\right) /(3,600 / \mathrm{h}) *\left(\right.$ Max Power $\left._{\mathrm{GEN}}\right)$

For example, the micro turbine Ga-K-100 has a capital cost of $\$ 574$, a heat rate of $15,220 \mathrm{~kJ} / \mathrm{kWh}$ and maximum power generation of $100 \mathrm{~kW}$. Cooling capacity is calculated to be:

Cooling Capacity $=(0.7) *(15,220 \mathrm{~kJ} / \mathrm{kWh}) /(3,600 / \mathrm{h}) *(100 \mathrm{~kW})$

$$
=300 \mathrm{~kJ}(\max )
$$

Assuming the maximum cooling capacity is $300 \mathrm{~kJ}$, the price per cooling capacity can be read off the chart in Figure 6. This is found to be roughly $\$ 500 / \mathrm{kW}$.

Therefore the total capital cost of the system is:

$$
\begin{aligned}
\text { Cost }_{\mathrm{TOTAL}} & =\$ 574+(2.5) * \$ 500 / \mathrm{kW} \\
& =\$ 1824
\end{aligned}
$$

\subsection{Data on Thermal and Electrical Loads}

\subsubsection{Introduction}

The objective of this study is to incorporate CHP technologies into DER-CAM and complete an example analysis based as much on real world load shapes as possible. Actual hourly end use metered load data are obviously more valuable than simulated data because the end results are more convincing when actual metered loads are used to obtain them. Where no actual metered load data could be found, such as with natural gas loads, simulated data was used. In fact neither customer level nor end use level metered natural gas loads are readily available because due to the historic stability of gas prices there has been no incentive for gas utilities to collect this information. 
Data availability was a major factor in choosing the buildings that comprise the sample $\mu$ Grid. All the business types are commercial, which tend not to be the customers who benefit from DER or CHP, but load data are more accessible than load data for industrial applications.

\subsubsection{Background}

Actual customer end-use load profiles for electricity and gas-fired loads are required for producing credible results representing the cost minimizing deployment of DER technology. Metered loads for commercial buildings are not widely available. Ernest Orlando Lawrence Berkeley National Laboratory (Berkeley Lab) had an archived set of commercial hourly load data, collected by Southern California Edison (SCE) in 1988-1989 (SCE 1989; Akbari 1993). Even though this data was collected years ago, it is still valuable for the purposes of this study, because the proportions between end-use loads for a single building, and between business types, are realistic. Results will indicate how a $\mu$ Grid might work in this given situation. Berkeley Lab recovered these data and recreated load shapes to be used in current modeling efforts.

Unfortunately the SCE data only included electrical loads for the buildings, not natural gas loads. Nor could actual gas loads be found through any other means. Since natural gas is the main fuel used to provide building heat and hot water, two major products of $\mathrm{CHP}$ technologies, finding plausible data for these loads was critical for this study. DOE-2, a building simulation program developed at Berkeley Lab, was used to simulate these heating loads for the same climate at which the electrical loads were recorded. DOE-2 uses Typical Meteorological Year weather data, or TMY, as one input to produce its simulations. The TMY method employed by DOE-2 analyzes the weather from 1961-1990 and chooses the most typical month out of the range of years to represent a given month. For example, the January weather could be the weather data from 1972, at the same time the February data could be from 1986.

Using end-use electric and gas loads is important in this study because only some end use loads can be met with CHP technologies. These include refrigeration and building cooling (HVAC), which are typically electrical loads, and hot water and building heating, which are usually gas loads. The DER-CAM model was adjusted to meet these end uses with CHP, when possible.

\subsubsection{Data Description and Preparation}

The initial version of the SCE electricity load data consisted of a SAS data set containing hourly total load data and some end use load data for 53 commercial premises located in the SCE service territory. For confidentiality reasons, detailed information on the businesses was suppressed, but for most premises, business type, total floor area, conditioned floor area and a corresponding set of hourly weather data were available.

This data was compiled into a database of total and end use loads for most premises as follows:

- average weekday by calendar month (1 day type x 12 months)

- average weekend by calendar month (1 day type x 12 months) 
Peak day averages, which were used in previous DER-CAM analysis that examined only total electrical loads, were not available for the electrical end use data. The model was modified to use only week and weekend day types.

For most buildings, electrical end uses, such as refrigeration, cooking, and HVAC, were available as separate values. However, not every building included data for each end use. Also, in most cases measured end use loads did not add up to the total load given for a specific property. To account for this "residual" electricity, an additional end use was calculated by taking the difference between the sum of the end uses and the total. This "residual" end-use load accounts for electrical end uses that were not measured for any building, such as plug power. It also includes end uses that were measured in some buildings but were not recorded for a given building, for whatever reason. For this study, the "residual" electrical load is considered an "electricity only" load, one that cannot be met by CHP.

The DOE-2 model was run for each building to produce end use natural gas load data sets. This entailed imputing the correct floor area for each building, choosing the appropriate end use loads, such as cooking, hot water and space heating, depending on the building type, and running the program. An output file was then produced, which was formatted and averaged into the same monthly format as the electrical loads. For the purposes of this analysis, it was assumed that only the hot water and space heating loads could be met through CHP.

\subsubsection{Selection of Microgrid Oaks}

In a previous DER-CAM study, a group of commercial building types were chosen to be members of the fictional group of businesses named Microgrid Oaks, which represents the $\mu$ Grid for this study. Because the goal of this study is to analyze how CHP and DER could benefit real-world groups of buildings, the business types were selected to represent the kinds of commercial business found in a typical strip mall. Buildings were also chosen based on availability and completeness of data. Matters such as load compatibility, which will be discussed later, were not considered.

Eight buildings were selected and analyzed as a $\mu$ Grid. Together, they are about the size of one small city block. A summary of these buildings is shown in Table 4. Each building type has a name, a floor area, total annual electricity, electrical density, peak electrical load, and electrical load factor. 


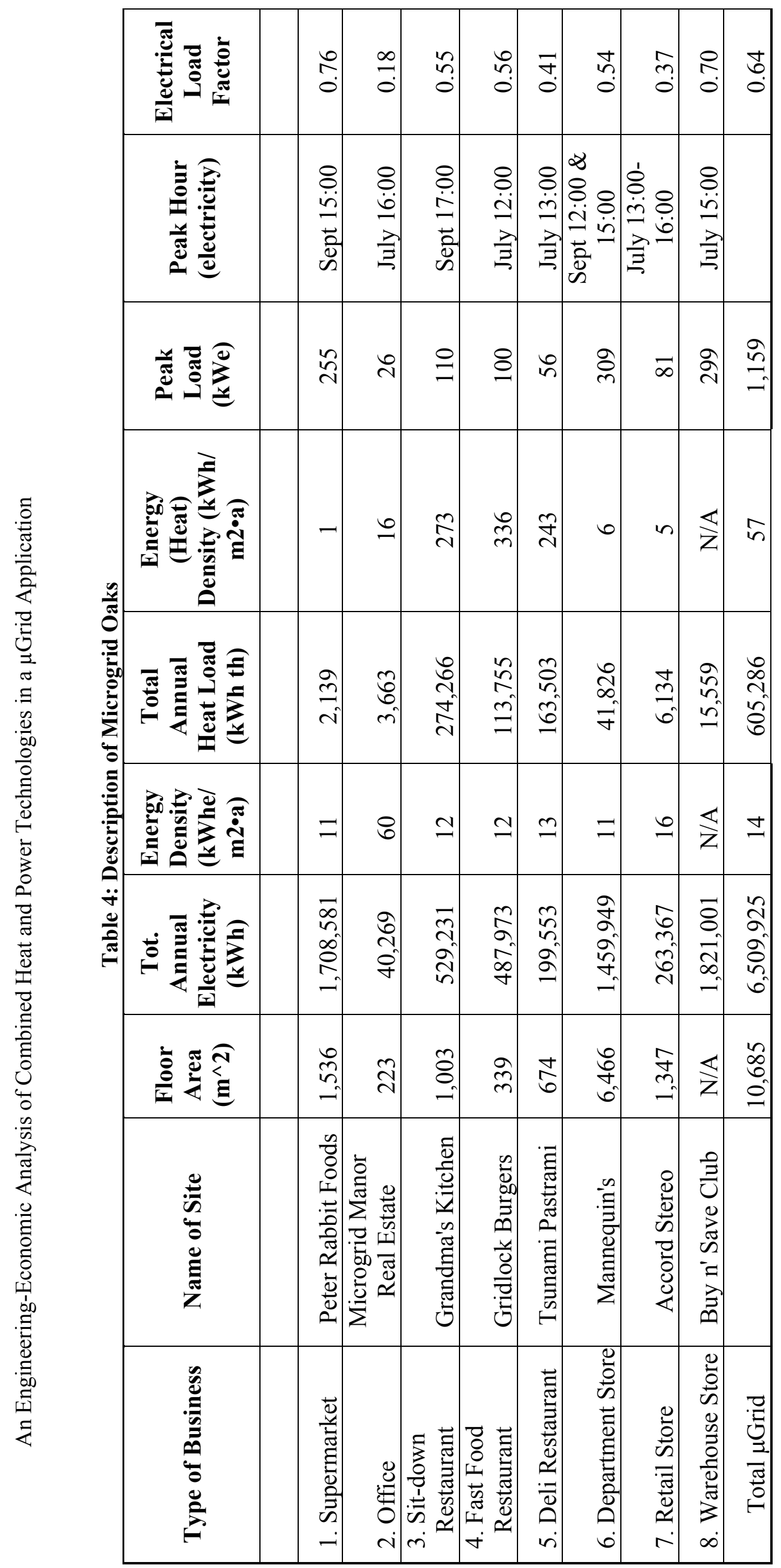


Only the office building, Microgrid Manor Real Estate, is missing data (the month of June). This missing electrical data was approximated by averaging the loads from the two adjacent months. The gas load for the missing month was simulated using DOE-2 the same as the other months.

The specific electrical end uses available for each building in the $\mu$ Grid are summarized below in Table 5. These end uses were then summed to create the end use load for the total $\mu$ Grid depicted in Figure 7. These illustrations show that the end uses important to a CHP analysis are well represented. HVAC is available for every building except Buy n' Save. Refrigeration is present for every business that would have that end use except Buy n' Save. Since the gas loads were simulated, end use loads exist for each building.

Table 5: End Uses Recorded for Buildings in Microgrid Oaks

\begin{tabular}{|l|c|c|c|c|c|c|c|c|}
\hline \multicolumn{1}{|c|}{ Name of Site } & exhaust & $\begin{array}{c}\text { cooking } \\
\text { (electric) }\end{array}$ & lighting & refrig. & HVAC & hot water & $\begin{array}{c}\text { space } \\
\text { heating }\end{array}$ & $\begin{array}{c}\text { cooking } \\
\text { (gas) }\end{array}$ \\
\hline & & & & & & & & \\
\hline Peter Rabbit Foods & & & $\mathrm{X}$ & $\mathrm{X}$ & $\mathrm{X}$ & $\mathrm{X}$ & $\mathrm{X}$ & \\
\hline $\begin{array}{l}\text { Microgrid Manor Real } \\
\text { Estate }\end{array}$ & & & $\mathrm{X}$ & & $\mathrm{X}$ & $\mathrm{X}$ & $\mathrm{X}$ & \\
\hline Grandma's Kitchen & $\mathrm{X}$ & $\mathrm{X}$ & $\mathrm{X}$ & $\mathrm{X}$ & $\mathrm{X}$ & $\mathrm{X}$ & $\mathrm{X}$ & $\mathrm{X}$ \\
\hline Gridlock Burgers & $\mathrm{X}$ & $\mathrm{X}$ & $\mathrm{X}$ & $\mathrm{X}$ & $\mathrm{X}$ & $\mathrm{X}$ & $\mathrm{X}$ & $\mathrm{X}$ \\
\hline Tsunami Pastrami & $\mathrm{X}$ & $\mathrm{X}$ & $\mathrm{X}$ & $\mathrm{X}$ & $\mathrm{X}$ & $\mathrm{X}$ & $\mathrm{X}$ & $\mathrm{X}$ \\
\hline Mannequin's & & & $\mathrm{X}$ & & $\mathrm{X}$ & $\mathrm{X}$ & $\mathrm{X}$ & \\
\hline Accord Stereo & & & $\mathrm{X}$ & & $\mathrm{X}$ & $\mathrm{X}$ & $\mathrm{X}$ & \\
\hline Buy n' Save Club & & & $\mathrm{X}$ & & & $\mathrm{X}$ & $\mathrm{X}$ & \\
\hline
\end{tabular}

This study focuses on how the $\mu$ Grid as a whole, not the individual businesses, could utilize DER and CHP. Therefore the load for the total $\mu$ Grid is more important than the loads for separate buildings. Some of the average monthly load shapes, input into the model, are shown in the following figures. 


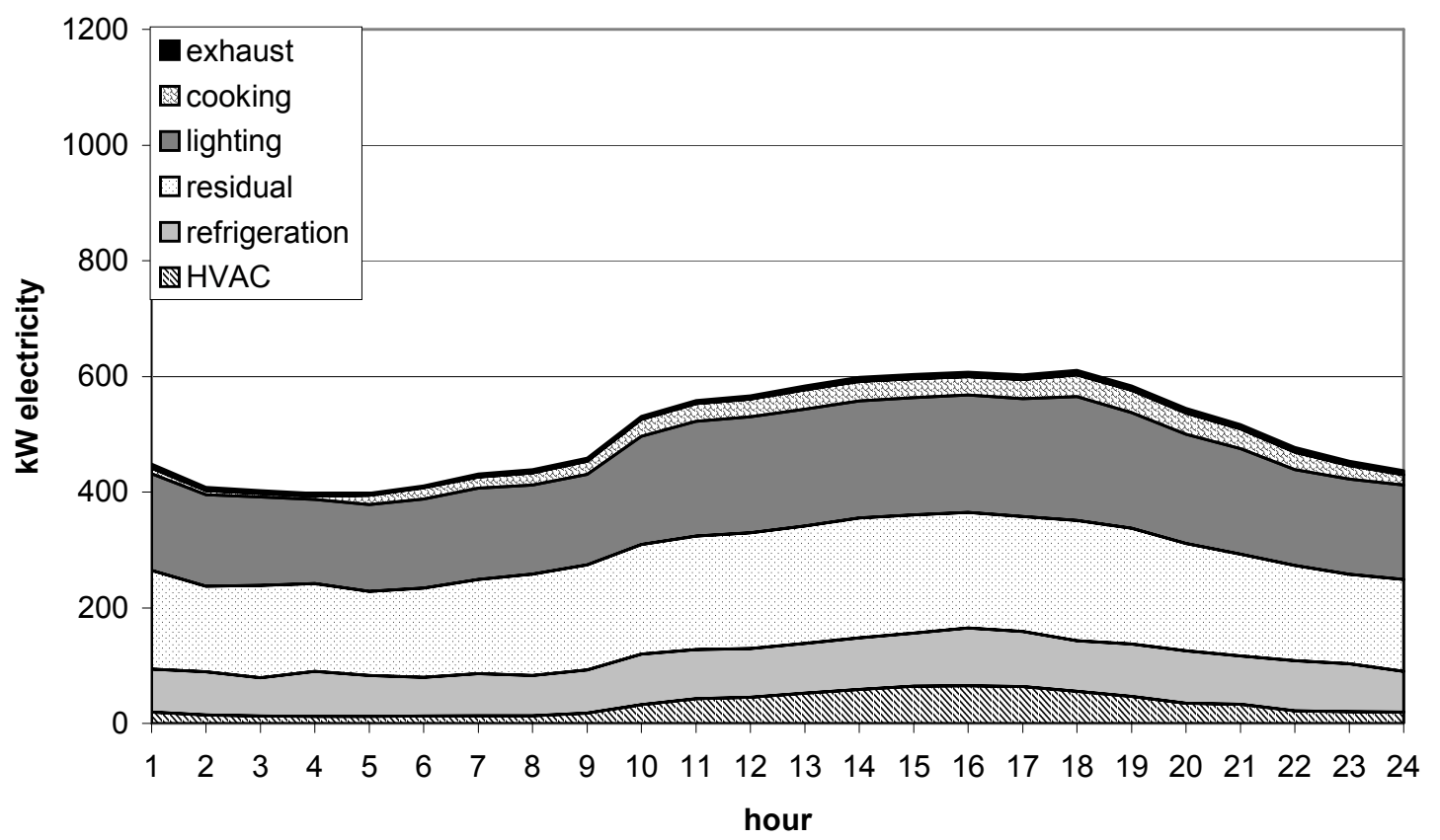

Figure 7: Microgrid Oaks January Weekend Electrical Load

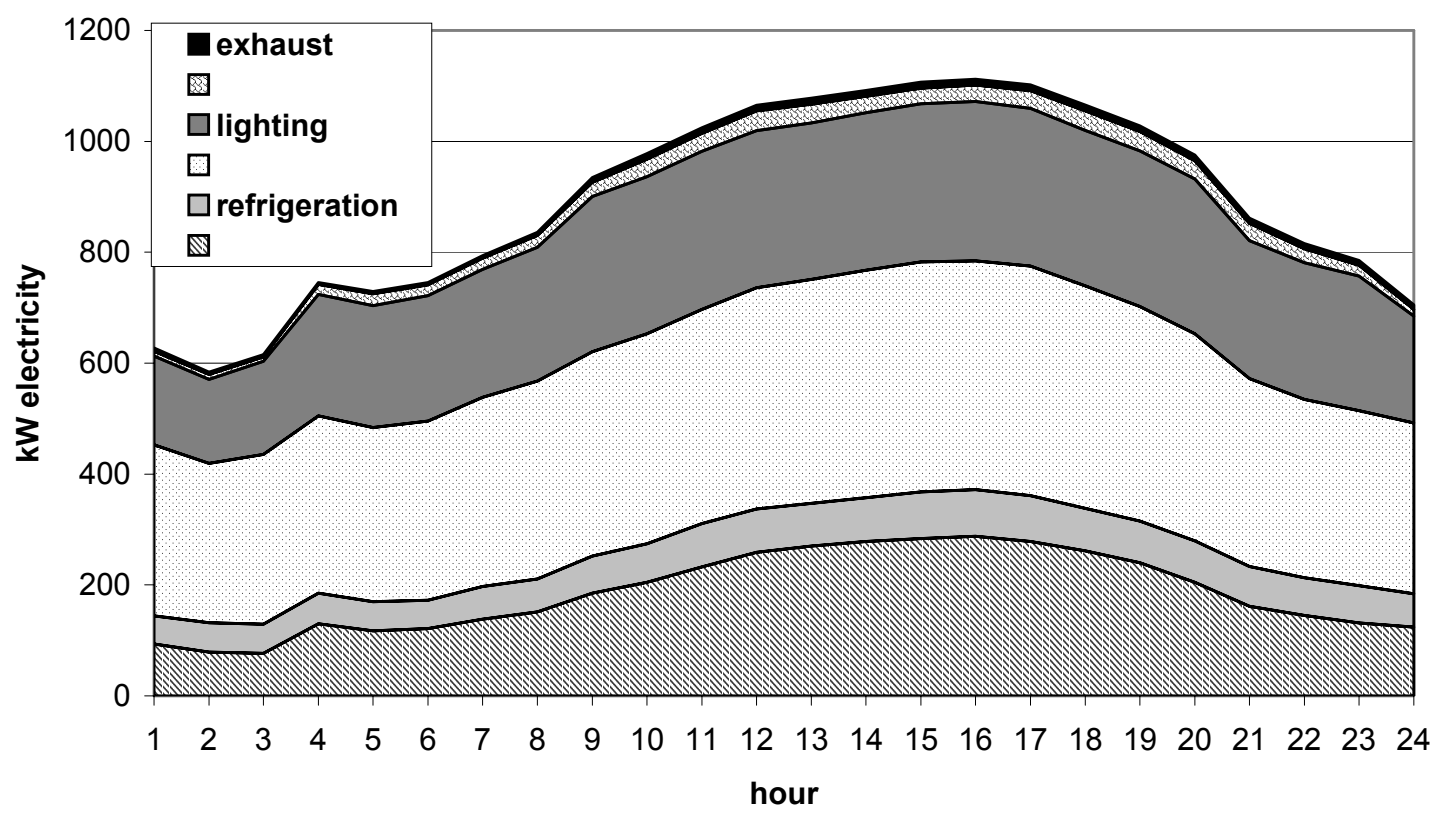

Figure 8: Microgrid Oaks July Weekday Electrical Load 


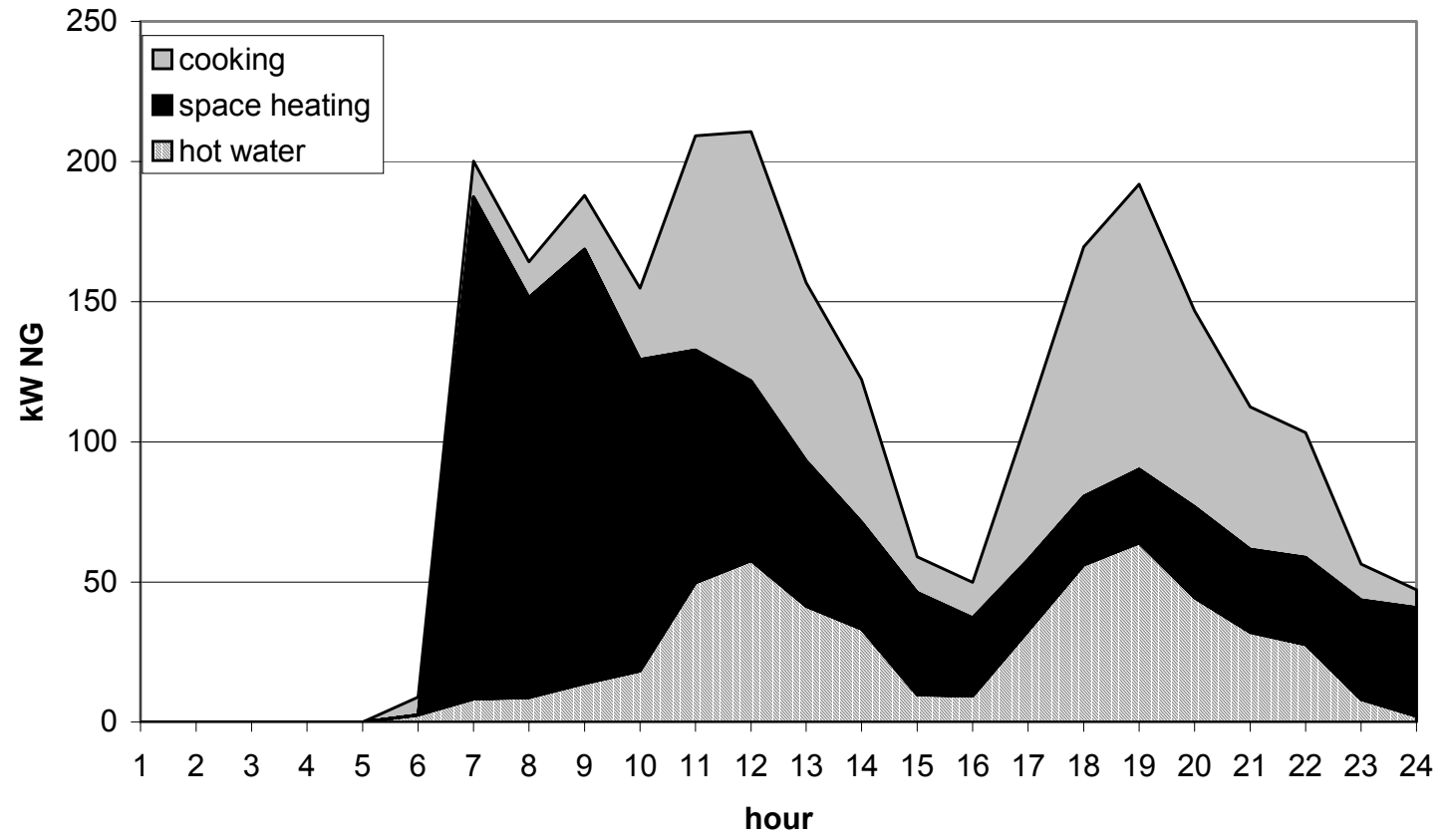

Figure 9: Microgrid Oaks January Weekend Natural Gas Load (simulated data)

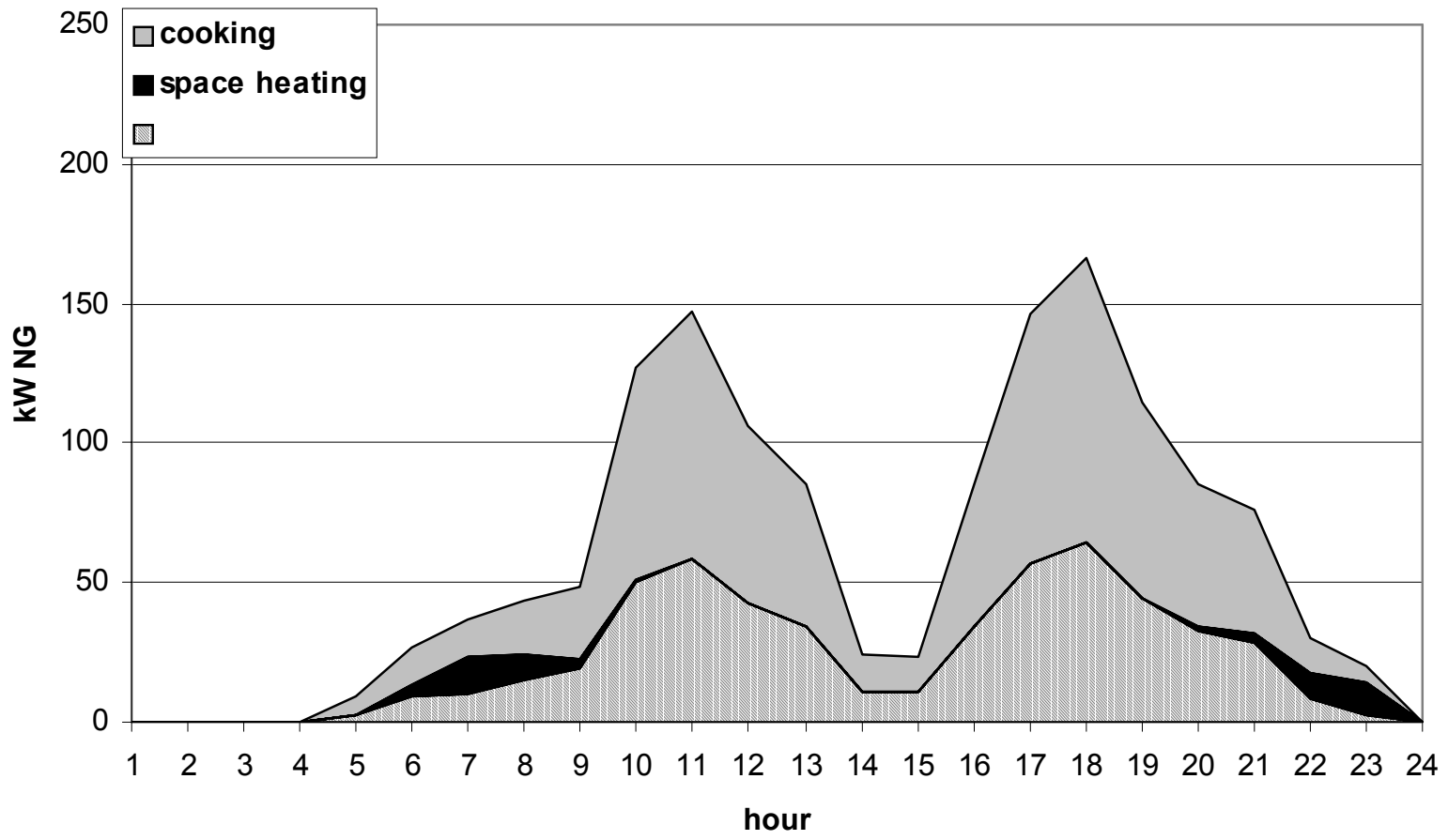

Figure 10: Microgrid Oaks July Weekday Natural Gas Load (simulated data) 
As can be seen in Figures 7 and 9, the electrical load for the $\mu$ Grid peaks in the mid- to lateafternoon, as would be expected. In contrast, the highest gas loads for the $\mu$ Grid occur in the morning until lunch and again at dinnertime. This is because the restaurants demand the most natural gas for hot water and cooking, and restaurants are most active around mealtimes. Space heating, which is the greatest during colder months, such as January shown in Figure 8, and peaks in the morning.

The greatest benefit from combining DER with CHP occurs when the electrical load and the heat load of the $\mu$ Grid occur at the same time. Microgrid Oaks displays some compatibility between loads in the early and late afternoon hours, but load coincidence is not great overall. When heat loads are small, the benefits of CHP are reduced.

Comparing monthly averages for electrical and heat loads, again, Microgrid Oaks is not found to be an optimal candidate for CHP. The highest electric load months occur in the summer months of July and August, opposite to the high heat load months of January and December. Figures 11 and 12 show the average total electrical and heat loads for the $\mu$ Grid.

In this $\mu$ Grid the heat loads are not that great, and the heat and electricity loads are not highly coincident. Because of this, on the whole Microgrid Oaks is not an optimal candidate for CHP. 
An Engineering-Economic Analysis of Combined Heat and Power Technologies in a $\mu$ Grid Application

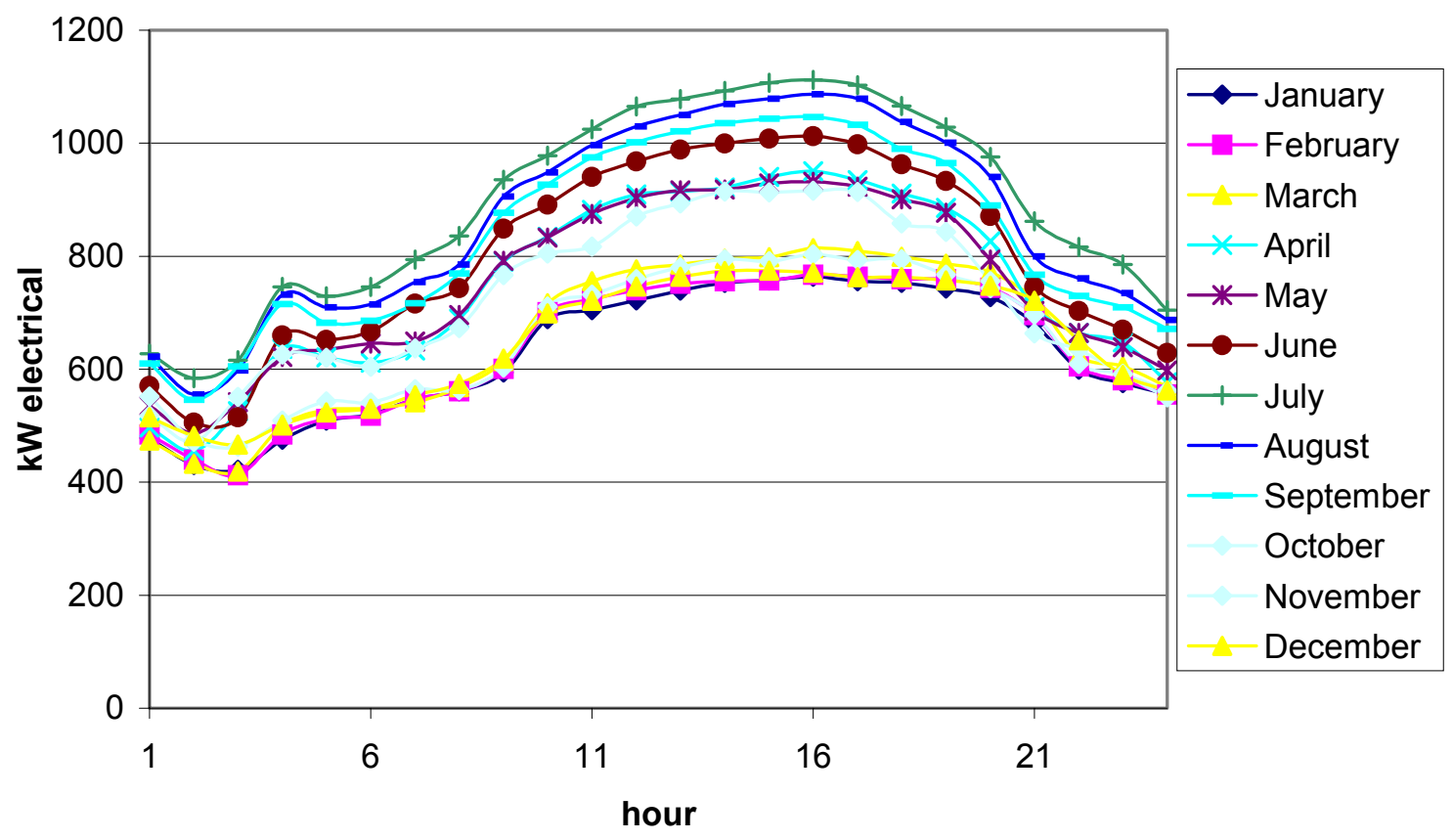

Figure 11: Monthly Average Electrical Load for Microgrid Oaks

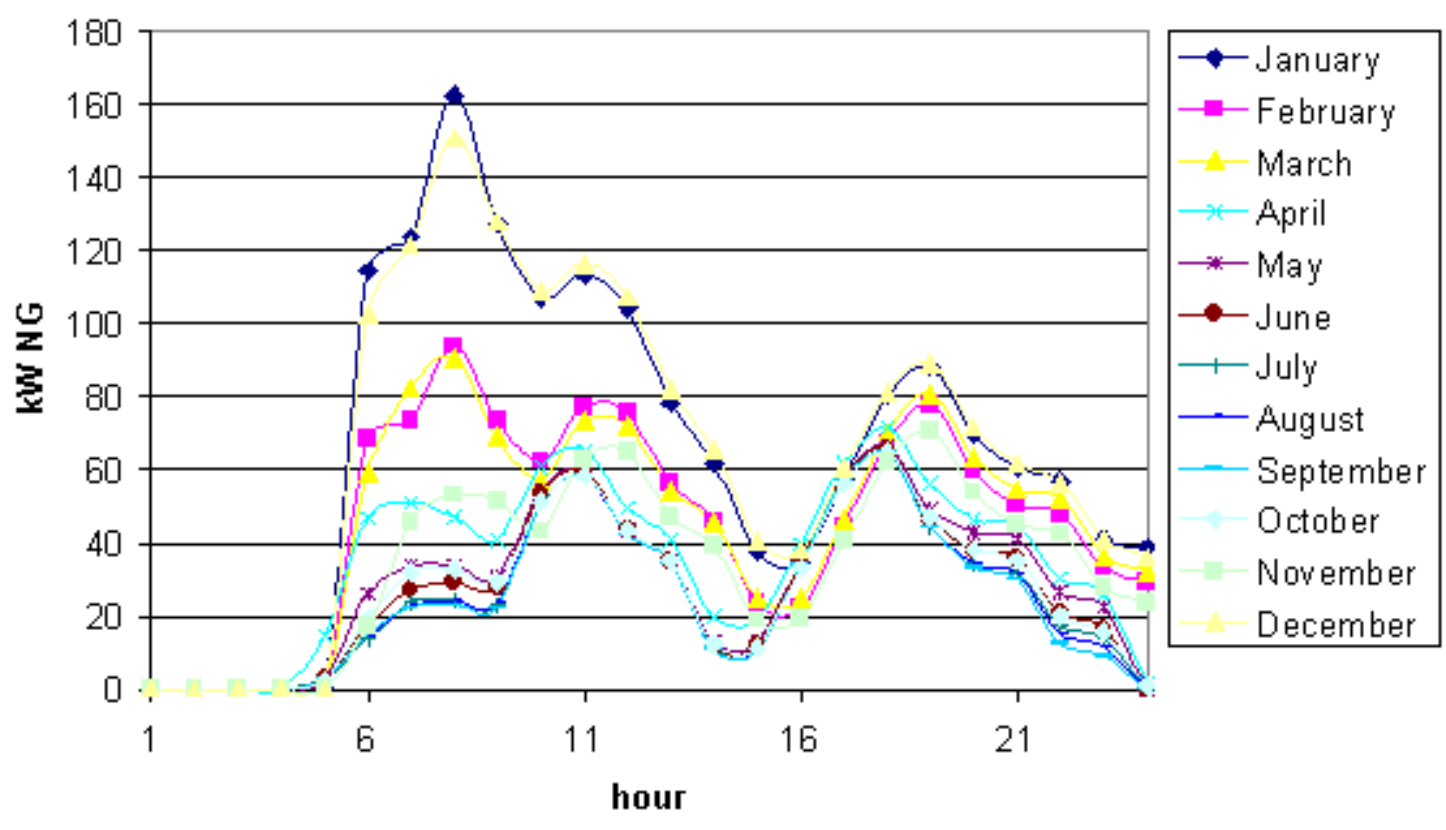

Figure 12: Monthly Average Gas Load for Microgrid Oaks 


\subsection{Assumptions of Model}

Feasibly modeling CHP systems in commercial buildings required many assumptions given the available information while still providing insight on the general patterns of CHP technology adoption for different types of customers.

All technologies in the model were one of four technology types, depending on its power outputs: DG (electricity) capability, DG with CHP (heat) capability, DG with absorption chiller (cooling) capability, or DG, CHP, and absorption cooling capability. In the model, each technology was assumed to be a black box that produces one of the four combinations of electricity, heat, and cooling capacity each hour with representative costs. In reality, the actual systems may not be integrated easily without additional electrical and mechanical equipment. The integrated packages included in the model represent only a few of the many combinations of CHP technologies possible.

The CHP systems were assumed to be retrofitted to existing heating and cooling systems in each building. However, the cost of retrofitting a business to use CHP heat or cooling was not included. This information is site specific and is therefore difficult to include in the model. The model also assumed that the heating and cooling distribution network exists and that no additional equipment needed to be installed to meet residual heating and cooling demand. It was assumed that each customer used a natural gas fired boiler or furnace to meet residual heating loads and a compressor driven air conditioning system to meet cooling loads. It was assumed this equipment for meeting residual loads operated at average efficiency.

Absorption cooling was used to displace compressor cooling. However, the electrical load data includes the load for compressor cooling and was input into the model. Linear programming optimization models are not able to modify input data, and so DER-CAM was not able to change the amount of electrical load by the amount that was displaced by absorption chilling. In order to simulate changing input data for cooling load, the absorption cooling was assigned a certain "phantom" electrical output at zero cost. As a result, the model accurately represented the capital and operating costs, and the performance characteristics of absorption cooling equipment while simultaneously substituting electricity powered cooling equipment without affecting the electrical load data.

It was assumed that each CHP unit operated at constant efficiency and COP over the range of output. That is, the amount of heating or cooling a unit produced was proportionally related to the percent of electrical capacity the unit is producing. The ratio of heating output, or cooling output, per unit of electric output was also assumed to be fixed. In other words, the efficiency of fuel input and energy outputs per unit of electricity production capacity were assumed fixed.

In the process of developing the heating and cooling loads for each particular building, only certain loads were assumed to be able to be met by CHP. Other loads were included in the model as "electricity only" or "natural gas only" loads. Another assumption was that the heating and cooling loads developed for this model accurately reflect the heating and cooling loads of the buildings being modeled. It was assumed that the DOE-2 model accurately estimated the heating and cooling loads and the specific portions of that load that are able to be met with CHP were selected. 
The manufacturer performance specifications were assumed to be correct and the price estimates from the manufacturer were assumed to be representative for the area and time period studied. Costs are assumed to be purchase costs and installation costs are included as additional costs if known.

Heat flow was modeled using $\mathrm{kW}$ (power) on an hourly basis. Heat was assumed to be all of the same quality, flowing where directed with no loses (100 percent efficient delivery to loads). The temperature, flow rates, and pressures of the heat transfer mediums were ignored. The specific type and capacity of the thermal end-use, temperatures, flow rates, distances, pressures, efficiency curves, become important in a specific application but were not included in this model. For example, the inlet temperatures of the hot water (cooling loop) or the chilled water (absorption cooling) were assumed to be ideal.

The CHP equipment was assumed to be able to maintain a load following capability. In other words, heating and cooling loads were met with CHP output (which is also based on electricity production), possibly with assistance from the supplementary heating and cooling systems.

Electrical loads of absorption chillers were ignored. This is a reasonable assumption since for a standard absorption cooling system there are only two water pumps and pumping a liquid requires substantially less electricity than running a compressor.

There is no thermal heat storage simulated in the building. The constraints to meet heating and cooling load with production have to be met for each hour of the day separately, with no carry-over of heating or cooling from previous hours. In other words, the building does not have thermal mass and cannot "inventory" heat from one hour to the next.

The prices for electricity were based on the CAISO year 2000 imbalance energy prices. The natural gas prices were fixed at a set price of $\$ 8.66 \times 10^{-6}$ per kJ, which was the average natural gas retail price in San Diego in 2000.

A number of efficiency parameters were established in the model. Section 3.8, Discussion of Results, examines the model sensitivity to some of these parameters with respect to energy efficiency. Residual heat is converted to useful heat at an efficiency of 0.7. Purchased natural gas is converted to useful heat at an efficiency of 0.85 . Electric generation efficiency was assumed to be 0.28 from the input fuel to a delivered $\mathrm{kWh}$. Absorption chillers were estimated to reduce electrical cooling load with an efficiency of 20 percent. This was derived from the approximation that an electric, compressor driven air-conditioning systems has a COP of 5.0, whereas absorption chillers have a COP of 1.0. Hence, it takes five times more thermal energy input to an absorption chiller to produce the same amount of cooling from an electric compressor driven chiller.

An estimated cost function for these technology combinations produced the cost of various combinations of DG, CHP, and absorption chiller technologies. The technology lifetimes were considered to be 12.5 years for most technologies except the PV panels, which are assumed to last for 20 years. Discounting cash flows to the present value was calculated at an interest rate of 0.075 . 


\subsection{Results of the Model}

Three separate test cases were modeled to determine the impact of using CHP to meet power and heating loads. For each run the entire $\mu$ Grid was analyzed as one customer. The first case was the "Do-Nothing" scenario, where no DER technologies were available. The customer had no alternative options for meeting loads; all energy was purchased from the macrogrid. This scenario provides the base-case for economic comparison of the next two scenarios. The second case, "No CHP", included on-site electricity generation as an option for Microgrid Oaks to meet electricity demand, but no CHP technologies were included. The third test case, "DER plus CHP", allowed both electricity generation and CHP technologies.

Table 6 summarizes the cost analysis and installed capacity for the three test cases.

Table 6: Results of DER-CAM CHP Model of $\mu$ Grid

\begin{tabular}{|l|l|l|l|}
\hline & \multicolumn{1}{|c|}{ Do-Nothing } & \multicolumn{1}{c|}{ No CHP } & \multicolumn{1}{c|}{ DER plus CHP } \\
\hline $\begin{array}{l}\text { Total Cost } \\
\text { (Cost Index) }\end{array}$ & $\begin{array}{l}\$ 1,700,00 \\
(1.0)\end{array}$ & $\begin{array}{l}\$ 700,000 \\
(.04)\end{array}$ & $\begin{array}{l}\$ 600,000 \\
(0.35)\end{array}$ \\
\hline Installed Capacity & 0 & $1,100 \mathrm{~kW}$ & $1,055 \mathrm{~kW}$ \\
\hline $\begin{array}{l}\text { On-site Generation } \\
\text { Technology }\end{array}$ & N/A & $\begin{array}{l}\text { One 100-kW natural } \\
\text { gas reciprocating } \\
\text { engine } \\
\text { Two 500-kW natural } \\
\text { gas reciprocating } \\
\text { engines }\end{array}$ & $\begin{array}{l}\text { One 55-kW natural gas } \\
\text { reciprocating engine with CHP } \\
\text { heating } \\
\text { Two 500-kW natural gas } \\
\text { reciprocating engines with } \\
\text { absorption chillers }\end{array}$ \\
\hline Cost Savings (\%) & 0 & $\begin{array}{l}60 \% \\
65 \%\end{array}$ \\
\hline
\end{tabular}

As can be seen in Table 6, installing CHP technologies decreased the cost of powering the $\mu$ Grid. The total cost to the $\mu$ Grid when no DG is installed was $\$ 1.7$ million. The cost for energy drops to $\$ .7$ million when only electrical generation is installed. Adding CHP to the electricity generation reduces the total cost by another 10 percent, to a total of $\$ 0.6$ million. Providing the $\mu$ Grid's power with DER, and no CHP technologies, reduces costs by about 60 percent. Providing the $\mu$ Grid's power and heat with CHP reduces the $\mu$ Grid's costs by about 65 percent.

The most cost effective DER installation does not necessarily mean that all of the $\mu$ Grid's power will be supplied by onsite generation. When DER is introduced, $1,100 \mathrm{~kW}$ of capacity is installed, which covers 95 percent of the $\mu$ Grid's peak load of $1,159 \mathrm{~kW}$. When CHP is also added, 91 percent of the peak electricity load is covered by the installed capacity. The reason the cost is lower must result from increasing the total amount of load being met by the total amount of purchased fuel. The natural gas purchased to run the generators is now serving heating loads at the same time, thus lowering overall purchase of natural gas. This difference offsets the amount of electricity bought to meet peak loads. Additionally, using CHP to meet peaky air conditioning loads lowers the actual peak load. It is important to remember also that the peak electrical demand happens only a 
few times a year, so for most of the year the entire electrical load of the $\mu$ Grid is met by the installed generation.

Table 7 is output data for the total annual electricity production of Microgrid Oaks. It should be noted that the CHP case has slightly less installed capacity, but on average the two scenarios produce about the same amount of electricity per year. Therefore, the CHP technologies must be operating at a slightly higher capacity factor, and/or operate more hours of the year.

This output only focuses on electricity and therefore does not provide any information about the thermal loads or how much of the thermal load is being met with the CHP system.

Table 7: Electricity Generation for Microgrid Oaks, Results of "DER plus CHP" Scenario

\begin{tabular}{|l|c|c|c|c|}
\hline & $\begin{array}{c}\text { "No CHP" } \\
\text { totals for year }\end{array}$ & Index & $\begin{array}{c}\text { "DER plus CHP" } \\
\text { totals for year }\end{array}$ & Index \\
\hline Installed Capacity & $1,100 \mathrm{~kW}$ & 1.0 & $1,055 \mathrm{~kW}$ & 0.96 \\
\hline Above Cap Hours & 63 hours & 1.0 & 239 hours & 3.79 \\
\hline Below Cap Hours & 8,697 hours & 1.0 & 8,521 hours & 0.98 \\
\hline Generated Load & $6,143,957 \mathrm{kWh}$ & 1.0 & $6,137,253 \mathrm{kWh}$ & 1.00 \\
\hline Purchased Load & $452 \mathrm{kWh}$ & 1.0 & $7,156 \mathrm{kWh}$ & 15.81 \\
\hline Total Consumed & $6,144,409 \mathrm{kWh}$ & 1.0 & $6,144,409 \mathrm{kWh}$ & 1.00 \\
\hline $\begin{array}{l}\text { Percent electricity } \\
\text { generated on site }\end{array}$ & $99.99 \%$ & 1.0 & $99.88 \%$ & 1.00 \\
\hline $\begin{array}{l}\text { Percent electricity } \\
\text { purchased }\end{array}$ & $7 \times 10^{-5} \%$ & 1.0 & $0.001 \%$ & 15.81 \\
\hline
\end{tabular}

Figure 13 displays the combined end use electrical load for the average weekday in July.

Figure 14 illustrates how these loads were met. It shows that all the electricity only loads, such as cooking, exhaust and lighting, are met by onsite generation. The HVAC and refrigeration, on the other hand, instead of being met by electricity, are being provided by absorption chillers powered by the residual heat produced by electricity generation. Natural gas consumption does not increase to meet the cooling load with absorption chillers because absorption chillers are run with residual heat produced from the electricity generated to meet the electrical end-use loads. 


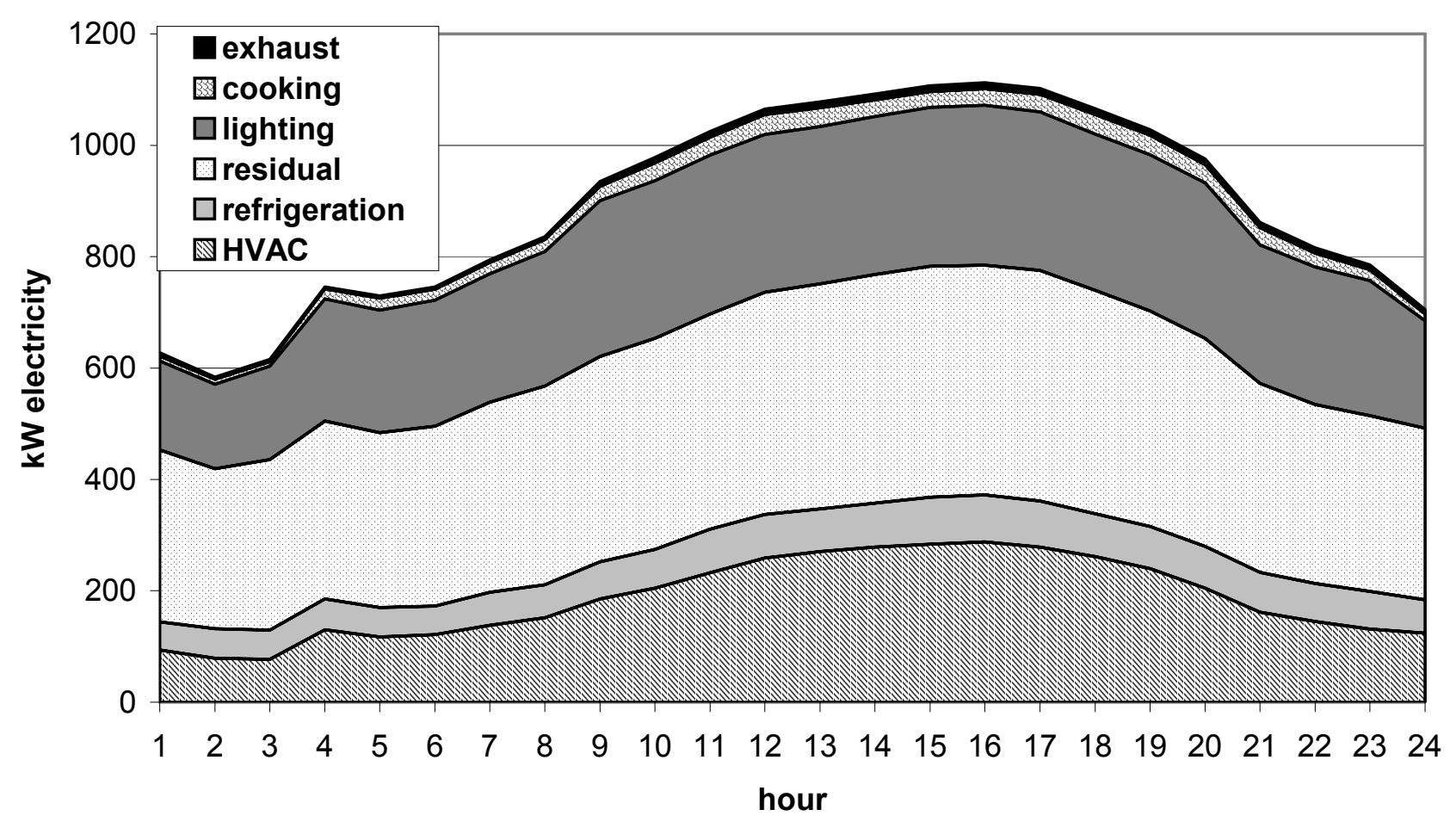

Figure 13: Electricity Loads for July Weekday

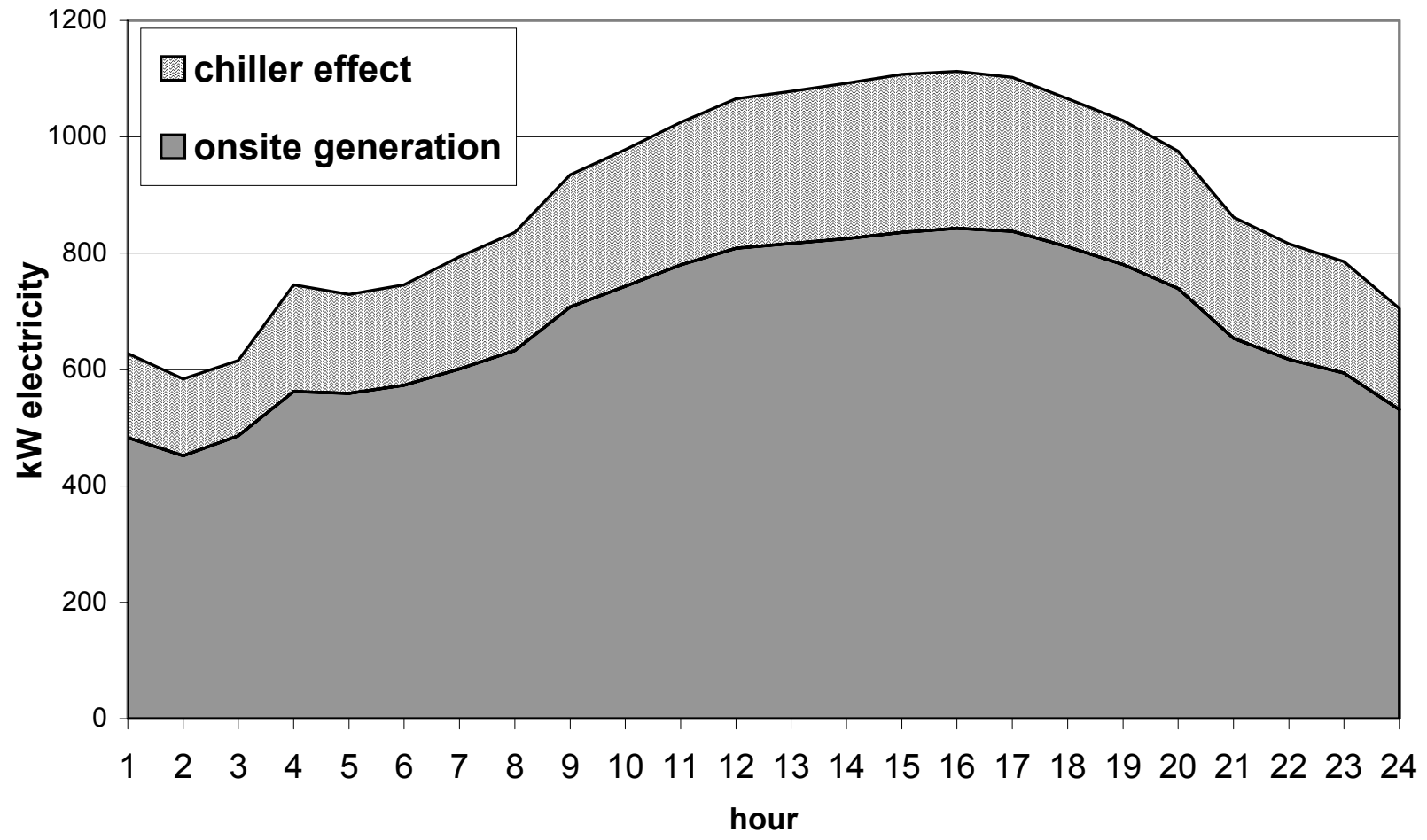

Figure 14: Electricity Loads Supplied by Installed Capacity and Cooling Effect 


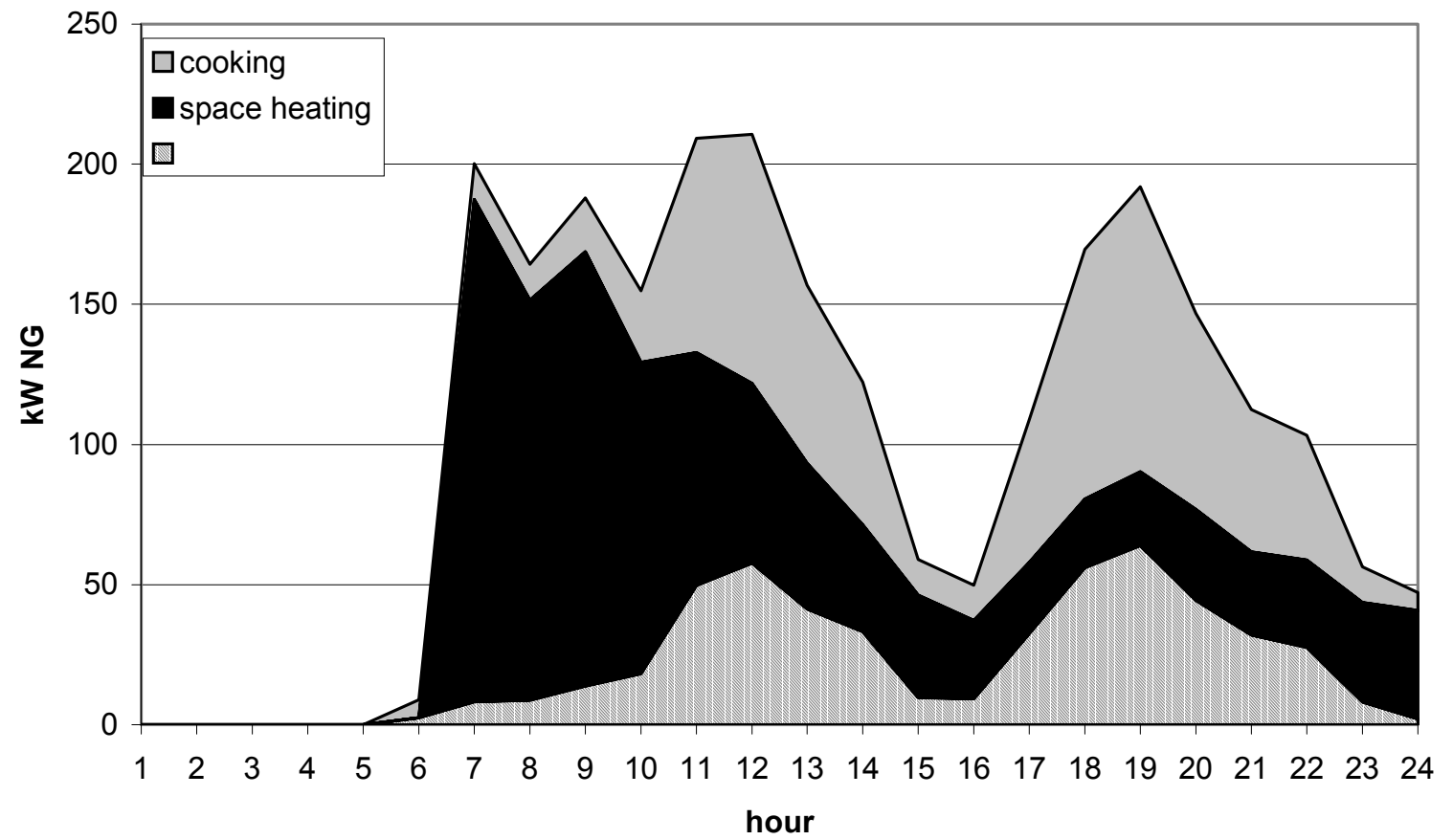

Figure 15: Heat Loads in January

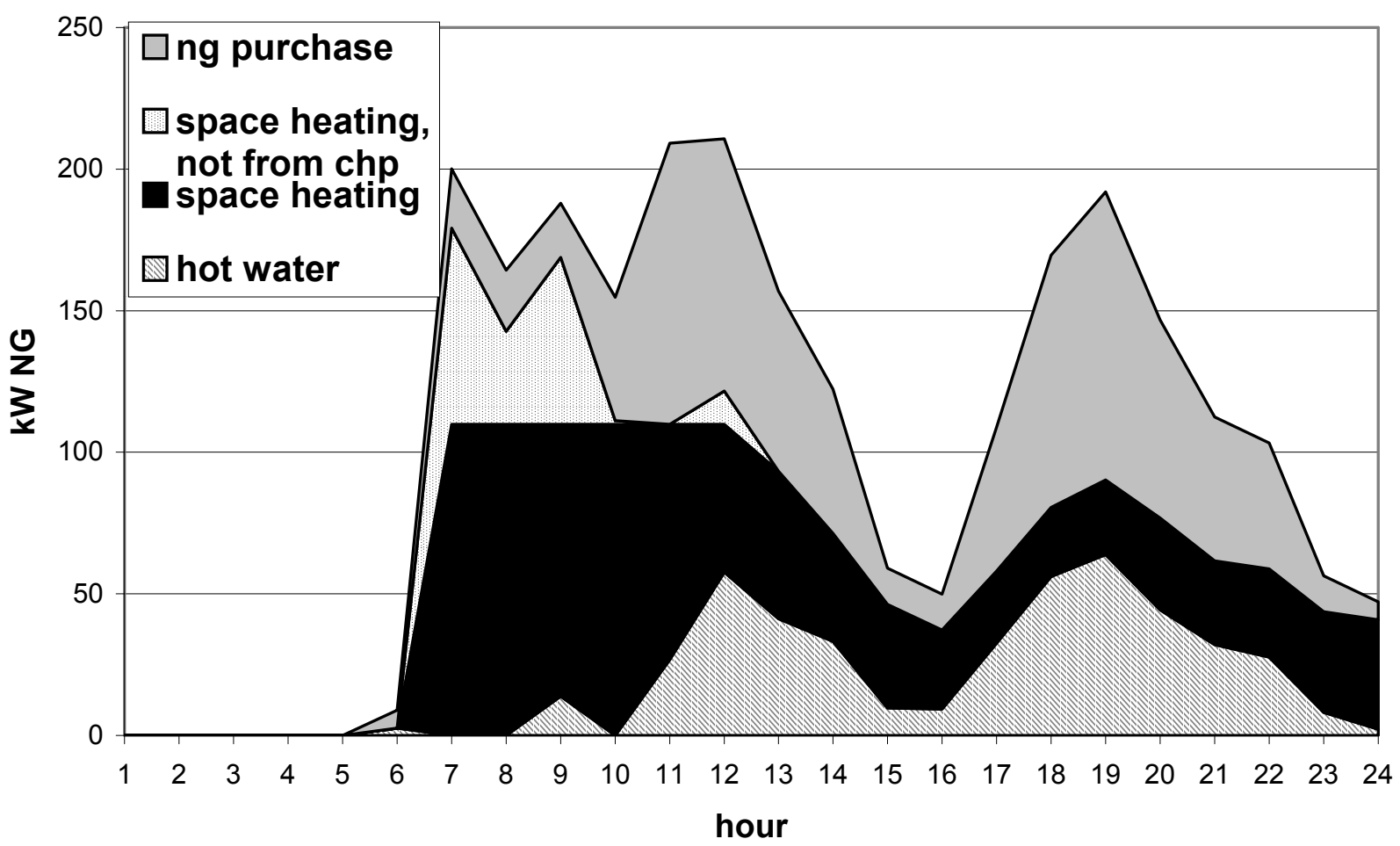

Figure 16: Heat Loads Supplied by NG purchases and CHP in January 
Figure 15 and 16 illustrate the CHP effect on the heat loads, which are met by natural gas (NG) when there is no CHP. In DER-CAM the gas load is subdivided into three different end uses: water heating, space heating and cooking. The water heating and space heating loads can be met with either natural gas or CHP technologies, whereas the cooking load can only be met by using natural gas. As shown in the figures, the model recovers some of the wasted heat produced by the generators to meet part of the space heating and water heating loads. However, in the morning hours, space-heating demand pushes the heat requirement beyond the level available from the one generator with CHP, about $110 \mathrm{~kW}$. The gap is met with purchased natural gas, as shown by the dotted area of Figure 16.

\subsection{Discussion of Results}

The installation of DER generation capacity results in significant savings over the "Do-Nothing" scenario. As discussed previously, customers acting together as a $\mu$ Grid are able to realize greater savings by using DER due to load balancing and economies of scale. In particular, prior work has shown that customers with higher load factors (i.e., flatter loads) are able to achieve greater percentage cost savings. This is because they need not install additional capacity or purchase from the IEM to meet peaking loads uneconomic to self-provide.

Installation of CHP was the least cost method of meeting energy services for the customers in this $\mu$ Grid. However, the $\mu$ Grid captures most of these financial benefits by installing only electricity generating technologies. The ability of the $\mu$ Grid to install, maintain and use cogeneration machines appears to contribute to, but not dominate, its lower costs.

A higher capacity of installed generation does not directly relate to lower energy costs. The $\mu$ Grid with no CHP, which pays slightly more for its energy, should install more capacity than the $\mu$ Grid with CHP to achieve least-cost energy. At the same time the $\mu$ Grid employing CHP covers more of its electricity and gas needs with a reduced installed capacity, thus reducing cost below that of simply installing DG with no CHP. This result demonstrates the possible reductions in cost that can be achieved through the strategic coordination of the onsite generation and cogeneration.

The total operating cost of each alternative is a net present value of all of the capital and operating costs of each system for one year and for each additional year of operation. Hence, installing a system with a lower annual operating cost than the Do-Nothing scenario is financially equivalent to receiving an annual benefit each year for the lifetime of the system. The size of this annual benefit is determined by the difference between the total annual cost of the Do-Nothing scenario and the alternative scenario. The results signify that by installing a DG system to provide electricity to the $\mu \mathrm{Grid}$ is equivalent to saving $\$ 1$ million each year for the lifetime of the DG system. Similarly, the investment in a CHP system is equivalent to the $\mu \mathrm{Grid}$ saving $\$ 1.1$ million each year for the lifetime of the CHP system.

From the macrogrid perspective, the reduction in power load to the $\mu$ Grid was considerable after installing DER systems. For the No CHP case and the DER plus CHP case, the $\mu$ Grid generated over 6,000 MWh of electricity, reducing its load on the macrogrid by the same amount. These 
cases represented a reduction of utility macrogrid purchased electricity of slightly less than 100 percent.

Installing DER also changed the amount of natural resources required to meet the same power loads. Adding DER to the base case increased energy-efficiencies to 30 percent. Modeling the CHP system resulted in a 10 percent reduction in energy resources consumed ( $\mathrm{kWh}$ of electricity and natural gas combined) and therefore a 33 percent over-all increase in energy efficiency. This reduction in resource consumption is the result of meeting more loads with the same fuel through capturing waste heat. The reason that the increase in energy efficiency is smaller than the 80 percent reduction potential is the small thermal- to electrical- load ratio in Microgrid Oaks. The electrical load in Microgrid Oaks is 10 times larger than the thermal load (6,000 MWh electric versus $600 \mathrm{MWh}$ thermal respectively). As a result, the residual heat from electricity generation is not all used productively. Increasing the thermal loads will result in system energy efficiency values from 33 percent to 80 percent with the higher efficiency level representing thermal- to electric- load ratios that are matched to the useable heat and electrical output ratios of the CHP technologies.

Increasing the heat load of Microgrid Oaks by a factor of 10, from $600 \mathrm{MWh}$ to 6,000 MWh thermal (roughly half of the useable residual heat produced) would increase the system energy efficiency to 60 percent resulting in a 30 percent decrease in resource consumption compared to the Do-Nothing case. If Microgrid Oaks has thermal and electrical loads exactly matched to the output of the CHP system it will produce a system energy efficiency of 93 percent and a reduction in resources of 45 percent compared to the base case.

The assumption that only 70 percent of this residual heat can be used for meeting heating loads due to losses in the capture and transfer of this heat from the DG technology to the end use does not influence the overall efficiency in this study. For this analysis the system energy efficiency is insensitive to this parameter at low thermal load levels, since there is typically more than enough useable residual heat to serve the heating load.

\subsection{Limitations of Analysis}

There are many complications in modeling CHP adoption that did not exist in the previous work that modeled DER without CHP. Many of these difficulties were the subject of assumptions made to construct the model. Six of the major limitations of this model are described below. The first two limitations deal with the simulated input data, the next three deal with the limitations of the model itself, and the final limitation discusses the wider accuracy of a customer adoption model predicting customer behavior.

The input thermal load data was simulated based on building type, and size, and weather. It was necessary to simulate thermal loads because there were no metered data. Simulating data involves some inherent inaccuracies, including assumptions made by the DOE-2 simulator (such as estimating building population and using TMY weather) and input to the simulator (including total thermal equipment load in the building). It was also necessary to estimate which thermal loads, among all the thermal loads, could in general be met with CHP systems. 
The DOE-2 building modeling software did not account for thermal mass.

The DOE-2 model did not consider each building's thermal mass characteristics and its influence on energy consumption. DOE-2 has the capability to consider some thermal mass and thermal energy storage but it does not do it well even when the input is done correctly. This input depends on specific geometry parameters from the modeled buildings, increasing the complexity of the model. For example, in the DOE-2 model used for this analysis, generic floor densities were defined (low, medium, high) which do not accurately represent thermal storage. The next version of the building energy simulation model, EnergyPlus, corrects for this issue.

\section{CHP heat output has many forms and qualities.}

This model assumed that all waste heat was of the same type and quality. However, in a real CHP system, the specific type and capacity of the thermal end-use, temperatures, flow rates, distances, pressures, efficiency curves, become important. To make this model more thermodynamically accurate all of these parameters would need to be defined. Because of the limitations of data available, this level of detail was not possible.

\section{Heat production varies functionally with electric production.}

Each CHP technology does not have fixed efficiency for converting fuel consumption to useful heat or cooling power; rather, it varies as the electricity production changes. Because of the difficulties of obtaining data for the various efficiencies and incorporating it into the model, the efficiencies are assumed to be fixed. This may not be a drastic limitation, however, because many technologies stay near their optimal efficiencies at a wide rage of operating capacities.

Specific applications determine technology performance and cost of retrofits and maintenance. Many of the details of designing and installing a CHP system were not included in the model. The extra plumbing and electrical hardware required to install and operate these systems could involve substantial costs and hassle. Hidden costs of maintaining the CHP systems were not included, such as the cost of contracting a turbine refurbishment specialist. Also, the heat distribution networks were assumed to operate at 100 efficiencies. In reality they would involve some losses based on the placement of generation in relation to load.

In order to use this model as a tool to predict actual customer adoption, the assumption was made that customers will make only economically frugal decisions. This model determines what the customers in a $\mu$ Grid should do minimizes cost. This is not necessarily the only factor that would affect customers. Other factors include changing prices and costs of technologies, perceptions about CHP technologies, specifics of customer sites that vary in ways not included in the model, energy and environmental policy regulations and incentives, and regional availability of technologies and expertise. The model is useful in exploring the sensitivities of CHP technology adoption decisions that relate to lowering cost. The model will most likely be extended further to explore scenarios involving various forms of CHP policy initiatives, technology performance improvements, and economic conditions. 


\section{Conclusion}

\subsection{Summary of Research}

This research explored the economic benefits of installing a DER system and a CHP system for a particular $\mu$ Grid by adding CHP technologies to the existing DER-CAM model, given a set of assumptions and limitations. This $\mu$ Grid was comprised of the following types of businesses: supermarket, office building, sit-down restaurant, fast-food restaurant, deli restaurant, department store, retail store, and a warehouse store.

It is notable that these business categories are not considered the most economic or feasible for CHP applications. In fact, previous research has stated that office buildings, restaurants, and supermarkets are generally economically infeasible to support CHP systems (OSEC 2000). Buildings were chosen based on availability and completeness of load data, not because of load ratios or compatibility.

By installing technologies to produce electricity, this $\mu$ Grid demonstrated cost savings of 60 percent, compared to the base case of purchasing electricity and gas from utility companies for all electric and thermal loads. Costs were reduced another 10 percent (a 65 percent reduction from the base case) by installing a CHP system to capture residual heat and direct it toward meeting the $\mu$ Grid's thermal heating and cooling loads.

The results of the model indicate that a $\mu$ Grid that installs DER to meet its electricity loads saves $\$ 1$ million each year, compared to purchasing all power from the macrogrid, for the lifetime of the DG system. Similarly, investment in a CHP system is equivalent to the $\mu$ Grid saving a $\$ 1.1$ million in energy costs each year for the lifetime of the DER and CHP systems.

The model also indicated that installing a CHP system was not a significant factor in the economic viability of the DER for this $\mu$ Grid configuration. That is, the CHP system was neither an economic nor uneconomic investment. The modeling process used demonstrates that installing DG was financially profitable on its own, and that adding CHP capability only marginally increased this profitability.

From the perspective of the macrogrid, installing DER systems reduced the load of the $\mu$ Grid considerably. Both by adding DER with no CHP, and DER with CHP, the $\mu$ Grid was able to generate over 6,000 MWh of electricity, reducing its load on the macrogrid by the same amount. These cases represented a reduction of utility macrogrid purchased electricity of slightly less than 100 percent.

The CHP system with absorption cooling capability resulted in a 10 percent reduction in energy resources consumed (kWh of electricity and natural gas combined). This reduction in resource consumption is the result of an energy efficiency increase for the total system from 30 percent, for the Do-Nothing scenario, to 33 percent, for the DER plus CHP scenario. The high electricity to thermal load ratio, a result of small thermal loads, is the reason for the small increase in efficiency from installing the CHP system. As a result, the residual heat from electricity generation is not all 
used productively. Increasing the thermal loads will result in system energy efficiency values from 33 percent to 90 percent with the higher efficiency level representing thermal to electric load ratios that are matched to the useable heat and electrical output ratios of the CHP technologies.

\subsection{Future Work}

There are many areas for additional research. Improving both the technology specifications and the thermal loads would increase the plausibility of the results. Including the installation and retrofit costs of CHP systems for different applications would make this result more accurate of the true costs facing businesses contemplating these systems. More detailed modeling of the thermodynamic realities of CHP systems would make the results more realistic. Examining buildings with substantial thermal loads, such as hospitals and hotels, would provide more information about areas CHP technologies are likely to be employed. The previous assumptions and limitations sections outline many areas of research to improve this model and the results.

Further areas for expansion of this model include:

- Incorporating GIS into the model to explore thermodynamic loss, changing energy prices, utility infrastructure, building codes, environmental regulations, environmental quality conditions such as air quality, types of businesses in commercial and industrial areas, and existing and planned development patterns

- Displaying the results of the technology adoption model, including estimates for pollution emissions, in a GIS format in order to analyze regional DER adoption patterns and the resulting effects on energy planning and environmental protection

- Emissions information $\left(\mathrm{CO}^{2}, \mathrm{NO}_{\mathrm{x}}, \mathrm{PM} 10, \mathrm{VOCs}\right)$ could be included for additional technologies in the DER-CAM model. This information could be used for future air quality studies or to compare the impacts of DER and central plant emissions

- Including interruptible loads and direct load controls into the model both as a customer option and utility level control mechanism

- Incorporating tax incentives and depreciation schedule changes

- Considering the potential for energy storage technologies

- Accounting for the thermal storage of heat loads within buildings

- Running a longer term simulation with estimates about future energy prices, volatilities, and technology costs and performance

- Modeling the costs and effects of utility power outages on the desirability of DER systems

- Evaluating emissions trading programs on the financial performance of CHP systems.

- Including additional information about energy efficiency and renewable energy into the DERCAM model and estimating potential savings by installing standard packages of energy efficiency technologies.

- Including a customer adoption of real-time pricing signals into the customer's energy demands. This may involve changing the model to a dynamic programming model to incorporate changing input data

- Investigate the reliability and power quality benefits of DER and CHP systems

- Integrate the DER-CAM model into a utility capacity expansion-planning model. Examining how DER adoption patterns are likely to evolve in a given region will provide information for 
distribution company planning. Integrating these two models will result in a more systematic planning process and increased efficiency of natural resource use.

This research is another step toward developing a demand-side generation model that integrates information about the customer adoption of DER with information about the larger geographic conditions. The long-term goal is to gain insight into regional energy systems by understanding the relationship between the end-use energy systems and the surrounding physical infrastructure of electricity and gas distribution networks, the regulations on environmental emissions and building codes, state interconnection standards for DER, and environmental conditions. 
An Engineering-Economic Analysis of Combined Heat and Power Technologies in a $\mu$ Grid Application 


\section{References}

American Council for an Energy Efficient Economy (ACEEE, 2000). Authors N. Martin, E. Worrell, M. Ruth, L. Price (LBNL) R. N. Elliott, A. M. Shipley, J. Thorne (ACEEE). Emerging Energy-Efficient Industrial Technologies.

Brennan, Palmer, Kopp, Krupnick, Stagliano, and Burtraw (1996). A Shock to the System: Restructuring America's Electricity Industry. Resources for the Future. Washington, DC.

Brown, Richard E, and Jonathan G Koomey. Electricity Use in California: Past Trends and Present Usage Patterns. Unpublished draft, 2001.

Danish Energy Agency (1998). Combined Heat and Power in Denmark. Version 1.0, World Wide Web Document, http://www.ens.dk/pub/chp/INDEX.HTM.

Department of Energy (DOE) (2001). CHP Initiative website http://www.eren.doe.gov/der/chp/.

Deppe, Andreas and Tina Kaarsberg (2001). The Residential Micro Combined Heat and Power Market.

Dunn, Seth (2000). Micropower: The Next Electrical Era. WorldWatch Institute.

Electric Power Research Institute (1999). TAG: Technical Assessment Guide, Volume 5:

Distributed Resources. TR-113165-V5.

Elliott, R. Neal, and Mark Spurr (1999). Combined Heat and Power: Capturing Wasted Energy. American Council for an Energy-Efficient Economy. Washington DC, (202) 429-8873.

Energy Information Administration (EIA) (2000). Carbon Dioxide Emissions from the Generation of Electric Power in the United States.

http://www.eia.doe.gov/cneaf/electricity/page/co2_report/co2report.html

EIA (1999). Emissions of Greenhouse Gases in the United States.

http://www.eia.doe.gov/oiaf/1605/ggrpt/index.html

E Source (1997). Space Cooling Technology Atlas. Boulder CO, (303) 440-8500.

E Source (1998). Tech Update TU-98-5, Desiccant Dehumidification by Gerald Cler. Boulder, CO, (303) 440-8500.

Golove, William H. and Joseph H. Eto (1996). Market Barriers to Energy Efficiency: A Critical Reappraisal of the Rational for Public Policies to Promote Energy Efficiency. Lawrence Berkeley National Laboratory, U.S. Department of Energy. 
An Engineering-Economic Analysis of Combined Heat and Power Technologies in a $\mu$ Grid Application

Grossman, Gershon (2001). Professor of Mechanical Engineering at Technion University in Israel. Visiting researcher at LBL. Provided me with insight into absorption cooling systems.

Hammar (1999). The case of CHP in Denmark - and Perspectives to Other Countries, Input to the OECD Annex I workshop on energy supply side policies and measures, Danish Energy Agency.

Hirschenhofer, J.H., D.B. Stauffer, R.R. Engleman, and M.G. Klett (1998). Fuel Cell Handbook, fourth edition. Prepared for U.S. Department of Energy, by Business/Technology Books, Orinda, CA.

Koomey, Jonathan (2001). Turning Numbers into Knowledge. Analytics Press: Oakland, CA.

Laitner, John, William Parks, Jennifer Schilling, and Richard Scheer (1999). Federal Strategies to Increase the Implementation of Combined Heat and Power Technologies in the United States.

Published on DOE's CHP Initiative website http://www.eren.doe.gov/der/chp.

Lovins, Amory B. (1996). Negawatts: Twelve Transitions, Eight Improvements, and One Distraction, Energy Policy's special issue on the future of demand-side management.

Lovins, Amory B. (1977). Soft Energy Paths: Toward a Durable Peace. San Francisco: Friends of the Earth International. 1977.

Lovins, Amory, and Andre Lehmann (2000). Small is Profitable: The Hidden Benefits of Making Electrical Resources the Right Size.

Marnay, Chris, J. Chard, K. Hamachi, T. Lipman, M. Moezzi, B. Ouaglal, F.J. Rubio, and A. Siddiqui (2001). Modeling of Distributed Energy Resources Customer Adoption. Prepared by the Consortium for electric Reliability Technology Solutions for California Energy Commission.

Marnay, Chris, R. Blanco, K. Hamachi, C. Kawaan, J. Osborn, and F.J. Rubio (2000). Integrated Assessment of Dispersed Energy Resources Deployment, Electricity Markets and Policy Group, Lawrence Berkeley National Lab.

OSEC (2000). Onsite Sycom Energy Corporation. The Market and Technical Potential for Combined Heat and Power in the Commercial/Institutional Sector, prepared for U.S. DOE, Energy Information Administration. http://www.eren.doe.gov/der/chp/docs_resources.html

OSEC (2000a). Onsite Sycom Energy Corporation. The Market and Technical Potential for Combined Heat and Power in the Industrial Sector. Prepared for the U.S. DOE, Energy Information Administration. http://www.eren.doe.gov/der/chp/docs_resources.html

OSEC (1999). Onsite Sycom Energy Corporation. Review of Combined Heat and Power Technologies. Prepared for California Energy Commission and Office of Industrial Technologies, U.S. DOE. http://www.eren.doe.gov/der/chp/docs_resources.html

PNL (2001), Pacific Northwest National Laboratory, Desiccant Cooling and Dehumidification, http://www.pnl.gov/techguide/10.htm, viewed 6 December 2001. 
Rubio, F.J., A. Siddiqui, C. Marnay, and K. Hamachi (2001). CERTS Customer Adoption Model, Electricity Markets and Policy Group, Lawrence Berkeley National Lab.

Sargent, Stephen (2001). The Combined Heat and Power Challenge, USDOE Denver Regional Office. Document http://www.eren.doe.gov/der/chp/pdfs/sargent.pdf

Scientific American (1990). Energy for Planet Earth, A collection of article from the September 1990 special issue.

Sweetser, Richard (2001). Exergy Parnters Corporation. Presentation to Second International CHP Symposium, Amsterdam.

United Nations (1999). Cogeneration as a means of Pollution Control and Energy Efficiency in Asia. Document http://www.eren.doe.gov/der/chp/doclibrary.html

U.S. DOE (2000), National Energy Technology Laboratory (NETL), Fuel Cells: Handbook (Revision 5). Available online at http://www.fuelcells.org/fchandbook.pdf

U.S. DOE (1998). Annual Energy Outlook 1999, Energy Information Administration, DOE/EIA0383(99).

Wang, J.F., G.C. Gao, and G.M. Chen. An improved absorption refrigeration cycle driven by unsteady thermal sources below $100^{\circ} \mathrm{C}$. International Journal of Energy Research, 2000; 24:633640 . 
An Engineering-Economic Analysis of Combined Heat and Power Technologies in a $\mu$ Grid Application 


\section{Appendix A: Mathematical Model}

\section{Introduction}

In this section the latest version of DER-CAM is presented. This version of the model has been programmed in GAMS. ${ }^{13}$ This section contains a brief description of the GAMS software and the reasons behind its selection for the task, concluding with a description of the present version of the model as well as its mathematical formulation. The results presented are not intended to represent a definitive analysis of the benefits of DER adoption, but rather as a demonstration of the current DER-CAM. For example, only equipment first cost as claimed by the manufacturer is available; delivery and installation costs are estimated. Indeed, developing better estimates of realistic customer costs is a key area in which improvement is not just possible but essential. While the model might underestimate equipment cost, it also excludes benefits accruing from reliability and CHP applications. Hence, although the model's results may not be completely accurate, they are not clearly biased in any particular direction. DER-CAM executes a straightforward optimization of one year's operation. Given the electricity purchasing options available, the cost of fuels, and the costs and operating characteristics of DER technologies available, DER-CAM picks the optimal combination of DER that any customer should have had in place during that year and shows an optimal output schedule for that DER combination.

\section{Model Description}

In a previous report, the first spreadsheet version of the Customer Adoption Model was described and implemented (Marnay 2000), with the subsequent report implementing the model in GAMS (Rubio 2001). The model's objective function, which has not changed, is "to minimize the cost of supplying electricity to a specific customer by optimizing the installation of distributed generation and the self-generation of part or all of its electricity." "In other words: the focus of this work continues to be strictly economic. In order to achieve this objective the following issues must be addressed:

- Which is the lowest $\operatorname{cost}^{15}$ combination of distributed generation technologies that a specific customer can install?

- What is the appropriate level of installed capacity of these technologies that minimizes cost?

- Will disconnecting from the grid be economically attractive to any kind of customer?

- How should the installed capacity be operated so as to minimize the total customer bill for meeting its electricity load?

For this study, it is assumed that the customer desires to install distributed generation to minimize the cost of electricity consumed on site. Consequently, it should be possible to determine the technologies and capacity the customer is likely to install, to predict when the customer will be selfgenerating and/or transacting with the grid, and to determine whether it is worthwhile for the customer to disconnect entirely from the grid.

\footnotetext{
${ }^{13}$ GAMS is a proprietary software product used for high-level modeling of mathematical programming problems. It is owned by the GAMS Development Corporation (http://www.gams.com) and is licensed to Berkeley Lab.

14 Marnay, et al., 2000.

${ }^{15}$ Here, costs include turnkey (purchase, delivery, and installation) costs as well as fixed and variable operational costs.
} 
Key inputs into the model are:

- the customer's load profile,

- the customer's electricity purchasing option, which could be open market prices or the default tariff San Diego Gas and Electric (SDG\&E) tariff,

- the capital, O\&M, and fuel costs of the various available DER technologies, together with the interest rate on customer investment, and

- the basic physical characteristics of alternative generating technologies.

Outputs to be determined by the optimization model are:

- optimal cost minimizing technology or combination of technologies,

- optimal capacity of each technology to be installed,

- when and how much of the capacity installed will be running, and

- total cost of supplying electricity.

Some of the assumptions that were established from the previous study (Rubio 2001) have been maintained while others have changed (see the following section, Additions to the Model). The key maintained assumptions are:

- Customer decisions are taken to be based only on direct economic criteria. In other words, the only DER benefit that the customer can achieve is a reduction in its electricity bill.

- All the electricity generated in excess of that consumed is sold to the grid. No technical constraints to selling back to the grid at any particular moment are considered. On the other hand, if more electricity is consumed than generated, then the customer will buy from the grid under pre-determined contractual agreements or at the default tariff rate. No other market opportunities, such as sale of ancillary services or bilateral contracts, are considered.

- No deterioration in output or efficiency during the lifetime of the equipment is considered. Furthermore, start-up and other ramping constraints are not included.

- CHP benefits, reliability and power quality benefits, and economies of scale in O\&M costs for multiple units of the same technology are not taken into account.

- Possible reliability or power quality improvements accruing to customers are not considered.

- DER equipment is perfectly reliable. That is, there are no forced outages.

\section{Additions to the Model}

The main advantage of DER-CAM is its flexibility. The use of GAMS enables the model to be complex without hindering the ability of researchers to make adjustments in the details. Consequently, run time is minimal, and ultimately this code could be embedded in a broader customer adoption decision tool.

The new features added to the customer adoption model are good examples of the flexibility that has been previously mentioned. In the previous study (Rubio 2001), the following features were added: 
- More DER options are evaluated. Currently, almost thirty different types of distributed energy generation options are considered simultaneously.

- More detailed hourly operation of adopted equipment is endogenously determined by the solution.

- The optimal investment combination and associated hourly operation is almost always a feasible and quickly identified solution.

- DER-CAM provides easier access to some important information, such as the effective marginal price of electricity to the customer, which could be either the net effect of the customer's monthly bill of an incremental $\mathrm{kW}$ in a certain hour or the marginal operating cost of an adopted technology.

- Implementation of new tariffs is now easier.

- The solution is obtained quickly, typically in seconds.

- More options are implemented: three different ways to handle sales, three different ways to purchase electricity, and application of a stand-by charge at will. These options will be explained later.

In the current work, the following additions have been made:

- A greater variety of DER options is now available, including PV systems. Towards this end, solar insulation data are collected to determine the power that PV can provide during any hour of the year.

- More reliable DER technology data is available.

- Electricity market prices have been updated to the remarkable 2000 data.

- More accurate customer load data have been gathered to use in constructing a viable $\mu$ Grid.

- Constraints on hours of diesel generation that approximate California air pollution permitting are implemented. The shadow prices on these constraints then yield the marginal value of hours allotted for diesel generation.

\section{Justification for Using GAMS}

Electricity utility expansion planning and operations simulation has a long history, and many methods have been developed for solving the utility scale problem that is very similar to the one addressed in this work. Some of the established approaches are based on rule-of-thumb chronological simulation of system operation, some are based on mathematical approximations of actual system operation, and yet others apply optimization techniques (Marnay 1989). The reason the economics of customer adoption can be readily modeled by a mathematical optimization problem rests on the assumption that the customer always tries to minimize internal cost. Moreover, the use of optimization techniques has the added advantage of offering robust and powerful tools that can almost guarantee finding an optimal solution quickly.

Obviously, the use of classic optimization techniques has some significant limitations; notably, some customer decisions (adoptions) are likely to be more qualitative than quantitative. For example: some "benefits," such as greater perceived control over electricity supply, cannot be easily translated to economic values. However, in the context of the present work these limitations are not expected to be important, although efforts will certainly be made in subsequent years to address them. There are additional purely mathematical limitations that will eventually arise. For example, 
neither the turnkey nor the operating costs of small-scale generators are fixed, as is required in DER-CAM's current formulation, but will tend to decrease as a customer's experience with a certain technology accumulates. In other words, while the first unit of a certain generating technology may not be the most attractive to a customer, subsequent units may become attractive as the customer gains experience with the technology.

In other work at Berkeley Lab, some less mature simulation tools, such as autonomous agents models were also reviewed. These are being applied to DER operational problems in some cases (Gibson 1999).

Ultimately, the GAMS software was selected because it:

- provides a high-level language for the compact representation of large and complex models

- allows changes to be made in model specifications simply and safely

- allows unambiguous statements of algebraic relationships

- $\quad$ permits model descriptions that are independent of solution algorithms

While there are some other optimization software packages that have these same qualities, GAMS is widely used and well known to the research team.

\section{Mathematical Formulation}

This section describes in detail the core mathematical problem solved by DER-CAM. It is structured into three main parts. First, the names of all input parameters are listed. Second, the decision variables are defined. And third, the mathematical formulation is presented for two possible tariff options.

Variables and Parameters Definition

Parameters (input information)

Customer Data

\begin{tabular}{|l|l|}
\hline Name & Description \\
\hline Cload $_{m, t, h}$ & Customer Load in $\mathrm{kW}$ during hour $h$, day type ${ }^{16} t$, and month $m$. \\
\hline
\end{tabular}

\section{Market Data}

\begin{tabular}{|l|l|}
\hline Name & Description \\
\hline RTPower $_{s, p}$ & $\begin{array}{l}\text { Regulated demand charge under the default tariff for season } \\
\text { period }^{18} p(\$ / \mathrm{kW})\end{array}$ \\
\hline RTEnergy $_{m, t, h}$ & $\begin{array}{l}\text { Regulated tariff for energy purchases during hour } h, \text { type of day } t, \\
\text { and month } m(\$ / \mathrm{kWh})\end{array}$ \\
\hline
\end{tabular}

\footnotetext{
${ }^{16}$ There are three day types: peak (the average of the three days with the biggest load), week (the remaining working days), and weekends.

${ }^{17}$ There are two seasons: summer and winter.

${ }^{18}$ There are three different time-of-use periods (for tariff purposes only): on-peak, mid-peak, and off-peak. Every tariff, TOU-8 for example, has a different definition of these periods.
} 
An Engineering-Economic Analysis of Combined Heat and Power Technologies in a $\mu$ Grid Application

\begin{tabular}{|l|l|}
\hline RTCCharge & Regulated tariff customer charge $(\$)$ \\
\hline RTFCharge & Regulated tariff facilities charge $(\$ / \mathrm{kW})$ \\
\hline$I E M_{m, t, h}$ & $\begin{array}{l}\text { CAISO (California Independent System Operator) IEM (imbalance } \\
\text { energy market) price during hour } h, \text { type of day } t, \text { and month } m \\
(\$ / \mathrm{kWh})\end{array}$ \\
\hline
\end{tabular}

\section{Distributed Energy Resource Technologies Information}

\begin{tabular}{|l|l|}
\hline Name & Description \\
\hline DERmaxp $_{i}$ & Nameplate power rating of technology $i(\mathrm{~kW})$ \\
\hline DERlifetime $_{i}$ & Expected lifetime of technology $i$ (years) \\
\hline DERcapcost $_{i}$ & Overnight capital cost of technology $i(\$ / \mathrm{kW})$ \\
\hline DEROMfix $_{i}$ & Fixed annual operation and maintenance costs of technology $i(\$ / \mathrm{kW})$ \\
\hline DEROMvar $_{i}$ & Variable operation and maintenance costs of technology $i(\$ / \mathrm{kWh})$ \\
\hline DERCostkWh $_{i}$ & Production cost of technology $i(\$ / \mathrm{kWh})$ \\
\hline DERhours $_{i}$ & $\begin{array}{l}\text { Maximum number of hours per annum that technology } i \text { is allowed to } \\
\text { generate (hours) }\end{array}$ \\
\hline
\end{tabular}

\section{Other parameters}

\begin{tabular}{|l|l|}
\hline Name & Description \\
\hline IntRate & Interest rate on DER investments $(\%)$ \\
\hline DiscoER & $\begin{array}{l}\text { UDC (utility distribution company) non-commodity revenue } \\
\text { neutrality adder }{ }^{19}(\$ / \mathrm{kWh})\end{array}$ \\
\hline FixRate & Fixed energy rate $(\phi / \mathrm{kWh})$ applied in some cases ${ }^{20}$ \\
\hline StandbyC & $\begin{array}{l}\text { Standby charge in } \$ / \mathrm{kW} / \mathrm{month} \text { that SCE currently applies to its } \\
\text { customers with autonomous generation }\end{array}$ \\
\hline Solar $_{m, h}$ & $\begin{array}{l}\text { Average solar insulation as a percentage of the maximum possible } \\
\text { during hour } h \text { and month } m(\%)\end{array}$ \\
\hline
\end{tabular}

\section{Variables}

\begin{tabular}{|l|l|}
\hline Name & Description \\
\hline InvGen $_{i}$ & Number of units of the $i$ technology installed by the customer \\
\hline${\text { Gen } L_{i, m, t, h}}_{\text {Gen }_{i, m, t, h}}$ & $\begin{array}{l}\text { Generated power by technology } i \text { during hour } h \text {, type of day } t, \text { and } \\
\text { month } m \text { to supply the customer's load ( } \mathrm{kW})\end{array}$ \\
\hline DRLoad $_{m, t, h}$ & $\begin{array}{l}\text { Generated power by technology } i \text { during hour } h \text {, type of day } t, \text { and } \\
\text { month } m \text { to sell in the wholesale market }(\mathrm{kW})\end{array}$ \\
\hline $\begin{array}{l}\text { Residual customer load (purchased power from the distribution } \\
\text { company by the customer) during hour } h, \text { type of day } t, \text { and month } m \\
(\mathrm{~kW})\end{array}$ \\
\hline
\end{tabular}

\footnotetext{
${ }^{19}$ This value is added to the IEM price when the customer buys its power directly to the wholesale market.

${ }^{20}$ If the model user selects this option the customer always buy its energy at the same price.
} 
Only the three first variables are decision ones. The fourth one (power purchased from the distribution company) could be expressed as a relationship between the second and third variables. However, for the sake of the model's clarity, it has been maintained.

\section{Problem Formulation}

There are two slightly different problems to be solved depending on how the customer acquires the residual electricity that it needs beyond its self generation:

- buying that power from the distribution company at the regulated tariff, and

- purchasing power at the IEM price plus an adder that would cover the non-commodity cost of electricity.

In this work, a surcharge was introduced in the form of a revenue reconciliation term that was added to the IEM price or the fixed price. This term was calculated such that, if the customer's usage pattern were identical under the IEM pricing option and the tariff option, the UDC would collect identical revenue from the customer.

Option 1: Buying at the Default Regulated Tariff

The mathematical formulation of the problem follows:

$$
\begin{aligned}
& \underset{\text { InvGen,GenL, GenX }}{\min } \sum_{m} \text { RTFCharge } \cdot \max \left(\text { DRLoad }_{m, t, h}\right)+\sum_{m} \text { RTCCharge } \\
& +\sum_{s} \sum_{m \in s} \sum_{p} \text { RTPower }_{s, p} \cdot \max \left(\text { DRLoad }_{m,(t, h) \in p}\right) \\
& +\sum_{i} \sum_{m} \sum_{t} \sum_{h}\left(\operatorname{GenL}_{i, m, t, h}+G e n X_{i, m, t, h}\right) \cdot D E R \operatorname{CostkWh} h_{i} \\
& +\sum_{i} \sum_{m} \sum_{t} \sum_{h}\left(\operatorname{GenL}_{i, m, t, h}+\operatorname{GenX}_{i, m, t, h}\right) \cdot \text { DEROMvar }_{i} \\
& +\sum_{i} \text { InvGen }_{i} \cdot\left(\text { DERcapcost }_{i}+\text { DEROMfix }_{i}\right) \cdot \text { Annuity } F \\
& +\sum_{m} \sum_{i} \operatorname{InvGen}_{i} \cdot \text { DERmaxp }_{i} \cdot \operatorname{StandbyC} \\
& -\sum_{i} \sum_{m} \sum_{t} \sum_{h}\left(\operatorname{GenX}_{i, m, t, h} \cdot I E M_{m, t, h}\right)
\end{aligned}
$$

Subject to:

$$
\begin{aligned}
& \text { Cload }_{m, t, h}=\sum_{i} \text { GenL }_{i, m, t, h}+\text { DRLoad }_{m, t, h} \quad \forall_{m, t, h} \\
& \operatorname{GenL}_{i, m, t, h}+\operatorname{GenX}_{i, m, t, h} \leq \operatorname{InvGen}_{i} \cdot \operatorname{DER\operatorname {max}} p_{i} \forall_{i, m, t, h}
\end{aligned}
$$


An Engineering-Economic Analysis of Combined Heat and Power Technologies in a $\mu$ Grid Application

$$
\begin{aligned}
& \text { GenX }_{i, m, t, h}=0 \text { if } \sum_{i} \text { GenL }_{i, m, t, h}<\text { Cload }_{m, t, h} \forall_{i, m, t, h} \\
& \text { Annuity } F=\frac{\text { IntRate }}{\left(1-\frac{1}{\left(1+\text { IntRate }^{\text {DERlifetime }_{i}}\right.}\right)} \\
& \text { GenL }_{j, m, t, h}+\operatorname{GenX}_{j, m, t, h} \leq \text { InvGen }_{j} \cdot \text { DER max }_{j} \cdot \text { Solar }_{m, h} \forall_{m, t, h} \text { if } j \in\{P V\} \\
& \sum_{m} \sum_{t} \sum_{h}\left(\text { GenL }_{i, m, t, h}+\text { GenX }_{i, m, t, h}\right) \leq \text { InvGen }_{i} \cdot \text { DER max } p_{i} \cdot \text { DERhours }_{i} \forall_{i}
\end{aligned}
$$

- Equation (1) is the objective function which says that the customer will try to minimize total cost, consisting of: total facilities and customer charges, total monthly demand charges, total on-site generation fuel and O\&M costs, total DER investment cost, total standby charges, and minus the revenues generated by any energy sales to the grid.

- Equation (2) enforces energy balance.

- Equation (3) enforces the on-site generating capacity constraint.

- Equation (4) prohibits the customer from buying and selling energy at the same time. When this constraint is removed, the model assumes that the customer has a "double meter," i.e., the customer can buy from the UDC and sell to the IEM at the same time, but cannot buy from the UDC and resell the same energy to the IEM. Indeed, this would create an unbounded arbitrage possibility in some circumstances.

- Equation (5) simply annualizes the capital cost of owning on-site generating equipment.

- In Equation (6), if the customer is operating any $\mathrm{PV}$ cells, then their actual energy output is their rated capacity scaled down by the amount of solar insulation.

- Finally, in Equation (7), the maximum total amount of energy that any given generator $i$ can produce throughout the year is effectively restricted by the parameter DERhours . This $^{\text {. Th }}$ constraint is intended mainly to prevent the diesel generators from operating more than the maximum legal allowable number of hours.

Option 2: Buying from Alternative Energy Providers

The problem mathematical formulation follows:

$$
\begin{aligned}
& \underset{\text { InveGen, GenL, GenX }}{\min } \sum_{m} \sum_{t} \sum_{h} \text { DRLoad }_{m, t, h} \cdot\left(\text { IEM }_{m, t, h}+\text { DiscoER }\right) \\
& +\sum_{i} \sum_{m} \sum_{t} \sum_{h}\left(\operatorname{GenL}_{i, m, t, h}+\operatorname{GenX}_{i, m, t, h}\right) \cdot \operatorname{DERCostkWh_{i}} \\
& +\sum_{i} \sum_{m} \sum_{t} \sum_{h}\left(\text { GenL }_{i, m, t, h}+\text { GenX }_{i, m, t, h}\right) \cdot \text { DEROMvar } \\
& +\sum_{i} \operatorname{InvGen}_{i} \cdot\left(\text { DERcapcost }_{i}+\text { DEROMfix }_{i}\right) \cdot \text { AnnuityF } \\
& +\sum_{m} \sum_{i} \operatorname{InvGen}_{i} \cdot \operatorname{DERmaxp}_{i} \cdot \operatorname{StandbyC}
\end{aligned}
$$




$$
-\sum_{i} \sum_{m} \sum_{t} \sum_{h}\left(\operatorname{GenX}_{i, m, t, h} \cdot \operatorname{IEM}_{m, t, h}\right)
$$

Subject to:

Equations (2) through (7)

This formulation differs only in the objective function, equation (1a), which now charges the IEM energy price for each hourly time step plus the non-commodity revenue neutrality adder. Note that the same mathematical formulation can be used if the model user wants to simulate a fixed price for all customer energy purchases. In that case, all IEM hourly prices are simply set to the fixed desired value. 


\section{Appendix B: Energy Analysis of Microgrid Oaks}

Performance specifications for installed technology

\begin{tabular}{|l|l|}
\hline Katolight reciprocating engine $500 \mathbf{~ k W}$ unit & \\
\hline $\begin{array}{l}\text { Heat rate in } \mathrm{kJ} \text { per } \mathrm{kWh} \text { (energy in per unit of } \\
\text { electricity out) }\end{array}$ & 12,000 \\
\hline $\mathrm{kWh}$ in per $\mathrm{kWh}$ out & 3.333 \\
\hline $\begin{array}{l}\text { Thermal to electric ratio of } 500 \mathrm{~kW} \\
\text { reciprocating engine }\end{array}$ & 3 \\
\hline
\end{tabular}

Input parameters

\begin{tabular}{|l|l|}
\hline Microgrid Oaks & \\
\hline kWh electricity demand & $6,144,410$ \\
\hline kWh electricity produced on site & $6,143,957$ \\
\hline Total annual heat load $(\mathrm{kWh})$ & 605,286 \\
\hline $\begin{array}{l}\text { Percent electricity generated on site at Microgrid } \\
\text { Oaks }\end{array}$ & 0.99993 \\
\hline
\end{tabular}

Assumptions

\begin{tabular}{|l|l|}
\hline $\begin{array}{l}\text { Efficiency of converting residual heat from DG } \\
\text { unit to usable heat at heating load }\end{array}$ & 0.7 \\
\hline Efficiency of utility gas to heat load & 0.85 \\
\hline Efficiency of utility fuel to electricity delivered & 0.28 \\
\hline $\begin{array}{l}\text { Contribution from } 55 \mathrm{~kW} \text { engine has same } \\
\text { characteristics as } 500 \mathrm{~kW} \text { engine }\end{array}$ & \\
\hline
\end{tabular}

Constants

\begin{tabular}{|l|l|}
\hline Number of Joules per kWh & $3,600,000$ \\
\hline
\end{tabular}

Calculations

\begin{tabular}{|l|l|}
\hline Gas Consumption & $\begin{array}{c}\text { Units in } \mathrm{kWh} \text { thermal } \\
\text { or } \mathrm{kWh} \text { electric } \\
\text { respectively }\end{array}$ \\
\hline Gas consumed in generating electricity & $20,479,857$ \\
\hline Residual heat generated & $18,431,871$ \\
\hline Useable residual heat & $12,902,310$ \\
\hline Gas load met with residual heat & 605,286 \\
\hline
\end{tabular}


An Engineering-Economic Analysis of Combined Heat and Power Technologies in a $\mu$ Grid Application

\begin{tabular}{|l|l|}
\hline Utility gas displaced & 712,101 \\
\hline Net gas consumption & \\
\hline & $19,767,756$ \\
\hline Electricity energy savings & \\
\hline Electricity consumption reduction from grid & $6,143,957$ \\
\hline Fuel displaced from generating this electricity & $21,942,704$ \\
\hline & \\
\hline Net energy result & $\mathbf{- 2 , 1 7 4 , 9 4 8}$ \\
\hline Percent change & $\mathbf{- 1 0 \%}$ \\
\hline & \\
\hline Efficiency of energy use & \\
\hline Pre-CHP efficiency & $\mathbf{0 . 3 0}$ \\
\hline Post CHP efficiency & $\mathbf{0 . 3 3}$ \\
\hline
\end{tabular}

